\title{
Giving Support and Mental Health in Older Adults at Risk for Vision Impairment
}

\author{
Merideth Smith \\ West Virginia University
}

Follow this and additional works at: https://researchrepository.wvu.edu/etd

\section{Recommended Citation}

Smith, Merideth, "Giving Support and Mental Health in Older Adults at Risk for Vision Impairment" (2013). Graduate Theses, Dissertations, and Problem Reports. 425.

https://researchrepository.wvu.edu/etd/425

This Dissertation is protected by copyright and/or related rights. It has been brought to you by the The Research Repository @ WVU with permission from the rights-holder(s). You are free to use this Dissertation in any way that is permitted by the copyright and related rights legislation that applies to your use. For other uses you must obtain permission from the rights-holder(s) directly, unless additional rights are indicated by a Creative Commons license in the record and/ or on the work itself. This Dissertation has been accepted for inclusion in WVU Graduate Theses, Dissertations, and Problem Reports collection by an authorized administrator of The Research Repository @ WVU.

For more information, please contact researchrepository@mail.wvu.edu. 
Giving Support and Mental Health in Older Adults at Risk for Vision Impairment

Merideth Smith, M.S.
Dissertation submitted to the Eberly College of Arts and Sciences
at West Virginia University in partial fulfillment of the requirements
for the degree of

\author{
Doctor of Philosophy \\ in \\ Psychology
}

\author{
Amy Fiske, Ph. D., Chair \\ Barry Edelstein, Ph.D. \\ Kevin Larkin, Ph.D. \\ Julie Hicks Patrick, Ph.D. \\ James Vernon Odom, Ph.D. \\ Department of Psychology \\ Morgantown, West Virginia \\ 2013
}

Keywords: Older Adults; Volunteer Behavior; Support Giving; Vision Impairment; Depressive Symptoms; Suicide Ideation; Life Satisfaction

Copyright 2013 Merideth Smith 


\section{ABSTRACT \\ Giving Support and Mental Health in Older Adults at Risk for Vision Impairment}

\section{Merideth Smith}

Physical disability and visual impairment place older adults at a doubled risk for depression and a seven-fold increased risk for death by suicide. Social interaction is one of the factors that may aid adaptation to vision impairment. Preliminary research suggests that giving support to others has a significant relation with fewer depressive symptoms, greater life satisfaction, and greater satisfaction with support received in older adults. There has been no study to date addressing the role of giving support to others in protecting against suicidal behaviors, or other factors related to suicide risk, such as reasons for living. Using a sample of older adults with vision related diagnoses $(N=101)$, this study investigated the direct, moderating, and mediating roles of informal and formal support giving behaviors and satisfaction with support received from others on depressive symptoms, suicide risk, reasons for living, and life satisfaction. Higher scores on a measure of informal support giving were related to lower likelihood of reported suicide ideation, $\mathrm{OR}=.82, \mathrm{CI}[.68, .99]$. Higher scores on measures of volunteer activity were directly related to higher levels of reasons for living (Number of hours volunteered during the past year: $\mathrm{b}=.07$, $\mathrm{SE}=.02, p=.05$; Volunteered during past year: $\mathrm{b}=.23, \mathrm{SE}=.09, p=.04$ ). Volunteer activity was an intervening variable in the indirect relation between lower levels of disability and higher levels of reasons for living (Number of hours volunteer: $b=.07, \mathrm{SE}=.04$; Number of volunteer organizations: $\mathrm{b}=.06, \mathrm{SE}=.03$ ). Satisfaction with support received from others was related to lower levels of depressive symptoms, $\beta=-.21, p=.03$, suicide ideation, $\mathrm{OR}=.02$, CI [<.001, .52 ], and higher levels of reasons for living, $\mathrm{b}=.51, \mathrm{SE}=.19, p=.005$. Satisfaction with support buffered the relation between disability and life satisfaction. Perceived satisfaction with support was also an intervening variable in the indirect relation between higher levels of visual functioning and lower levels of depressive symptoms, $\mathrm{b}=-.002, \mathrm{SE}=.001$, as well as higher levels of reasons for living, $\mathrm{b}=.001, \mathrm{SE}=.0005$. This study provides several important insights into the relation between visual functioning, support giving behaviors, and mental health in older adults with vision related diagnoses. Informal and formal support giving may be two targets for decreasing suicide risk and increasing protective factors. Satisfaction with support received from others is an important construct in understanding both positive and negative aspects of mental health in older adults. These results shed light on the role giving support and perceived satisfaction with support have on mental health outcomes within the context of visual disability. 


\section{Acknowledgments}

There are many people I would like to thank for their roles in the completion of this study. First, I would like to thank my advisor, Amy Fiske, Ph.D., for her help in all stages of this study. Her guidance and support is always greatly appreciated. I would also like to extend my thanks to the other members of my committee, Kevin Larkin, PhD, Barry Edelstein, PhD, Julie Hicks, PhD, and James Vernon Odom, Ph.D., for their time, feedback, and encouragement throughout this project.

I am grateful to the West Virginia Eye Institute for allowing me to work with their physicians and staff and for allowing me access to their clinics. I would especially like to thank Dr. Monique Leys for her help in conceptualizing this study and developing the recruitment techniques, as well as her invaluable help in recruiting patients from her clinic. Additionally, I would like to thank Dr. Jamie Miller, Dr. Charles Moore, and Dr. Ken Mitchell for allowing me to come into their clinics and recruit participants. I would like to thank Dr. Priyanka Jain for her help in chart review and explaining the vision data. I would especially like to thank the Retina Clinic for allowing me to take up valuable space and always having an encouraging word. The support and help from the nursing staff, technicians, administrators, residents, and fellows at the Eye Institute was greatly appreciated and indispensable to the completion of this study.

I would like to thank my friends and the Mental Health and Aging Lab for their continued support, feedback and encouragement. I would like to thank my mom, dad, brother, and sister for their love and support. And thank you to my partner Matt Brummond for his listening ear, words of encouragement, and understanding. Finally, I would like to thank the patients at the Eye Institute for taking the time to talk with me and helping me complete this project. 


\section{Table of Contents}

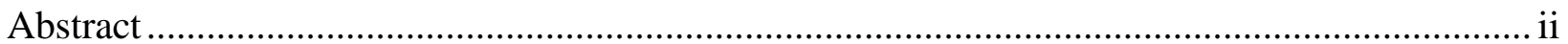

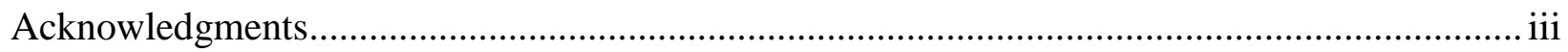

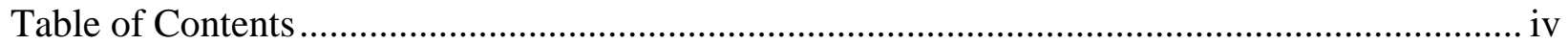

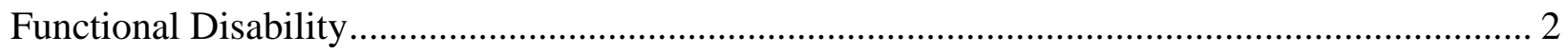

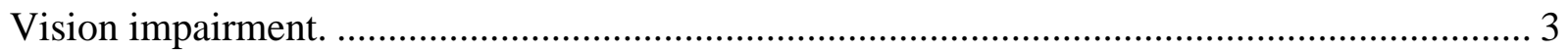

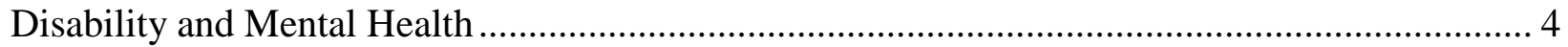

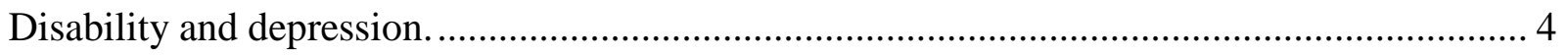

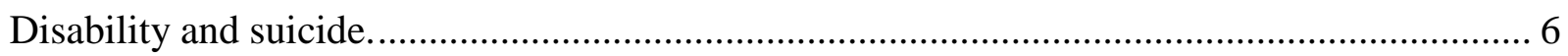

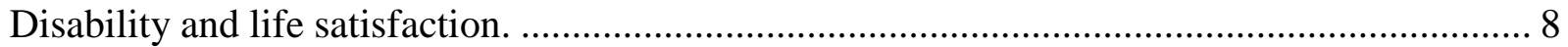

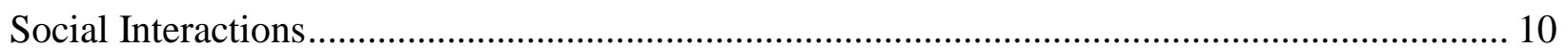

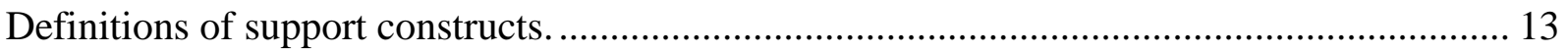

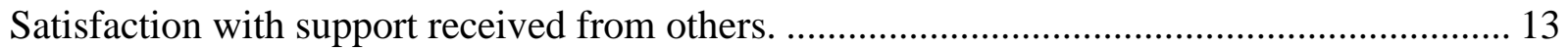

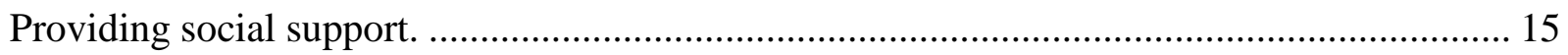

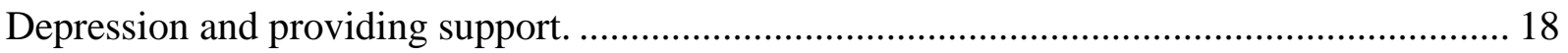

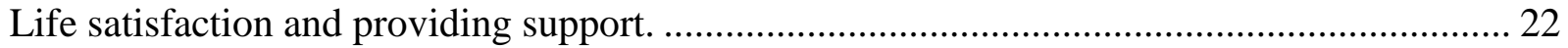

Satisfaction with support received and providing support............................................ 24

Main, buffering, and mediating effects of social support.............................................. 25

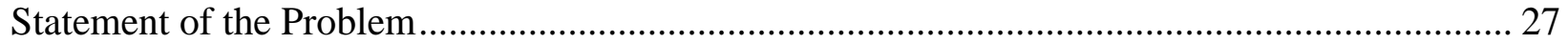

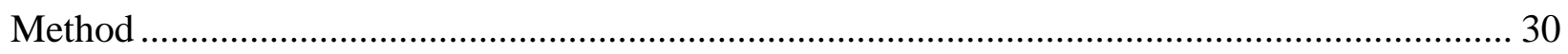

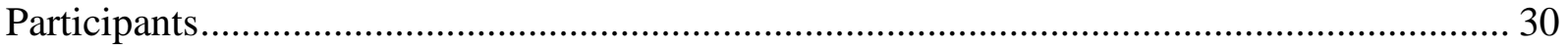

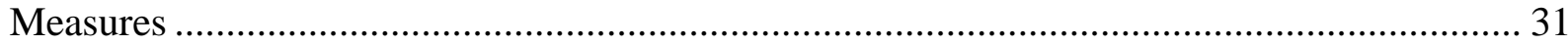

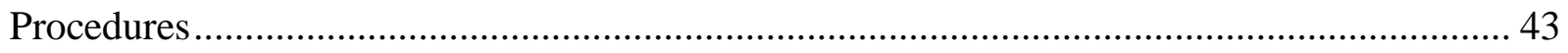

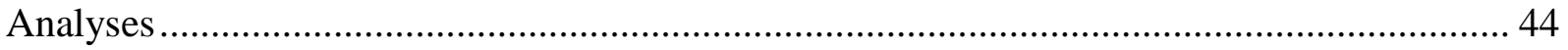

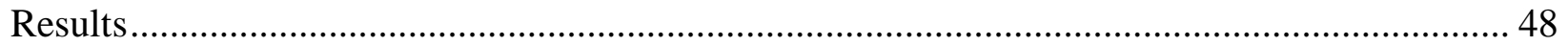

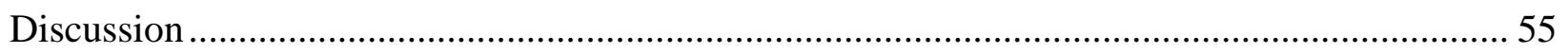

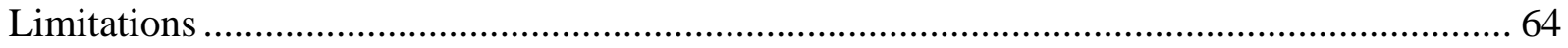

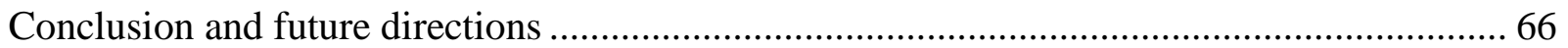

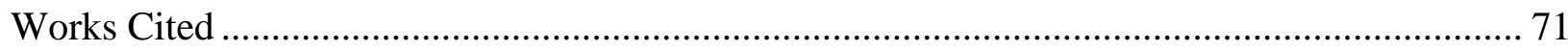

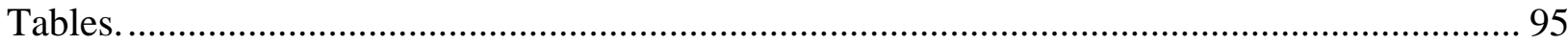

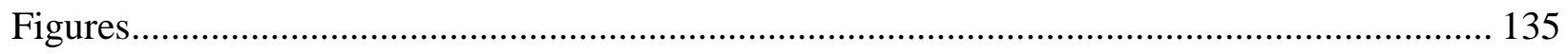




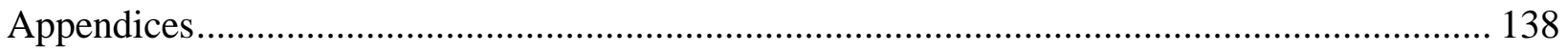


Giving Support and Mental Health in Older Adults at Risk for Vision Impairment

Severe visual impairment increase the risk for negative mental health outcomes in older adults, including a doubled risk for depression and a seven-fold risk for death by suicide (Evans, Fletcher, \& Wormald, 2007; Waern et al., 2002). There is a moderate effect of visual impairment on psychological well-being in older adults $(d=-.53)$ (Pinquart \& Pfeiffer, 2011). The limitations in activities of daily living that could arise from visual impairment place older adults at a significantly increased risk for depressive symptoms, suicide ideation, and death by suicide (Duberstein, Conwell, Conner, Eberly, \& Caine, 2004; Pirkis, Burgess, \& Dunt, 2000; Zeiss, Lewinsohn, Rohde, \& Seeley, 1996). With 9.8\% of older adults with visual impairment, the significant mental health risks of these physical impairments create a public health concern (Brault, 2012). Targeting modifiable factors that mitigate negative mental health outcomes in older adults with visual impairment can promote resiliency and adaptation.

Social interaction is one such factor that may aid adaptation through its buffering of the negative impact of functional impairment (Cohen, 1988). The satisfaction with support received from others is a well-established factor in lower negative mental health outcomes and higher positive outcomes in older adults with chronic health problems (Horowitz, Reinhardt, Boerner, \& Travis, 2003). In contrast, the perception that one is providing support to others within the social network, either formally (i.e. volunteering) or informally (i.e. giving support to family), has received limited but growing attention. The importance of this construct has been dramatically illustrated by research showing that providing informal and formal support is related to decreased mortality independent of the amount of support received from others (S. Brown, Nesse, Vinokur, \& Smith, 2003; Okun, August, Rook, \& Newsom, 2010). Preliminary research suggests that older adults who report giving support to others also report lower levels of depressive symptoms, higher levels of life satisfaction and better satisfaction with support 
received from others compared to older adults who do not report giving support to others (Dyeson, 2000; Krause, 1995; Reinhardt, 2001). Although support giving behaviors have been found to be positively related to other constructs related to positive mental health qualities such as well-being (Piliavin \& Siegl, 2007), self-esteem (Y Li, 2007), or positive affect (Greenfield \& Marks, 2004), life satisfaction has received the most consistent attention in the literature. Limited attention has been given to the impact of providing support to other individuals either through formal volunteer activity or through informal support giving in older adults with functional impairments. There has been no study to date addressing the role of older adults giving support as a protective factor against suicidal thoughts and behaviors, or other factors related to suicide risk, such as lower levels of reasons for living. This study investigated the relation between providing support and depressive symptoms, suicidal ideation, reasons for living, and life satisfaction in an older adult population at risk for functional disability.

\section{Functional Disability}

Utilizing a biopsychosocial model, the World Health Organization's International Classification of Functioning, Disability, and Health (ICF) defined disability as the level of decreased ability to engage in activities of daily living (ADLs) due to a health condition like stroke, diabetes, macular degeneration, or muscle loss (Bornman, 2004; Verbrugge \& Jette, 1994). These health conditions result in impairments in bodily structures (i.e., change in binocular depth perception or change to the retina), which when interacting with the individual's environment and personal characteristics result in the inability to perform or participate in activities of daily living. For example, impairments like changes to the retina can lead to decreased clarity in vision, making activities such as driving or reading more difficult (Femia, Zarit, \& Johansson, 2001; LeBrasseur, Sayers, Ouellette, \& Fielding, 2006). The ability to eat, dress oneself, or use the toilet are examples of basic activities of personal care and living known 
as physical activities of daily living (PADLs). The ability to cook, manage finances, shop, and negotiate transportation are examples of activities needed to maintain independence in a community, known as instrumental activities of daily living (IADLs) (Katz, 1983). Functional disability is a public health problem found primarily in the older adult population. Whereas $49.8 \%$ of adults over the age of 65 reported experiencing at least one symptom of disability, only $16.6 \%$ of adults ages 21-64 reported experiencing disability (Brault, 2012). Of the older adults who reported experiencing disability, $11.4 \%$ reported experiencing severe disability. The prevalence of disability increases substantially with age, with $70.5 \%$ of adults over the age of 80 reporting at least one symptom of disability. Of the older adults with disability, $6.9 \%$ of adults ages 65 to 79 reported needing some assistance with ADLs, while $30.2 \%$ of adults over the age of 80 report needing assistance. Approximately $87 \%$ of individuals with a disability have a secondary condition, such as chronic pain, fatigue, vulnerability to falling, sleep problems, or memory problems, that results in increased distress and possible further disablement (Kinne, Patrick, \& Doyle, 2004; Nosek et al., 2006).

\section{Vision impairment.}

Change in vision is a common physical impairment that can result in difficulty performing ADLs. Examples of conditions that can result in vision changes include age-related macular degeneration, diabetic retinopathy, cataracts, and glaucoma. These conditions can result in changes in visual acuity, the ability to distinguish details, or change in visual fields, the ability to perceive visual stimuli in the field of view (Social Security Administration, 2008). Vision impairment results in disability in $9.8 \%$ of the older adult population and of those $2.7 \%$ report experiencing severe disability (Brault, 2012). In 2004, a random survey of 1042 West Virginia households identified $23 \%$ of participants who reported a member of their household had a vision problem (e.g., cataracts or glaucoma) and $5 \%$ of participants who reported a member of 
their household had self-reported poor vision (Walter, Humble, Althouse, \& Odom, 2005).

Further, individuals with a visual health problem or low vision were more than three times more likely to be over the age of 55. Older adults with vision impairment are more likely to experience limitations in ADLs including walking, taking medications, and getting out of bed compared to individuals with unimpaired vision (Campbell, Crews, Moriarty, Zack, \& Blackman, 1999). As the population ages and as illnesses that can result in vision impairment, like diabetes, increase it is likely the rate of vision impairment will also increase (Kelly, 1993). With the high rate of disability in the older adult population, it is important that effective interventions be developed to help older adults adapt to these changes in functioning.

\section{Disability and Mental Health}

The disability process can have significant influence on a person's living arrangements, health, and mental well-being (Lenze et al., 2001). Disability has been linked to higher levels of depressive symptoms and death by suicide (Gale et al., 2011; Kaplan, McFarland, Huguet, \& Newsom, 2007). In addition, individuals reporting disability symptoms also report lower levels of quality of life, life satisfaction, and well-being (Penning \& Strain, 1994; Verbrugge \& Jette, 1994).

\section{Disability and depression.}

Older adults who experience limitations in ADLs are at an increased risk for experiencing clinically significant depressive symptoms (Djernes, 2006). Diagnosed depression rates in older adults range from 1-4\% in the community and reports of clinically significant depressive symptoms range from 7.2 to $15 \%$. The risk for depression is increased when the individual becomes physically ill and with the onset of disability (Fauth, Gerstorf, Ram, \& Malmberg, 2012). The level of disability was a stronger predictor of increased depressive symptoms than the original illness for adults over the age of 50 (Zeiss et al., 1996), suggesting one depressive 
quality of physical illness arises from the impairment in functioning. Older adults who had experienced the onset of disability reported increased levels of depressive symptoms at one-year follow up (Yang \& George, 2005). Further, an increase in limitations in independent activities of daily living was related to increased symptoms of depression over time (X. Li et al., 2012).

Visual impairment also places older adults at increased risk for negative mental health outcomes. In a meta-analysis of adults over the age of 60 , there was an increased risk for depression amongst adults with visual impairment compared to adults without visual impairment $(\mathrm{RR}=2.38)$ (Huang, Dong, Lu, Yue, \& Liu, 2010). Pinquart and Pfeiffer (2011) found a small effect for the impact of visual impairment on depression $(d=-.26)$. In a community sample of British adults over the age of $75,13.5 \%$ of individuals with vision impairment reported clinically significant depressive symptoms as measured by the Geriatric Depression Scale, compared to $4.6 \%$ of older adults without vision impairment (Evans et al., 2007). In a study of older adults seeking vision rehabilitation services, $7 \%$ of older adults with vision impairment met criteria for a major depressive disorder, $4.3 \%$ met criteria for minor depression, and $21.2 \%$ reported clinically significant depressive symptoms as defined by a score of 16 or more on the Center for Epidemiological Studies Depression scale (Horowitz, Reinhardt, \& Kennedy, 2005). The inclusion of disability reduced the association between vision impairment and depressive symptoms in this sample, indicating that the association between visual impairment and depressive symptoms was at least partially explained by the presence of disability (Horowitz, Reinhardt, \& Boerner, 2005). Horowitz et al. (2005) also reported that the severity of vision impairment did not differentiate individuals with clinically significant depressive symptoms or the presence of a depression diagnosis. Nonetheless, functional disability did differentiate individuals with clinically significant depressive symptoms from individuals who did not endorse clinically significant depressive symptoms. In community dwelling adults over the age 
of 60 , the presence of visual impairment at baseline predicted an increase in depressive symptoms over a three year period (R. Brown \& Barrett, 2011). The limitation of ADLs due to visual impairment explained $28 \%$ of the relation between visual impairment and depressive symptoms.

\section{Disability and suicide.}

Older adults have the highest rate of death by suicide in the United States. In 2010, the death by suicide rate for adults over the age of 60 in the United States was 15.1 per 100,000 compared to 12.01 per 100,000 for individuals under the age of 60 (Centers for Disease Control, 2010). There is evidence to suggest that physical illness and functional disability increase the risk for death by suicide, suicide attempts, and suicide ideation. Physical illness, which may result in functional limitations, was significantly related to increased risk for death by suicide in adults over the age of 50 compared to living older adults who were matched on age, gender, race, and county of residence $(\mathrm{OR}=5.75)$ (Duberstein, Conwell, Conner, Eberly, Evinger, et al., 2004). Functional disability was a significant risk factor for dying by suicide in individuals ranging in age from 18 to $65+$ with a relative risk of 2.78 (Kaplan et al., 2007). Functional impairment was related to death by suicide by an odds ratio of 1.5 in older adults over the age of 50 who die by suicide compared to living community dwelling adults over the age of 50 (Conwell et al., 2010). Functional impairment was related to death by suicide in older adult women, but not men in a psychological autopsy of older adults in Sweden $(\mathrm{OR}=6.3)$ (Rubenowitz, Waern, Wilhelmson, \& Allebeck, 2001). Adults, over the age of 18, with impairments in functioning had a higher risk of reporting suicide ideation $(R R=1.69)$ and suicide attempts $(\mathrm{RR}=1.16)$ compared to adults without impairments in functioning (Pirkis et al., 2000). Adults ages 50 to 69 with disability also reported increased suicide ideation compared to same age peers without disability (Russell, Turner, \& Joiner, 2009). However, Russell et al. 
(2009) did not find a difference in the rate of suicide ideation between adults with disabilities and adults without disabilities between the ages of 70 and 96 . In a sample of community dwelling adults over the age of 70 in Japan, individuals with impairments in instrumental activities of daily living were twice as likely to express suicide ideation compared to adults who did not experience impairments, even after controlling for depressive symptoms (Awata et al., 2005). However, other studies of older adults who died by suicide found no difference between cases of death by suicide and a living comparison group in functional autonomy (Préville, Hébert, Boyer, Bravo, \& Seguin, 2005; Turvey et al., 2002). Further research is needed to understand the impact of disability across the different domains of suicidal behavior.

Disability due to vision impairments and suicidal behavior has also been examined in the literature. In a sample of Swedish citizens over the age of 70, physician diagnosed visual impairment and physical disability was associated with increased suicidal ideation (Forsell, Jorm, \& Winblad, 1997). In a case control study, older adults who had experienced vision impairment were at a sevenfold higher risk for dying by suicide (Waern et al., 2002). When this relation was examined by age there was not a significant relation between death by suicide and vision impairment for adults ages 65 to 74 (Waern, Rubenowitz, \& Wilhelmson, 2003). Rather, the significant relation between death by suicide and vision impairment appeared in adults over the age of 75, among whom adults with vision impairment were eight times more likely to have died by suicide compared to a living control.

In addition to understanding the relation between disability and suicide risk, it is important to understand how disability interacts with factors that may change an individual's overall risk. Reasons for living have been identified as protective against suicidal behavior, in that individuals who are able to express higher levels of reasons for living are less likely to express suicidal ideation or to have attempted suicide (Linehan, Goodstein, Nielsen, \& Chiles, 
1983). In older adults, the level of reasons for living was a significant predictor of current suicide ideation, the worst episode of suicide ideation, and past suicidal behaviors, even when controlling for depression (Edelstein et al., 2009). In a study of 125 patients with a possible mood disorder, individuals who reported higher levels of reasons for living also reported less suicide ideation (Britton et al., 2008). Specifically, moral objections to suicide and responsibilities to family were significantly related to lower reports of suicide ideation. Surprisingly, the interaction between family responsibilities and hopelessness was related to increased reports of suicide ideation. One explanation might be older adults who perceive a sense of responsibility, but also feel hopeless about the future may have an increased sense of being a burden to their family members. In a sample of community dwelling older adults, an individual's perception of their health was significantly related to scores on the Reasons for Living Scale above and beyond depression, life stressors, and optimism (Segal, Lebenson, \& Coolidge, 2008). Currently, no study has addressed reasons for living in a population of older adults with functional limitations or vision impairment. A focus on reasons for living may allow researchers to better conceptualize suicide risk in older adults with disabilities.

\section{Disability and life satisfaction.}

In addition to influencing an individual's affective state, a person's health and physical limitations can play a role in influencing an individual's life satisfaction (Pavot \& Diener, 2008). Life satisfaction is an important component of successful aging as it captures an individual's assessment of the overall quality of his or her life (Diener, Emmons, Larsen, \& Griffin, 1985; Ryff, 1989). Life satisfaction represents a cognitive appraisal of the totality of one's life at the time of evaluation (Pavot \& Diener, 2008). The decline in life satisfaction over the life-span is often attributed to an individual's perceived quality of health, not their objective health status In adults over the age 65 living in Sweden, the ability to engage in basic self-care activities was 
significantly related to life satisfaction (Borg, Hallberg, \& Blomqvist, 2006). Individuals with severe impairment in self-care activities were three times more likely to have lower life satisfaction scores compared to individuals who were independent in self-care activities (Gwozdz \& Sousa-Poza, 2010). Individuals who were completely dependent on others for selfcare activities were four times more likely to report lower life satisfaction scores compared to individuals who were not dependent.

Additionally, vision problems can have a detrimental impact on life satisfaction and quality of life (Bradley, 2006). In a meta-analysis of vision impairment and well-being, visual impairment had a small to moderate negative impact on life satisfaction with an overall moderate effect size ( $d=-.41)$ (Pinquart \& Pfeiffer, 2011). In adults with visual impairment ages 50 to 70 , a lower rate of functional impairment was directly related to better quality of life $(\beta=.50)$ and indirectly related to quality of life through its positive association with better emotional adjustment $(\beta=.67)$ (La Grow, Yeung, Towers, Alpass, \& Stephens, 2011). Older adults with age-related macular degeneration reported lower life satisfaction than adults without age-related macular degeneration (Davis, Lovie-Kitchin, \& Thompson, 1995). In a comparison study of older adults with vision impairment and older adults without vision impairment in New Zealand, older adults with vision impairment endorsed lower levels of life satisfaction $\left(\eta^{2}=.03\right)($ Good, 2008). There was an age interaction, such that the adults ages $65-84$ with vision impairment reported significantly lower scores of life satisfaction compared to sighted older adults of the same age $\left(\eta^{2}=.02\right)$. The oldest-old adults with vision impairment had no significant difference in life satisfaction compared to the sample of sighted adults of the same age. The older adults with vision impairment attributed their poor life satisfaction to factors related to sensory loss, including poor vision, and inability to drive. Visual impairment predicted lower levels of life satisfaction over a period of three years (R. Brown \& Barrett, 2011). The interaction between 
the level of functional impairment and visual impairment explained $26 \%$ of the variance between the relation between visual impairment and life satisfaction. In a sample of older adults identified as legally blind, life satisfaction scores were significantly lower at the initial measurement, as well as at four, five, and six years post-baseline compared to older adults who identified as sighted (Heyl \& Wahl, 2001).

Taken together the published literature supports several conclusions. Older adults with functional limitations are at an increased risk for experiencing clinically significant depressive symptoms and depressive disorders (Bruce, 2001; Djernes, 2006). Further, older adults with functional limitations are at risk for experiencing suicide ideation and death by suicide (Kaplan et al., 2007; Pirkis et al., 2000). Older adults with vision impairment are also at an increased risk for reporting clinically significant depressive symptoms and depressive disorders (Evans et al., 2007; Horowitz, Brennan, \& Reinhardt, 2005). Vision impairment places older adults at risk for suicide ideation and death by suicide (Forsell et al., 1997; Waern et al., 2002; Waern et al., 2003). It is unknown how functional disability and vision impairment may impact reasons for living, a measure of protective factors against suicide. Both functional disability and vision impairment are related to decreased reports of life satisfaction in older adults (Borg et al., 2006;

Good, 2008) Thus, both the limitations in the ability to perform activities of daily living and the presence of visual impairment are related to poor mental health functioning in older adults.

\section{Social Interactions}

In order to develop interventions to help older adults adapt to functional disability, it is important to understand the potential targets for intervention that influence the pathway from disability to negative mental health outcomes. Social interactions are consistently found to be targets for intervention due to the impact on mental health (Cohen, 1988; Reinhardt, 2001; Rowe, Conwell, Schulberg, \& Bruce, 2006). Social support is a construct comprised of many 
facets that have different influences on the relation between disability and depression in older adults (Vaux, 1988). One facet is the structural component of social support. This construct includes characteristics such as size of network (i.e. the number of individuals), the physical proximity to the members of the network, and the frequency of contact with network members (Berkman, Glass, Brissette, \& Seeman, 2000). Another important facet of social support is the specific function that the received support serves (Oxman \& Berkman, 1990). Functions can include emotional (e.g., listening, trying to cheer up someone), instrumental (e.g., driving, completing a chore for someone), or informational (e.g., giving advice, explaining instructions) (Cohen, 1988; Oxman \& Berkman, 1990). Perceived satisfaction with social support, a third component, is the appraisal of the availability and adequacy of support received from others (Oxman \& Berkman, 1990). Perceived satisfaction with social support takes into account whether the support the individual receives meets the needs created by the functional limitations and whether that support is available when needed (Cohen \& Wills, 1985).

Support received from others can be viewed as either positive or negative. Negative social interactions, or negative support, can have a dramatic impact on health and functioning and may reduce the beneficial effects of positive social interactions (Uchino, 2006). Examples of negative support include interactions that increase distress, critical messages, feeling overwhelmed by support, or support that threatens an individuals' self-perception or perception of independence (Cohen, 2004; Newsom, 1999). Negative support received from others can increase a feeling of distress by decreasing perceived personal control, reinforcing fatalistic attitudes, and lowering self-esteem (Newsom \& Schulz, 1998). In older adults, negative exchanges (e.g., unwanted advice, unsympathetic behavior, rejection, or neglect) were significantly related to increased distress $(\beta=.349)$ and decreased life-satisfaction $(\beta=-.249)$ (Newsom, Rook, Nishishiba, Sorkin, \& Mahan, 2005). Specifically receiving informational 
support and family/friends engaging in unsympathetic behavior had a direct effect in increased distress $(\beta=.218$ and $\beta=.164)$. Negative interactions also influenced negative affect over a period of thirteen weeks $(\beta=.173)$ (Newsom, Nishishiba, Morgan, \& Rook, 2003). Additionally, negative interactions had a similar adverse impact on positive affect over thirteen weeks $(\beta=-.158)$. In adults, critical messages from family members were associated with increased suicidal ideation $(\beta=.19)$, specifically in adults who were in poor health or experienced more depression (S. L. Brown \& Vinokur, 2003). This suggests that in addition to increasing negative affect and decreasing positive affect, negative social interactions can result in increased risk for suicide.

Negative interactions can also influence an individual's satisfaction with support received from others. Negative interactions (e.g., family and friends making too many demands, prying, receiving critical messages, or being taken advantage of) decreased satisfaction with support received from others for both older adults who provided support to others $(\beta=-.554)$ and older adults who did not provide support to others $(\beta=-.379)$ (Krause, 1995). In summary, satisfaction with support is comprised of several components including information regarding the individual's assessment of the availability and adequacy of support received as well as the emotional valence assigned to the social interactions.

Whereas the receiving of support from others and the perception of the quality of that support have received considerable attention in the literature, giving support to others has been historically overlooked as an important component of social interactions. The act of giving support to others can occur in different contexts and can take the form of formal support giving (volunteering) or informal support giving (unpaid support given to family, friends, or neighbors) (Krause, Herzog, \& Baker, 1992). Older adults report providing instrumental/tangible support (e.g., providing transportation), informational support (e.g., giving advice), and emotional 
support (e.g., providing comfort) to members of their social network (Antonucci \& Akiyama, 1987; Cohen \& Wills, 1985).

\section{Definitions of support constructs.}

In this study, informal support giving to others will be defined as the private and/or unorganized provision of instrumental, informational, and emotional support to members of the social network, including family, friends, or neighbors (Krause et al., 1992). Volunteer work, or formal support giving will be defined using Thoits and Hewitt's modification of the President's Task Force on Private Sector Initiatives (1982), as providing support through formal organizations, such as citizen action groups, advocacy groups, private/public agencies, and other organized groups, with no expectation of financial compensation (Thoits \& Hewitt, 2001). The support the participant receives from other individuals will be referred to as received support. The perception of the availability and adequacy of support the participant receives from others will be referred to as satisfaction with support received.

\section{Satisfaction with support received from others.}

The perceived quality and availability of support from friends, family, and neighbors has been found to play a substantial role in influencing the pathway from disability to depressive symptoms (Chwalisz \& Vaux, 2000). As an individual experiences more disability, they are more likely to require additional support from others and their perception of that support will change (Taylor \& Lynch, 2004). In older adults with functional disability, lower perceived quality of the support received from others was related to increased reports of depressive symptoms (Jang, Haley, Small, \& Mortimer, 2002; Taylor \& Lynch, 2004). Satisfaction with support moderated the relation between disability status and depressive symptoms for older adults, such that individuals with high levels of disability and high levels of satisfaction with support received from others were less likely to be depressed compared to individuals with high 
levels of disability and lower levels of satisfaction with support (Bierman \& Statland, 2010). In adults over the age of 55 with dual sensory loss (i.e. hearing and vision), perceived satisfaction with support and satisfaction with social activities was associated with decreased depressive symptoms in a model that contained other factors such as activity levels, functional disability, severity of sensory loss, and communication difficulties $(\beta=-.18$ and $\beta=-.21)$ (McDonnall, 2009). Older adults with vision impairment who perceived their social networks as not providing adequate support were more likely to experience clinically significant depressive symptoms compared to older adults with vision impairment who were satisfied with the support they received from others $\left(\eta^{2}=.09\right)$ (A. Horowitz et al., 2005).

Social support is also an important factor in explaining suicide risk in older adults. Communities with few social ties and social isolation have higher suicide rates compared to communities with strong social ties and less isolation (Durkheim, 1951). Older adults who have died by suicide were more likely to live alone $(\mathrm{OR}=5.33)$ or to not be married $(\mathrm{OR}=5.00)$ compared to a comparison group of older adults who were still alive (Duberstein, Conwell, Conner, Eberly, Evinger, et al., 2004). Older adults hospitalized after a suicide attempt were more likely to report living alone $(\mathrm{OR}=1.90)$ compared to a comparison group of living older adults (Wiktorsson, Runeson, Skoog, Östling, \& Waern, 2010). Having friends or relatives to confide in was related to lower risk of death by suicide in older adults $(\mathrm{OR}=.41$ and .54 , respectively) (Turvey et al., 2002). In a sample of older adults receiving home care, lower satisfaction with support was related to increased rate of reported suicide ideation (Rowe et al., 2006). The satisfaction with support received was also related to reasons for living. Better perceived satisfaction of the support received from others was related to higher reports of reason of living in Caucasian older adults (June, Segal, Coolidge, \& Klebe, 2009). This relation was not found in African American older adults. 
Additionally, the perception of social support has been found to be related to successful aging and positive qualities of mental health. The perceived quality of one's social network was significantly related to higher levels of life satisfaction in older adults (Berg, Hassing, McClearn, \& Johansson, 2006). In older adults living in Taiwan, better satisfaction with support was related to higher levels of life satisfaction at baseline, but did not impact changes in life satisfaction over time (Hsu, 2012). In older adults with reported physical impairments, the perceived satisfaction with instrumental support (e.g., receiving physical assistance) and the individual's sense of belonging were significantly related to life satisfaction (Newsom \& Schulz, 1996). Older adults with vision impairment who perceived good emotional support and stable friendships reported fewer depressive symptoms at baseline (Horowitz et al., 2003). At a two year follow-up, the perceived stability of friendships was related to fewer depressive symptoms.

Overall, the perceived adequacy and availability of support from family, friends, or neighbors is an important construct in the pathway between disability and mental health in older adults (Oxman \& Berkman, 1990). Poor satisfaction with support was related to increased depressive symptoms and suicide risk (Duberstein, Conwell, Conner, Eberly, Evinger, et al., 2004; A. Horowitz et al., 2005; Wiktorsson et al., 2010). The perception of social support also plays an important role in improving well-being, as it has been found to be related to higher reports of life satisfaction (Berg et al., 2006; Hsu, 2012; Newsom \& Schulz, 1996). As disability changes over time, satisfaction with support also fluctuates (Taylor \& Lynch, 2004), which makes this facet of social support an important target for improving well-being in older adults with functional impairment.

\section{Providing social support.}

Older adults report high rates of giving formal support. In 2011, $24 \%$ of adults over the age of 65 reported volunteering a median of 96 hours per year, which was the highest amount of 
volunteer hours in all age groups (U.S. Bureau of Labor Statistics). Of those who volunteered, most volunteered for only one organization (67\%); however, $20.5 \%$ volunteered for two organizations, and $7.6 \%$ volunteered for three groups. Religious organizations were the most common (44.9\%), followed by social/community organizations (18.3\%). Overall, older adults have a high rate of volunteer behavior. Older adults do report a decrease in providing informal instrumental and emotional support to family members and friends as they age and this trend was also found in older adults with vision impairment (Boerner \& Reinhardt, 2003; Shaw, Krause, Liang, \& Bennett, 2007). This decline in support provision highlights the potential to improve rates of support giving activity.

Providing support to others may be a potentially modifiable protective factor in at-risk older adults via several possible mechanisms. Giving support may promote increased participation in meaningful or valuable activities (Herzog \& House, 1991). An increase in activity can result in improved well-being and decreased depressive symptoms (Herzog \& House, 1991; Warr, Butcher, \& Robertson, 2004; Williamson, 1998). Older adults who reported engaging in more helping behaviors were more likely to report fewer depressive symptoms and increased feelings of vigor (Sarid, Melzer, Kurz, Shahar, \& Ruch, 2010). Sedentary older women who participated in a volunteer activity intervention demonstrated increased physical activity during the volunteer activity as well as at three years post intervention (Tan et al., 2009). Further, older adults who reported being sedentary reported a greater rate of increase in activity level compared to the rate of increase in activity levels in already active adults (Morrow-Howell, Hong, McCrary, \& Blinne, 2012). Older adults who become sedentary due to physical health problems may benefit from engagement in meaningful activity, like volunteering or helping a family member. 
Older adults who report giving support to others may also have an increased sense of social integration. Emile Durkheim used the theory of social integration to explain geographical variation in suicide rates. Communities that had close social ties and strong social roles had lower suicide rates than communities with fewer social ties and more isolation (Durkheim, 1951). According to the theory of social integration, participation in social activities and developing salient social roles are important in maintaining and improving mental health (Berkman et al., 2000). The need to develop new roles may be particularly important for older adults, due to the changes in social roles that result from life events like retirement or death of a spouse (Kim \& Pai, 2010; Y Li, 2007; Wethington, Moen, Glasgow, \& Pillemer, 2000). Volunteering and informal support giving may allow older adults, who have become isolated or have lost significant social roles, to develop new social relationships and new social roles that promote good mental health (Areán \& Ayalon, 2005; Van Willigen, 2000).

Giving support to others may influence mental health outcomes by promoting a sense of reciprocity, or balance within relationships (Liang, Krause, \& Bennett, 2001; Walster, Berscheid, $\&$ Walster, 1973). The concept of reciprocity has come out of the work evaluating the theory of equity (Liang et al., 2001; Walster et al., 1973). Reciprocity is the social norm dictating that within a relationship both members must engage in a balance of providing and receiving support, so both members maximize the benefits derived from the relationship (Walster et al., 1973). Under the theory of equity, deviations from the balance in a relationship cause distress to the individual who over benefits (receives more support than gives) and to the individual who under benefits (provides more support than receives). Older adults may have an increased need to engage in activities designed to reestablish equitable relationships due to increasing physical illness and disability that increase their need to receive more support (Femia et al., 2001; McPherson, Wilson, Chyurlia, \& Leclerc, 2010). 
Providing support to other individuals may also positively influence mental health by influencing an individual's perception of him/herself, such as increasing self-efficacy and selfesteem. Self-efficacy is defined as the belief that one is able to successfully engage in a behavior that is required to produce a specific outcome (Bandura, 1977). Increases in self-efficacy can lead to increases in a sense of mastery, personal control, and self-esteem (Hunter, Linn, \& Harris, 1981; Yang, 2006). Successful provision of support to other individuals can help an older adult develop a positive evaluation of him or herself and a perception of mastery and control (Krause et al., 1992). An increased sense of control can also lead to improved mental health (Pruchno, Burant, \& Peters, 1997). The relation between providing support and increased quality of life was mediated by both an enhanced sense of self-esteem and personal control (Warner, Schüz, Wurm, Ziegelmann, \& Tesch-Römer, 2010). Older adults with a low sense of personal control and who receive care from family members were more likely to experience depressive symptoms compared to older adults who expressed a sense of control (E. Brown, 2007).

\section{Depression and providing support.}

The fledgling literature investigating giving support and depressive symptoms has mixed findings. In a study of community dwelling older adults receiving care for a chronic illness, the acts of giving of help, advice, or a listening ear to caregivers were significantly related to fewer depressive symptoms (Dyeson, 2000). Older adult women receiving care from family or friends reported more depressive symptoms if they also perceived the relationship with the caregiver as not being reciprocal $(\mathrm{OR}=1.42)$ (Wolff \& Agree, 2004). In a sample of widows and widowers, providing instrumental support to others was related to accelerated decline in depressive symptoms over a period of 18 months compared to individuals who did not give help (S Brown, Brown, House, \& Smith, 2008). In a nursing home, older adults who reported providing support to people in their social network reported fewer depressive symptoms ( $\beta=-.28)$ (Cheng, Lee, \& 
Chow, 2010). Krause et al. (1992) reported providing support to family and friends was indirectly related to depressive symptoms $(\beta=-.089)$ through its relation to increased perception of personal control $(\beta=.187)$. In a sample of older married couples, providing emotional support to a spouse was related to higher quality of perceived support received from the spouse, which was subsequently related to lower depressive symptoms (Ko \& Lewis, 2011).

Nonetheless, in other samples of community dwelling older adults, older adults' provision of support to family and friends who did not live in the same household was not directly related to depressive symptoms (Krause et al., 1992; Y. Li \& Ferraro, 2005). In another sample of older adults, providing tangible, information, or emotional support to family or friends was not significantly related to negative affect or somatic symptoms measured by the CES-D (Liang et al., 2001). There was a small indirect effect between providing support and higher depressive symptoms $(\beta=.01)$ through the direct relation between higher rates of informal support giving and higher rates of negative interactions like critical messages, too much demand, and prying into personal affairs $(\beta=.47)$. In a sample of older adults with visual impairment, older adults providing negative support to family members (i.e. the number of family members the participant made angry or upset) was related to higher depressive symptoms $(\beta=.09)$ (Reinhardt, 2001). Only one study touched on the relation between providing support and suicide risk. In a sample of older adults receiving home care, feeling useful to their friends and family was related to lower levels of suicide ideation $(\mathrm{OR}=.50)$ (Rowe et al., 2006). However, no study has directly addressed the relation between giving support behaviors and suicide risk.

There is evidence to support a relation between formal support giving and depressive symptoms (Hunter \& Linn, 1980). In a sample of older adult, older adults who volunteered reported fewer depressive symptoms compared to older adults who did not volunteer (Hunter \& Linn, 1980). Several longitudinal studies have demonstrated a relation between volunteering and 
depression. Participants from the Asset and Health Dynamics Among the Oldest Old Study (AHEAD) who were 70 years old or older and volunteered 100 hours or more during the past twelve months had fewer depressive symptoms over a seven year period $(\beta=-.31)$ (Lum \& Lightfoot, 2005). In older adult participants from the Americans' Changing Lives Study (ACL), volunteer status and the number of volunteer hours was related to fewer depressive symptoms over a period of eight years (Morrow-Howell, Hinterlong, Rozario, \& Tang, 2003). However, this relation was not seen in older adults who volunteered more than 100 hours in the past twelve months. In this same population, when examining a composite variable of volunteer hours and number of volunteer groups, volunteering at baseline was related to fewer depressive symptoms three years later $(\beta=-.03)$ (Y. Li \& Ferraro, 2005). However, volunteering at baseline or three years later did not have a direct impact on depressive symptoms eight years post-baseline. Cumulative volunteering over the waves of measurement (baseline, three years post-baseline, and eight years post-baseline) was related to fewer depressive symptoms at 8 years post-baseline $(\beta=-.42)$ (Musick \& Wilson, 2003), suggesting that the sustained volunteer activity had mental health benefits. Volunteering behavior was also related to steeper declines in depression in older adults (mean slope $=.51)($ Kim \& Pai, 2010). In a sample of older adults who attempted suicide, none reported volunteer behavior, whereas a third of older adults who were depressed and a third of the older adults with no depression reported some volunteer behavior (Szanto et al., 2012). No other study has addressed volunteer behavior and its relation to suicide risk.

Nonetheless, not all studies have found a significant relation between volunteering and decreased depressive symptoms. Krause, Herzog, and Baker (1992) did not find that volunteering was related to negative affect in older adults in a cross sectional study. However, volunteering was related to fewer somatic symptoms. In an intervention study, older adults who participated in a foster grandparent program for children with developmental disabilities did not 
experience a decrease in depressive symptoms compared to older adults who participated in an alternative group (social senior citizen's group), and older adults randomly selected from the community (Rook \& Sorkin, 2003).

Thus, literature investigating support giving behaviors in older adults has produced mixed results. Some studies suggest informal support giving and reciprocity within relations are related to depressive symptoms either directly or through variables such as personal control (Cheng et al., 2010; Dyeson, 2000; Ko \& Lewis, 2011; Krause et al., 1992; Wolff \& Agree, 2004). However, many studies have not found a significant relation between depression and informal giving support in older adults, including a sample of older adults with vision impairment (Y. Li \& Ferraro, 2005; Liang et al., 2001; Reinhardt, 2001). Volunteer behavior has more evidence supporting a relation between giving and depression (Hunter \& Linn, 1980; Kim \& Pai, 2010; Y. Li \& Ferraro, 2005; Lum \& Lightfoot, 2005; Morrow-Howell et al., 2003; Musick \& Wilson, 2003), but some studies, including an intervention study, have not found this relation (Krause et al., 1992; Rook \& Sorkin, 2003). Only two studies addressed suicide behavior, volunteering, and cognitive appraisals related to support giving behavior; these studies suggest there may be a significant relation between giving and suicide risk (Rowe et al., 2006; Szanto et al., 2012).

The literature investigating support giving in relation to negative mental health outcomes is limited in several areas The literature has not consistently investigated the effect of either informal or formal support provision in older adults with functional impairment. To date, no study has directly addressed the influence of giving support, either informally or formally, on suicide risk in older adults. Rowe et al. (2006) reported that older adults who felt useful to others reported less suicidal ideation and Szanto et al. (2012) reported a possible difference in volunteer behavior in older adults who attempted suicide compared to older adults who have not attempted suicide. However, giving behaviors as a protective factor against suicide has not been 
investigated directly or within a population of older adults at risk for functional impairments. There is evidence to suggest that a sense of responsibility and a sense of belonging may be related to a reduced suicide risk and increased levels of reasons for living (McLaren, Gomez, Bailey, \& Van Der Horst, 2007). A sense of responsibility to family and children is related to decreased suicide ideation (Britton et al., 2008). Although sense of responsibility to family and children is not a direct measure of providing support, it may be an indication of a desire or motivation to provide support to family and children. Further, a sense of belonging and a desire to interact with social networks are moderately correlated with reasons for living $(r=.40$ and $r=$ .31 respectively), and both are strongly correlated with responsibility to children $(r=.70)$ and responsibility to family $(r=.73)$ (Kissane \& McLaren, 2006). There is a need for research to address the role of giving support on suicide risk and correlates of suicide risk in older adults.

\section{Life satisfaction and providing support.}

Informal support giving may also be related to life satisfaction. In older adults with vision impairment, giving emotional support to family members was related to life satisfaction ( $\beta$ $=.12)$ (Reinhardt, 2001). In adults over the age of 75 who were receiving care from adult children, the act of providing support to their adult children was significantly related to higher reports of life satisfaction $(\beta=.14)$ (Lowenstein, Katz, \& Gur-Yaish, 2007). Nonetheless, the provision of support did not remain a significant predictor when physical functioning was entered into the model, suggesting that better physical functioning explained the relation between provision of support and life satisfaction. In nursing home residents, older adults who reported being able to provide support to others reported higher life-satisfaction $(\beta=.28)$ (Cheng et al., 2010). However, in a sample of older adults from Hong Kong, emotionally reciprocal relationships with friends was not related to life satisfaction, while over benefiting in emotional 
relationships with friends was associated with increased life satisfaction (T. Li, Fok, \& Fung, 2011).

Formal support giving may also positively impact life satisfaction and factors related to successful aging. A meta-analysis of the volunteer literature until 1998 reported that volunteering was significantly related to measures of well-being, $r_{\text {mean }}=.252, p<.001$ (Wheeler, Gorey, \& Greenblatt, 1998). Cross-sectional studies have consistently found a relation between volunteering and higher reports of life satisfaction (Hunter \& Linn, 1980; Wu, Tang, \& Yan, 2005). In a sample of older adults in China, older adults who reported volunteering after retirement were more likely to report higher levels of life satisfaction than older adult who did not volunteer $(\beta=.143)$ (Wu et al., 2005). In a sample of older adults, volunteer status, number of hours, and number of volunteer organizations at baseline were related to increased life satisfaction three years post-baseline $(\beta=.221, .002$, and .254 respectively) (Van Willigen, 2000). In older women, volunteer work was related to higher well-being and life satisfaction (Parkinson, Warburton, Sibbritt, \& Byles, 2010; Waddell \& Jacobs-Lawson, 2010). Older adults who self-selected into a volunteer intervention for teaching English to adult English as a second language students reported higher life satisfaction than older adults who did not participate in the volunteer intervention (Yuen, 2002).

In summary, the past research looking at support giving and life satisfaction has produced mixed results. There are some studies that have found a significant relation between life satisfaction and informal support giving (Cheng et al., 2010; Reinhardt, 2001). However, several studies have not found this relation (Y. Li \& Ferraro, 2005; Lowenstein et al., 2007). Volunteer behavior and its relation to life satisfaction has demonstrated more consistent positive results (Hunter \& Linn, 1980; Parkinson et al., 2010; Van Willigen, 2000; Wheeler et al., 1998; Wu et al., 2005; Yuen, 2002). This literature presents some limitations. A limited number of studies 
have addressed the relation between providing support, both formally and informally, to life satisfaction. The literature addressing life satisfaction has included older adults receiving care and older adults with vision impairment. Nonetheless, there is conflicting evidence regarding whether physical functioning explains the relation between providing support and life satisfaction in older adults (Lowenstein et al., 2007; Reinhardt, 2001).

\section{Satisfaction with support received and providing support.}

In addition to direct effects on mental health outcomes, informal support giving to others may also influence the perceived satisfaction with the support received from others, which as discussed above is an important factor in adaptation to physical health problems (Horowitz et al., 2003). As would be expected, the amount of support received from others was related to the perception of availability and satisfaction with support with an average correlation of $r=.35, p$ $<.001$ (Haber, Cohen, Lucas, \& Baltes, 2007). Nonetheless, this moderate correlation implies the satisfaction with social support was not fully explained by the amount of support received. The act of giving support within a relationship may exert influence on how the support received from others is perceived. In community samples of older adults, individuals who reported giving support were more likely to report a better perception of the support received from others compared to older adults who reported low rates of giving support $(\beta=.373)$ (Krause, 1995). In older couples, providing emotional support was significantly related to the satisfaction with the emotional support received from the spouse in both men $(\beta=.58)$ and women $(\beta=.63)$ (Ko \& Lewis, 2011). In couples where one member provided care to the other member, improvements in the perceived reciprocity of the relationship was related to improvements in the perceived quality of the relationship for both members of the couple (Kuijer, Buunk, De Jong, Ybema, \& Sanderman, 2004). In Parkinson, Warburton, Sibbritt, and Byles (2010), older women who volunteered also reported more satisfaction with the support received from others. 
The significant relation between support giving behavior and improved satisfaction with support lends support to the theory that support giving is important due to its ability to balance social exchanges. In addition to the adequacy and availability of support, the amount of support given back to the social network may be important in the cognitive appraisal of support received from others. Understanding how these components of social exchanges interact with each other may inform how interventions can strengthen the positive impact of social support on mental health in older adults with functional disabilities.

\section{Main, buffering, and mediating effects of social support.}

In order to utilize components of social support in an intervention, it is important to understand the mechanism by which the components influence mental health. Several models seek to explain how social support could influence mental health outcomes in the context of disability (Chwalisz \& Vaux, 2000; Cohen, 1988; Vaux, 1988). The most prominent theories include the main effect model, the stress-buffering model, and the indirect-mediator model (Cohen \& Wills, 1985; Pearlin, Menaghan, Lieberman, \& Mullan, 1981). The main effects model emphasizes the potential benefits that an individual derives from social support regardless of distress or stressors (Krause, 1990). The literature reviewed above provides preliminary evidence that giving support and volunteering have a direct effect on depressive symptoms and life satisfaction (Cheng et al., 2010; Dyeson, 2000; Hunter \& Linn, 1980; Y. Li \& Ferraro, 2005; Morrow-Howell et al., 2003; Musick \& Wilson, 2003; Reinhardt, 2001). There is also evidence that satisfaction with support received exerts a significant direct effect on mental health in older adults (Horowitz et al., 2003; McDonnall, 2011).

The stress-buffering model of social support asserts that social support moderates the relation between a stressor (e.g. disability) and an outcome (e.g. depressive symptoms) (Cohen \& Wills, 1985). Social support acts as a protective factor for the individual experiencing the 
stressor by decreasing distress. In this model, individuals who experience higher levels of disability may benefit more from providing social support or having better satisfaction with support compared to individuals who are not experiencing high levels of disability. Currently, there is evidence to suggest that satisfaction with support modifies the relation between disability and depressive symptoms (Jang et al., 2002; Wallsten, Tweed, Blazer, \& George, 1999). Nevertheless, this literature is mixed, with some studies not finding a moderating effect of satisfaction with support received on the relation between disability and depression (Yang, 2006). There have been no studies to date investigating the modifying effect of giving support to others on the relation between disability and mental health outcomes.

In an indirect-mediator model of social support, changes in social support are thought to explain the relation between the stressor (disability) and the potential outcome (mental health). The concept of an indirect-mediator effect of social support on negative outcomes within the context of disability is derived from the stress process model (Pearlin et al., 1981). The stress process model posits that when confronted with a stressor, such as disability, the individual engages or disengages in behaviors, such as engaging in less volunteer behavior or seeking out more support, and the individual experiences the eventual outcome, like depression, due to these changes. The change in behavior as a result of the stressor either fully or partially explains the relation between the stressor and outcome. As disability increases, individuals may find it difficult to continue to provide the same level of support to others (Boerner \& Reinhardt, 2003; Shaw et al., 2007) and may experience changes in how they perceive the support received from others (Taylor \& Lynch, 2004). As the amount of support given to others decreases, depressive symptoms may increase and life satisfaction may decrease (Dyeson, 2000; Hunter \& Linn, 1980; Reinhardt, 2001). There is evidence to suggest a partial indirect effect of perceived satisfaction with support on the relation between disability and depression as well as life satisfaction 
(Newsom \& Schulz, 1996; Taylor \& Lynch, 2004). Similar to the stress-buffering model of social support, there have been no studies to date investigating the mediating effect of support giving behavior to others on the relation between disability and mental health outcomes.

\section{Statement of the Problem}

Older adults with vision impairment are at an increased risk for depressive symptoms, suicide ideation, and lower life satisfaction. There is evidence to suggest that providing support to others may ameliorate the negative impact of decreased functioning on mental health and increase positive mental health outcomes. Nonetheless, the literature addressing the act of providing support to others is sparse with mixed results. The effects of giving support to others among older adults with functional impairments have received limited attention. The effect of giving support to others among older adults with vision impairment has only been addressed in one study (Reinhardt, 1996). This study utilizes a population at risk for experiencing disability due to the presence of vision diagnoses, expanding the understanding of social exchanges as older adults experience increased impairments in functioning. This study also contributes to the literature by investigating the effect of giving support to others on suicidality. Previous literature has established the importance of perceived satisfaction with support and social integration in protecting against suicide risk in older adults. This study expands the understanding of how other components of social exchanges impact suicide risk. The relation between satisfaction with support and the provision of support has also received limited attention; this study addresses the relation between providing support and satisfaction with support received in a population at risk for disability. This focus will provide a better understanding of what contributes to an individual's assessment of the support received from family and friends. Finally, an investigation of the mechanism of change for providing support has not been addressed and there is mixed evidence for the mediating and moderating roles of perceived quality of support 
received from others. Better understanding of the different facets of social support may lead to the development of better interventions to help older adults adapt to changes in health and functioning. Informal and formal support giving offer two potential methods of improving the well-being of older adults with disabilities. This study advances the understanding of social exchanges within a disability context by examining the differential relations between support giving behaviors, perceived satisfaction with support received from others, and mental health and by investigating the mechanism by which these constructs impact mental health.

The objective of this study was to expand the understanding of how giving support to others influences negative and positive aspects of mental health in older adults with vision related diagnoses. A secondary objective of this study was to expand the understanding of how satisfaction with support influences negative and positive aspects of mental health in older adults. An exploratory objective of this study was to investigate the potential mechanisms of change through which giving support may influence mental health in older adults.

The central hypothesis was that providing support to others would be related to lower levels of depressive symptoms, lower levels of suicide ideation, and higher levels of reasons for living, higher levels life satisfaction, and better satisfaction of the support received from others. Two exploratory questions addressed the mechanism of change by which giving support and satisfaction with support received from others would influence mental health in older adults. The following specific aims of this study addressed the central hypothesis and exploratory questions.

\section{Specific Aim 1}

Determine the cross-sectional direct effect of providing informal support (instrumental, emotional, and informational) to others, volunteer behavior, and satisfaction with support received from others on mental health outcomes in older adults with vision related diagnoses. 
Based on published research, it was hypothesized that provision of greater amounts of informal support to others would be associated with a lower level of depressive symptoms, lower levels of suicide ideation, higher levels of reasons for living, and higher levels of life satisfaction among older adults with vision related diagnoses.

Based on published research, it was hypothesized that higher rates of volunteering would be associated with lower level of depressive symptoms, lower levels of suicide ideation, higher levels of reasons for living, and higher levels of life satisfaction among older adults with vision related diagnoses.

Based on published research, it was hypothesized that better satisfaction with support received from others would be associated with lower levels of depressive symptoms, lower levels of suicide ideation, higher levels of reasons for living, and higher levels of life satisfaction among older adults with vision related diagnoses.

\section{Specific Aim 2}

Examine the cross-sectional association between providing informal support (instrumental, emotional, and informational) to others with the perception of quality of social support received from others in older adults with vision related diagnoses.

Based on previous literature, it was hypothesized that the provision of greater amounts of support to others would be associated with better satisfaction with support received from others among older adults with vision related diagnoses.

\section{Specific Aim 3 (Exploratory)}

Examine the moderating model of support and the mediating model of support on mental health outcomes in older adults with vision related diagnoses. 
Question 1: Does giving informal and formal support moderate the relation between disability and depressive symptoms, suicide ideation, reasons for living, and life satisfaction in older adults with vision related diagnoses?

Question 2: Does the satisfaction with support received from others moderate the relation between disability and depressive symptoms, suicide ideation, reasons for living, and life satisfaction in older adults with vision related diagnoses?

Question 3: Does giving informal and formal support mediate the relation between disability and depressive symptoms, suicide ideation, reasons for living, and life satisfaction in older adults with vision related diagnoses?

Question 4: Does the satisfaction with support received from others mediate the relation between disability and depressive symptoms, suicide ideation, reasons for living, and life satisfaction in older adults with vision related diagnoses?

\section{Method}

\section{Participants}

Two hundred and seventeen West Virginia University Eye Institute patients were approached and 53.4\% $(n=116)$ declined to participate, were lost to follow-up, or were ineligible to participate (See Figure 1 for details). Of the individuals who agreed to participate in the study and were screened, 9\% scored below a 15 on the TELE cognitive screener $(n=20)$. Table 1 lists the demographic characteristics of individuals who screened positive for possible cognitive impairment. Participants with TELE scores below 15 were more likely to be older, $\mathrm{t}(119)=-2.56, p=.01$ and were less likely to have post high school education, $\chi^{2}(5, N=122)=$ $8.96, p=.003$, compared to participants who were eligible to participate in the study. The participants who screened positive and completed the interview, $(N=101)$ ranged in age from 60 
to 94 , were predominantly female, Caucasian, married, and with some college education. Three individuals indicated they were of mixed Caucasian and Native American race and one individual identified as Indian. For full demographic information, see Table 2. The mean $\log$ MAR in the eye with the best vision was $.22, S D=.29$ with a range of 0 to 1.30 . Seven percent of the sample had a logMAR of one or greater in the better eye, indicating legal blindness (Social Security Administration, 2008). Within this sample, $72.73 \%$ of the participants did not have visual field restriction, $19.19 \%$ had mild to moderate field restriction, and $8.08 \%$ had marked field restriction. All participants had at least one vision related diagnosis. Most participants had more than one vision related diagnosis $(n=58)$. The five most common diagnoses were age related macular degeneration $(n=48)$, retinopathy $(n=22)$, glaucoma $(n=$ 12), and diabetic macular edema $(n=11)$.

\section{Measures}

\section{Informal support giving.}

Informal support provided to others was assessed using thirteen items developed to examine social support provided to others in older adults (Krause \& Markides, 1990) (See Appendix A). Four items assessed emotional support provided to others (e.g., showed physical affection). Five items assessed tangible support provided to others (e.g., provided transportation). Four items assessed informational support provided to others (e.g., provided advice). Participants were asked to rate how often they provide each type of support to family, friends, or neighbors over the past twelve months; response choices range from never, once in a while, fairly often, to very often. Higher scores indicated more support provided. The total scale score was derived by adding all item responses, with a response floor of 13 and a ceiling of 52 . A latent variable analysis of a composite score of all three forms of provided support revealed good model fit suggesting this measure has strong internal consistency (Adjusted Goodness-of- 
Fit index $=.989$, and Bentler-Bonnett Normed Fit index $=.989)($ Krause, 1995). This measure of informal support giving has been found to be moderately correlated with the amount of support received from others $(r=.51)$ (Liang et al., 2001) and was significantly related to higher levels of meaning of life $(\beta=.25)$ (Krause \& Hayward, 2012), and lower levels of hostility $(\beta=-.27)$ (Krause, 2011). Within this sample, the mean total scale score for informal support given was $27.85(S D=7.12)$, with a range between $13-50$. There were no missing data for this measure. Within this sample, the inter-item consistency of the total scale score was consistent with previous research $(\alpha=.82)$ (Krause, 1999). The total scale score of support provided was normally distributed and was not transformed.

\section{Formal Support Giving.}

To assess formal support giving, six questions from the Americans Changing Lives Study were used (House, 1997) (See Appendix B). The items assessed whether the participant volunteered for a religious organization, an educational organization, a political group/labor union, senior citizen group, or any other national/local organization during the past twelve months. If the participant indicated volunteer activity in any of the five types of organizations, they were asked to describe the specific volunteer behavior. The seventh question assessed the number of hours volunteered in any of the five types of organizations during the past twelve months. Response choices range from less than 20 hours, 20-39 hours, 40-79 hours, 80-159 hours, and 160 hours or more. Participants were classified as volunteers if they responded affirmatively to any of the five items assessing volunteer behavior for organizations. Participants who denied volunteering for any type of organization were classified as nonvolunteers. Participants who indicated no volunteer activity within the past twelve months were recorded as providing zero volunteer hours. The number of different types of volunteer organizations with which the participant engaged was calculated by adding the number of organizations in which 
the participants indicated they volunteered with during the year. This measure of volunteer hours has been found to be related to depressive symptoms and life satisfaction in older adults (Y Li, 2007; Y. Li \& Ferraro, 2005; Morrow-Howell et al., 2003; Van Willigen, 2000).

Additionally, volunteer status and the number of volunteer organizations have also been found to be related to depressive symptoms and life satisfaction (Lum \& Lightfoot, 2005; Musick \& Wilson, 2003; Van Willigen, 2000; Wu et al., 2005).

There were no missing data for this measure. Almost half of the participants indicated they participated in some volunteer activity $(49.5 \%)$ with $35.64 \%$ volunteering for a religious organization, $14.85 \%$ volunteering for an educational organization, $7.92 \%$ volunteering for a political group or labor union, 4.95\% volunteering for a senior citizens' organization, and $24.75 \%$ volunteering for a local or national organization, which is consistent with national averages (U.S. Bureau of Labor Statistics, 2012). Examples of volunteer activity within a religious organization included participating in food or clothing drives, serving dinners at shelters/soup kitchens, fundraising, leading bible study/children's bible school, helping with worship service (e.g., setting up decorations or preaching), visiting homebound individuals, bringing food to bereaved individuals, administrative duties (e.g., committees, record keeping), and helping with church functions/groups. Examples of volunteer activity for an educational organization included administrative duties, providing programming to students, and fundraising. Political volunteer activity included participating in political campaigns, participating in political committees, fundraising, and running local elections. Volunteer activity with senior citizen's groups included visiting nursing homes, administrative duties, and participating in senior citizen centers' committees. Finally, other volunteer activity included participating in local service clubs such as Lions Club, United Way, or Rotary Clubs, participating in food/clothing donations (e.g., working at food pantries, clothing drives), delivering/serving food (e.g., meals on wheels), 
fundraising for community groups, participating in local government (e.g., library, agricultural boards), providing services to professional organizations, running cub scout groups, and volunteering at local hospitals/nursing homes.

Within the sample, $24.75 \%$ indicated they volunteered for one type of organization, $12.87 \%$ volunteered for two types organizations, $9.90 \%$ volunteered for three organizations, and $1.99 \%$ volunteered for four types of organizations. Additionally, $12.87 \%$ volunteered less than 20 hours during the past month, $11.88 \%$ volunteered between $20-39$ hours, $5.94 \%$ volunteered 40-79 hours, 5.94\% volunteered 80-159 hours, and $12.87 \%$ volunteered for 160 hours or more.

\section{Received social support.}

Received social support was assessed by twenty-seven items developed to examine social support received from others in older adults (Krause, 1990) (See Appendix C). Eleven items assessed emotional support received from others (e.g., someone present for during a stressful situation). Nine items assessed tangible support received from others (e.g., someone provided a place to get away to). Seven items assessed informational support received from others (e.g., someone gave you advice). Participants were asked to rate how often they received each type of support from family, friends, or neighbors during the past twelve months; response choices range from never, once in a while, fairly often, to very often. The total scale score was developed by adding all item responses, with a response floor of 27 and a ceiling of 108 . Higher scores indicated more support received. A latent variable analysis of a composite score of all three forms of received support revealed good model fit (Adjusted Goodness-of-Fit index $=.987$, and Bentler-Bonnett Normed Fit index $=.986)($ Krause, 1995). Higher levels of support received from others was associated with lower negative affect in bereaved older adults (Krause, 1995) as well as in a community sample of older adults (Liang et al., 2001). Support received was also positively associated with the amount of support the older adult anticipated receiving in the 
Giving Support 35

future. Within this sample, the mean support received from others total was 51.08 (14.70), with a range between 27-96. There were no missing data for this measure. Within this sample, the total scale score had excellent inter-item consistency $(\alpha=.92)$, which is consistent with previous research (Krause, 1999). This measure was normally distributed and no transformation was applied.

\section{Perceived satisfaction with support received from others.}

Perceived satisfaction with support received from others (PSR) was assessed by three items developed to examine the satisfaction with emotional, tangible, and information support received from family, friends, and neighbors over the past twelve months in older adults (Krause \& Markides, 1990) (See Appendix D). Each item asked the participant whether they were satisfied with the support they received or if they wished that others had given them that kind of help more often or less often. The total PSR score was derived by adding the number of items in which the participant indicated they were satisfied with the support received. Higher scores indicated more satisfaction, with response floor of 0 and a ceiling of 3 . In previous studies the PSR items loaded onto one latent variable, satisfaction with support (tangible support: $\beta=.771$, $\mathrm{SE}=.406 ;$ Emotional support $\beta=.902, \mathrm{SE}=.186$; Informational support: $\beta=.838, \mathrm{SE}=.297$ ) suggesting good inter-item consistency (Krause, 1995). Higher scores of PSR were related to lower levels of negative affect in bereaved older adults (Krause \& Markides, 1990). The mean PSR score was $2.44(.98)$, with a range between $0-3$. There were no missing data for this measure. Seventy percent of the sample indicated they were satisfied with all three areas of support received from others as indicated by a PSR total score of three. Within the sample, $14.85 \%$ of the sample reported desiring more informational support while $4.95 \%$ reported receiving too much informational support. For tangible support $14.85 \%$ reported wanting more support, while $5.94 \%$ felt they received too much tangible support. Finally, $12.87 \%$ reported 
desiring more emotional support, while $1.98 \%$ reported receiving too much emotional support. However, in this study inter-item consistency of the PSR total was low $(\alpha=.59)$. The small number of items within the measure may have negatively influenced the inter-item consistency. The PSR total score exhibited an abnormal distribution with negative skew (-1.64) and positive kurtosis (1.32). The PSR total scores were reflected using a constant as suggested by Tabachnick and Fidell (2007). A logarithmic transformation was applied to the reflected scale. Transformed scores were reflected using a constant so the scale maintained the original direction, such that higher scores on the transformed scale indicated better satisfaction with support received. The distribution of the transformed PSR total continued to exhibit skew (skew $=-1.28$; kurtosis $=.06)$; however the skew was reduced.

\section{Depressive symptoms.}

The Center for Epidemiological Studies Depression Scale - Revised (CESD-R) was used to obtain a measure of the frequency of depressive symptoms (Eaton, Smith, Ybarra, Muntaner, \& Tien, 2004) (See Appendix E). The CESD-R was designed to better correspond with the depression diagnosis in the Diagnostic and Statistical Manual-Fourth edition than the original CES-D. Revisions include the elimination of reverse scored items, the inclusion of questions for the nine symptom groups described in the DSM-IV (dysphoria, anhedonia, appetite, sleep, concentration, guilt, fatigue, movement, and suicidal ideation). The scale contained 20 Likerttype four-point scale items that asked participants to rate the frequency of symptom occurrence during the past week (for example: "During the past week, I was bothered by things that usually don't bother me"). Response choices include: not at all or less than one day, 1-2 days, 3-4 days, 5-7 days, or nearly every day for 2 weeks. The response option, nearly every day for 2 weeks, was collapsed into the same response category as 5-7 days as suggested by Eaton et al. (2004). Higher scores indicated higher frequency of experiencing depressive symptoms, with a response 
floor of 0 and a ceiling of 60 . Previous research has demonstrated the CES-D has good internal consistency and predictive validity with respect to depressive disorders when used in community-dwelling older adults (Lewinsohn, Seeley, Roberts, \& Allen, 1997) and in older adults attending primary care (Lyness et al., 1997). Within this sample, the mean CESD-R total score was $7.19(8.08)$, with a range between 0 - 37. There were no missing data for this measure. The inter-item consistency of the CESD-R was consistent with previous studies ( $\alpha=$ .85) (Eaton et al., 2004). The total CESD-R score had a positive skew (1.69) and kurtosis (2.50) and a logarithmic transformation was applied. This transformation resulted in a skew of -.18 and kurtosis of -.83 .

\section{Suicide ideation.}

The Modified Beck Scales for Suicide Ideation (MSSI) (Miller, Norman, Bishop, \& Dow, 1986), a semi-structured version of the Beck Scales for Suicide Ideation (Beck \& Steer, 1991), was used to measure suicide ideation (See Appendix F). The MSSI is semi-structured interview with 18-item Likert-type three-point rating scale that assesses wish to die, wish to live, reason for living or dying, active suicidal desire, and passive suicidal desire. The response options range from 0 to 3 , with higher scores indicating more suicide ideation. The first four items assessed the participants wish to die, wish to live, desire to make active suicide attempt, and desire to make a passive suicide attempt (e.g., leave death or life up to chance). These four items were used to screen for suicide ideation. Participants who responded with a two or higher on items one (wish to die) or two (wish to die) or scored above a zero on items three (active suicide thoughts) or four (passive suicide thoughts) were administered the remaining 14 items. The screening items of the MSSI had good internal reliability $(\alpha=.89)$ and demonstrated a higher false positive rate $(21 \%)$ than false negative rate $(6 \%)$ when compared to an expert clinician's assessment of suicide, which indicates the four items functioned as good screeners for suicidal 
ideation (Miller et al., 1986). The total MSSI score also demonstrated good internal reliability ( $\alpha$ $=.94$ ) and convergent validity with other measures of suicidal ideation (Miller et al., 1986; Rudd \& Rajab, 1995), consistent with psychometric results for the SSI (Beck, Kovacs, \& Weissman, 1979). There were no missing data for this measure. Six participants (5.94\%) indicated the presence of any suicidal ideation, resulting in a highly non-normal distribution and three potential outliers with standardized scores greater than 3.29 (Tabachnick \& Fidell, 2007). To address the non-normality and presence of outliers, a dichotomous variable was created in which individuals were categorized as having no suicidal ideation and participants who indicated the presence of any suicidal ideation.

\section{Reasons for living.}

The Reasons for Living-Older Adults Scale (RFL-OA) was used to assess reasons for living in older adults (Edelstein et al., 2009) (See Appendix G). The RFL-OA is a 69-item Likert-type six-point scale that asked participants to rate the importance of each item in deterring suicidal behavior. RFL-OA scores were negatively correlated with current suicide ideation $(r=-$ $.40)$ and depressive symptoms $(r=-.43)$ (Edelstein et al., 2009). The response options range from quite unimportant to extremely important. Total scores were derived by adding all item responses, with higher scores indicating higher levels of reasons for living. The total scale score had a floor response of 69 and a ceiling of 414. Within this sample the mean RFL total score was 336.80 (54.17), with a range between 121 - 411. Inter-item consistency was similar to previous research $(\alpha=.97)$ (Britton et al., 2008; Edelstein et al., 2009). The total RFL score had a negative skew (-1.69) and positive kurtosis (3.87), with two potential outliers as defined by Tabachnick and Fidell (2007). The scores were reflected using a constant and a logarithmic transformation was applied as suggested by Tabachnick and Fidell (2007). The transformed scale was reflected using a constant in order to maintain the original direction, such that higher 
Giving Support 39

scores on the transformed scale indicated higher levels of reasons for living. This transformation resulted in a skew of -1.40 and kurtosis of 3.54 , and eliminated potential outliers.

Within this measure, $43 \%$ of participants had missing data. Five participants had $20 \%$ or more of the RFL data missing. Thirty-nine participants had less than $20 \%$ of the data missing. Reasons given for not completing this measure or not responding to an item included believing the item was not applicable to their life (for example, never experienced suicidal ideation or questions about a spouse when the participant was not married), not understanding the instructions of the measure, and test fatigue. Due to missing data on the reasons for living scale, multiple imputations on the item level were used to estimate regression pathways. Covariates (age, gender, education level, disability, and visual functioning) and predictor variables were included as auxiliary variables. The SAS 9.3 Proc MI procedure was used with 10 imputations to ensure relative efficiency of $95 \%$ or greater for all analyses. The pooled parameter estimates across the 10 imputations and the ranger of estimates are reported.

\section{Life satisfaction.}

The Satisfaction with life scale (SWLS) was used to assess life satisfaction (Diener, Emmons, Larsen, \& Griffin, 1985) (See Appendix H). The SWLS is a five item scale that asked participants to rate the degree to which they agree with a statement (i.e. strongly disagree, disagree, slightly disagree, neither agree or disagree, slightly agree, agree, or strongly agree), with higher scores indicating a greater degree of life satisfaction. This measure has been used in older adult populations, including community dwelling older adults (Bryant et al., 2012), and older adults with visual impairment (Dreer, Elliott, Fletcher, \& Swanson, 2005; Good, 2008). SWLS has been found to have moderate positive correlations with other measures of life satisfaction(McDowell, 2010) and can distinguish between psychiatric patients and individuals residing in the community (Pavot \& Diener, 2008). The total scale score was derived by adding 
all item responses, with a response floor of 5 and a ceiling of 35 . The mean SWLS scale score was 26.84 (6.90), with a range between 5 - 35. Higher scores indicted higher level of life satisfaction. There were no missing data on this measure. The inter-item consistency was good $(\alpha=.80)$ and was consistent with previous research (McDowell, 2010; Pavot \& Diener, 2008). This measure was normally distributed and not transformed.

\section{Self-reported general disability.}

The Functional Disability Scale (ADLs) was used to assess functional disability. The scale consisted of 21 items assessing activities of daily living (ADL) including physical activities of daily living and instrumental activities of daily living (Katz, 1983) (See Appendix I). The physical activities of daily living (PADL) questions asked the participants to rate their ability to perform eleven basic self-care activities (e.g., eating, dressing one's self). Instrumental activities of daily living questions asked the participants to rate their ability to perform nine instrumental activities (e.g., using the telephone, taking medicine). Responses choices range from can perform the task with no help, can perform the task with help, and cannot perform the task at all. All item responses were summed to derive the total scale score. Higher scores indicated better functioning, with a response floor of 20 and a ceiling of 63 . This measure has good convergent validity with performance based measures of functioning, measures of mobility, and disease burden in older adults (Bravell, Zarit, \& Johansson, 2011) The mean ADL score was 59.77 (5.04), with a range between 35 and 63. There were no missing data for this measure. This measure had good inter-item consistency $(\alpha=.88)$, consistent with previous research (Haynie, Berg, Johansson, Gatz, \& Zarit, 2001). This measure was not normally distributed with high negative skew (-2.60) and positive kurtosis (8.08). Further, the data contained two potential outliers. The total scores were reflected and a logarithmic transformation was applied. The transformed scale was reflected using a constant in order to maintain the original direction, 
higher scores on the transformed scale indicated better functioning. This transformation resulted in the elimination of outliers and a normal distribution (skew $=.41$ and kurtosis $=.17$ ).

\section{Self-reported visual functioning.}

The National Eye Institute 25-item Visual Function Questionnaire (VFQ-25) was used to assess self-reported disability related to vision impairment (Mangione et al., 2001) (See Appendix J). The VFQ-25 was developed to assess visual functioning in chronic eye diseases including age related vision diseases (Finger, Fleckenstein, Holz, \& Scholl, 2008). The VFQ-25 assessed general health and vision, difficulty with activities (e.g., driving, reading), response to vision difficulties (e.g., pain, limitations), difficulties due to near vision problems, difficulties due to distance vision, difficulty with distance vision activities, limitations in social functioning due to vision, role limitations due to vision, and dependency on others due to vision. The VFQ25 had good psychometric properties in older adult populations with advanced age-related macular degeneration in one or both eyes, severe nuclear opacity, and reduced visual acuity (Clemons, Chew, Bressler, \& McBee, 2003) and was found to be related to visual acuity in an older population (Owen et al., 2006) . Scoring followed the algorithm suggested in Mangione (2001). Scores were converted to represent a percentage of disablement, such that a higher percentage indicated more ability. Sub-scale totals were created by averaging the items contained in each scale. A composite score was derived by averaging the sub-scale scores, so that all sub-scales were weighted equally regardless of the items contained within each scale. A higher score on the VFQ composite indicated more visual ability, with a response floor of 0 and a ceiling of 100. Within this sample, the mean VFQ composite score was 75.75 (20.89), with a range of 18.48 - 99.43. There were no missing data on this measure. The VFQ- composite score had good inter-item consistency ( $\alpha=.94)$, which was consistent with previous research (Clemons et al., 2003). This measure was normally distributed and not transformed. 


\section{Demographics.}

A demographic questionnaire (Appendix K) was used to collect information on age, gender, race, marital status, education level, past job/occupation, and yearly income. A medical resident on the research team collected information on visual acuity in both eyes, vision diagnosis, and field of vision from the visit closes to the time of the interview through chart review. Visual acuity was measured in the Log of the minimum angle of resolution (LogMAR). A LogMAR of zero is equivalent to a 20/20 Snellen acuity (Holladay, 1997). A higher LogMAR score indicated worse visual acuity. Visual field was categorized into no restriction, mild to moderate restriction, and marked restriction as determined by the medical resident.

\section{Cognitive functioning.}

The TELE was used as a screener for cognitive impairment to exclude individuals incapable of accurate reporting due to impaired cognitive functioning (Gatz et al., 1995) (See Appendix L). The TELE is an 11 item self-report interview designed to assess orientation, shortterm memory, and long-term memory orally. The TELE has demonstrated good sensitivity $(100 \%)$ and specificity (91\%) when identifying individuals with dementia, and excellent interrater reliability $($ Kappa $=.90)$. Gatz et al. $(1995)$ found neither age nor education levels were related to scores on the TELE. Standard receiver operating characteristic analysis suggests an optimal cutoff score of 16 out of 20 points (Gatz et al., 2002). The current version of the TELE is a 19 point measure that has eliminated one point for the participant correctly identifying his/her name. This item did not provide incremental validity in distinguishing cases of possible dementia as most individuals, regardless of cognitive functioning, answered this question correctly (Gatz et al., 1995). A cut off score of 15 out of 19 points on the current version of the TELE is in line with the original articles and allows for a balance of potential false positives and false negatives. Participants with total scores below 15 were excluded from the study. 
Giving Support 43

\section{Procedures}

Participants age 60 or older were recruited from four ophthalmologists at the West Virginia University Eye Institute. Physicians, technicians, nurses, medical residents, and medical fellows approached potential participants to receive permission for the research staff to approach the participants. Participants could also self-refer to the study. Informational fliers were placed in the Eye Institute. Participants were given the choice to sign the consent form immediately or were provided stamped and addressed envelopes to return the consent forms at a later time. All participants received a list of local mental health resources and the phone number for the national suicide hotline during this first encounter. Participants who consented to participate identified a time and day for an approximately one hour telephone interview or inperson interview that was conducted at the participant's location of choice. As part of the eligibility screening, participants were given a five-minute cognitive screener (TELE) during the scheduled interview. Participants who screened positive for possible cognitive impairment were asked basic demographic information, but did not receive the full battery of measures.

Participants who screened negative for possible cognitive impairment received the full interview battery. All participants who participated in the telephone or in-person survey received a small monetary compensation of a $\$ 5$ gift card to a national store.

A suicidal risk assessment, using the Suicide Older Adults Protocol (Fremouw, McCoy, Tyner, \& Musick, 2009), was conducted on the six participants who expressed suicidal ideation during the course of the interview in order to ensure the safety of these participants. Information collected on the suicide protocol was not included in the data analysis. A participant was defined as endorsing current active or passive suicidal ideation if any of the following occurred:

endorsement of either items 14 and 15 on the CESD-R scale, a score of 2 or more on items 1 or 2 on the MSSI, or a score of 1 or more on items 3 or 4 on the MSSI. After the suicide risk 
assessment was administered, the supervising psychologist was consulted and appropriate referrals were provided to these participants.

\section{Analyses}

To address the three specific aims of this study, all analyses were performed using SAS 9.3 statistical software ("SAS for Windows (9.3) ").

For descriptive statistics, Pearson product-moment correlation was used for continuous variables and Spearman's rho rank correlation was used for ordinal variables. Biserial correlation was used for volunteer status and suicide, as these variables were dichotomized from continuous variables.

The three volunteer variables (status, number of groups, and hours) had high correlations, which increased the risk of multicollinearity (see Table 3). Further, previous research suggests these volunteer variables may have differing strengths of relations with mental health outcomes, suggesting they are similar, but conceptually different variables (Morrow-Howell et al., 2003). Therefore, the variable, volunteer hours, was used as the primary measure of volunteer activity. Volunteer status and the number of volunteer groups were included in additional regression models as independent variables; differences in the three variables were noted.

The informal and formal support giving measures also appeared to be measuring different constructs as evidenced by the reviewed literature suggesting differential relations between the measures of support and the dependent variables. Additionally, the small to moderate size correlation between the support variables within this study suggest conceptually different constructs. As such, these two measures were maintained as separate independent variables.

Age, gender, education, general disability, and visual functioning were included as control variables due to evidence from past literature and the variables' relations to dependent variables within this data. Age has been found to be associated with depression (Kessler, Foster, 
Webster, \& House, 1992), life satisfaction (Chen, 2001), and suicide risk (Caine \& Conwell, 2001). Further, age was significantly correlated with reasons for living in this study. Gender has been found to be associated with depression (Kuchibhatla, Fillenbaum, Hybels, \& Blazer, 2012; Leveille, Penninx, Melzer, Izmirlian, \& Guralnik, 2000), life satisfaction (Enkvist, Ekström, \& Elmståhl, 2012), reasons for living (Edelstein et al., 2009), and suicide risk (Caine \& Conwell, 2001). Gender was also related to reasons for living within this study. Finally, education has been associated with depression (Kuchibhatla et al., 2012), life satisfaction (Enkvist et al., 2012; Meeks \& Murrell, 2001), reasons for living (Edelstein et al., 2009), and suicide risk (Rubenowitz et al., 2001; Wiktorsson et al., 2010). Disability variables (general disability and visual functioning) were also included as covariates due to their correlations with depression, suicide, and life satisfaction variables within this study and their possible confounding relation between social support and mental health (Lowenstein et al., 2007). Multicollinerity between disability variables was not detected in analyses using conditioning index and variance proportion criteria established in Tabachnick and Fidell (2007).

For the primary hypotheses, three sets of hierarchical regressions were used to test whether the dependent variables, depressive symptoms, life satisfaction, and reasons for living, were related to the independent variables, informal support giving, volunteer hours, and satisfaction with support received. Age, gender, education, general disability, and visual functioning were included in the first step; the independent variable was included in the second step. Multiple imputation was used for reasons for living as described due to missing data. Hierarchical logistic regressions were used to model the relation between the presence of suicidal ideation and the support variables. Age, gender, education, general disability, and visual functioning were included in the first step; the independent variable was included in the second 
step. With a sample size of 101 participants, one predictor variable, and five control variables, this study was powered at .80 to find a moderate effect size.

Additionally, a hierarchical regression analysis was used to model the influence of support received from others and informal support given to others on satisfaction with support received. Age, gender, education, general disability, visual functioning, and support received from others were included in the first step, informal support given to others was included in the second step. With a sample size of 101 participants, one predictor variable, and six control variables, this study was powered at .80 to find a moderate effect size.

Standardized beta weights were reported for the outcomes: depressive symptoms and life satisfaction. The standardized beta weight is a parameter measure that indicates the change in the dependent variable when the predictor variable increases or decreases by one standard deviation. Unstandardized coefficients were reported for reasons for living. This parameter measure indicates the unit change in the dependent variable when the predictor variable increases or decreases by one unit on the variable's scale. Odds ratios were reported for models using suicide ideation as the predictor variable. The odds ratio is the odds that an outcome will occur given an increase or decrease in the predictor variable.

To investigate the stress-buffering model of social support on general disability and mental health outcomes, the interaction of support provided, volunteer hours, and perceived satisfaction with support received from others with general disability were included in three sets of hierarchical regression models predicting depressive symptoms, life satisfaction, and reasons for living. Age, gender, education, the centered disability variable, and centered independent variable were included in the first step, the interaction term between the independent variable and disability variable was included in the second step. Multiple imputation was used to estimate regression pathways when using reasons for living as the outcome variable. The 
interactions of support provided, volunteer hours, and perceived satisfaction with support received from others with general disability were included in a hierarchical logistic regression model predicting the presence of suicide ideation. Age, gender, education, the centered disability variable, and centered independent variable were included in the first step, the interaction term between the independent variable and disability variable was included in the second step.

To investigate the stress-buffering model of social support on visual functioning and mental health outcomes, the interaction of support provided, volunteer hours, and perceived satisfaction of support received from others with visual functioning were included in three sets of hierarchical regression models predicting depressive symptoms, life satisfaction, and reasons for living. Age, gender, education, the centered visual functioning variable, and centered independent variable were included in the first step, the interaction term between the independent variable and visual functioning variable was included in the second step. Multiple imputation was used to estimate regression pathways for the outcome reasons for living. The interaction terms for support provided, volunteer hours, and perceived satisfaction of support received from others with visual functioning were included in a hierarchical logistic regression predicting the presence of suicide ideation. Age, gender, education, the centered visual functioning variable, and centered independent variable were included in the first step, the interaction term between the independent variable and visual functioning variable was included in the second step. Differences in the interactions between volunteer status and volunteer groups and disability were reported. With a sample size of 101 participants, one predictor variable, and six control variables, this study was powered at .80 to find a moderate effect size.

To investigate the mediation model, the PROCESS bootstrapping test of mediation was used (Hayes, 2012). This macro estimates the direct and indirect effects of independent, 
mediator, and dependent variables using 1,000 random resampling with replacement of the current data, also referred to as bootstrapping. The means of the direct and indirect pathways and the bias-corrected upper and lower limits using 95\% confidence intervals are derived from the 1,000 bootstrap samples. Pathways are deemed significant if the confidence intervals do not cross zero (Hayes, 2012; Preacher \& Hayes, 2008). The bootstrapping test of mediation has improved power, improved type 1 error rates when compared to the traditional Baron and Kenny model of mediation, and do not require normality in distribution of the data (MacKinnon, Lockwood, Hoffman, West, \& Sheets, 2002; Preacher \& Hayes, 2004).

\section{Results}

Table 3 displays the correlations between variables included in the models. Visual acuity in the better eye, visual field restriction, visual functioning, general disability, informal support provided, satisfaction with support received from others, reasons for living, depressive symptoms, and life satisfaction were related to the presence of suicidal ideation. General disability, visual functioning, visual acuity in the better eye, visual field restriction, perception of social support, and life satisfaction were correlated with total depressive symptoms. Age, gender, and the amount of support received from family, friends, and neighbors were correlated with reasons for living. Depressive symptoms, life satisfaction, and the presence of suicide ideation were correlated with each other in the expected direction. Suicide ideation and reasons for living were also correlated in the expected direction.

Providing support was positively correlated with volunteer status, the number of volunteer organizations, and the number of hours volunteered, such that higher rates of giving support to family and friends was related to higher reported volunteer activity. Informal support giving was also related to the total support received from others, general disability, the amount of education of the individual, and income; individuals who provided more support to family and 
friends also reported receiving more support. Support giving was related to better visual functioning, higher levels of education, and higher income levels. Age was negatively correlated with the provision of support; older individuals reported lower levels of support giving.

The number of hours volunteered over the past twelve months was positively correlated with education, income, general disability, and visual functioning; individuals who reported more education, income, general functioning, and visual functioning also reported more volunteer behavior over the past twelve months. Visual field restriction and lower acuity in the better eye were negatively correlated with the number of hours volunteered. Volunteer status and the number of volunteer organizations had similar correlations as the number of volunteer hours, except volunteer status was not significantly correlated with visual functioning.

Individuals who reported feeling more satisfied with support received from others reported fewer levels of depressive symptoms and were less likely to report suicidal ideation. Further, individuals with better visual impairment and general functioning also reported more satisfaction with support received. Life satisfaction was positively related to satisfaction with support received. Individuals with better satisfaction with support also reported more lifesatisfaction.

The first specific aim of this study was to determine the cross-sectional direct effects of providing informal support, volunteer activity, and satisfaction with support on depressive symptoms, life satisfaction, suicide ideation, and reasons for living in older adults with vision related diagnoses.

The first hypothesis was that giving greater amounts of informal support to others would be associated with lower levels of depressive symptoms, the absence of suicidal ideation, higher levels of reasons for living, and higher levels of life satisfaction among older adults with vision related diagnoses (See Tables 4-6). Providing support to others was a significant predictor of the 
presence of suicide ideation, while controlling for age, gender, education, disability, and visual functioning, $\Delta \chi^{2}(1, N=101)=5.95, p=.01$. Individuals who reported giving more support were less likely to report suicide ideation. Informal support giving did not significantly predict depressive symptoms, $\Delta R^{2}=.01, \Delta F(1,94)=1.56, p=.21$, life satisfaction, $\Delta R^{2}=.002 \Delta F$ $(1,94)=.21, p=.65$, or reasons for living, $\Delta R_{\text {average }}^{2}=.004, \Delta F_{\text {average }}(1,94)=.11, p=.74$.

The second hypothesis was that volunteering would predict lower levels of depressive symptoms, the absence of suicide ideation, higher levels of reasons for living, and higher levels of life satisfaction among older adults with vision related diagnoses (See Tables 7-9). The multiple imputation regression pathways predicting reasons for living, while controlling for age, gender, education, disability, and visual functioning, yielded significant results. The number of volunteer hours was a significant predictor of reasons for living, such that participants who reported more hours spent volunteering also reported higher levels of reasons for living; however, the inclusion of volunteer hours did not significantly improve the model above and beyond the control variables, $\Delta R_{\text {average }}^{2}=.004, \Delta F_{\text {average }}(1,94)=2.93, p=.09$. Volunteer status was also a significant predictor of reasons for living in the same direction. However, the number of organizations with which the participant volunteered during the past twelve months was not related to reasons for living. The number of hours volunteered did not predict depressive symptoms, $\Delta R^{2}=.002, \Delta F(1,94)=.27, p=.60$, life satisfaction, $\Delta R^{2}=.00, \Delta F(1,94)=.02, p=$ .88 , or the presence of suicide ideation, $\Delta \chi^{2}(1, N=101)=1.44, p=.23$, when controlling for age, gender, education, disability, and visual functioning.

The third hypothesis of the study was that better satisfaction with support would be associated with lower levels of depressive symptoms, absence of suicidal ideation, higher levels of reasons for living, and higher life satisfaction in older adults with vision related diagnoses (See Tables 10-12). Satisfaction with support received from others was a significant predictor of 
depressive symptoms while controlling for age, gender, education, disability, and visual functioning, $\Delta R^{2}=.04, \Delta F(1,94)=4.67, p=.03$. Satisfaction with support received was a significant predictor of suicide ideation, while controlling for age, gender, education, general disability, and visual functioning, $\Delta \chi^{2}(1, N=101)=6.30, p=.01$. Satisfaction with support was also significantly related to reasons for living while controlling for age, gender, education, disability, and visual functioning, $\Delta R_{\text {average }}^{2}=.03, \Delta F_{\text {average }}(1,94)=4.55, p=.04$. Individuals with higher satisfaction with support reported higher levels of reasons for living, fewer depressive symptoms, and were less likely to report suicidal ideation. Perceived satisfaction with support was not a significant predictor of life satisfaction, $\Delta R^{2}=.02, \Delta F(1,94)=1.92$, $p=.17$.

The second specific aim of this study was to examine the cross-sectional association between providing informal support to others and the perception of quality of social support received from others in older adults with vision related diagnoses. It was hypothesized that the provision of greater amounts of support to others would be associated with better perceived quality of social support received from others among older adults with vision related diagnoses. However, informal support given was not significantly related to satisfaction with support received, $\Delta R^{2}=.02, \Delta F(1,94)=1.72, p=.19$ (See Table 13). Support received from others was also not related to the perception of the quality of support received.

The first exploratory question addressed the moderating role of giving informal support, volunteering, and satisfaction with support on disability and depressive symptoms, suicide ideation, reasons for living, and life satisfaction. In the model testing the interactive effect of satisfaction with support received and measures of disability, while controlling for age, gender, and education, the interaction between the satisfaction with support and general disability significantly predicted life satisfaction, $\Delta R^{2}=.05, \Delta F(1,94)=4.71, p=.03$ (See Table 14). To 
explore the interactive effects of disability and perceived satisfaction with support, disability was spilt at the median (ADL $M d n=62.70)$ to create a dichotomous variable of high functional impairment and low functional impairment. Satisfaction with support received was split at the median (PSR $M d n=3$ ) to create a dichotomous variable of high satisfaction with support received and low satisfaction with support received. The relation between experiencing more functional disability and lower life satisfaction was found only in individuals who also expressed lower levels of satisfaction with support received from others (See Figure 2).

The interaction of visual functioning and satisfaction with support was also significant when predicting life satisfaction, $\Delta R^{2}=.08, \Delta F(1,94)=10.01, p=.002$. The visual function composite score was split at the median (VFQ $M d n=82.46)$ to create a dichotomous variable of high visual functioning and low visual functioning. The dichotomized satisfaction with support variable described above was used to model high and low perceived quality of support. Consistent with the interaction effect found with general disability, individuals with lower levels of satisfaction with support and lower visual functioning reported lower life satisfaction compared to individuals with higher levels of satisfaction with support (See Figure 3).

Satisfaction with support received from others did not moderate the relation between measures of general disability and visual functioning and depressive symptoms (ADLs: $\Delta R^{2}=.02, \Delta F(1,94)$ $=2.34, p=.13$; VFQ: $\left.\Delta R^{2}=.01, \Delta F(1,94)=2.36, p=.13\right)$, reasons for living (ADLs: $\Delta R_{\text {average }}^{2}$ $\left.=.01, \Delta F_{\text {average }}(1,94)=1.61, p=.21 ; \mathrm{VFQ}: \Delta R_{\text {average }}^{2}=.002, \Delta F_{\text {average }}(1,94)=.66, p=.42\right)$, or suicide ideation $\left(\mathrm{ADLs}: \Delta \chi^{2}(1, N=101)=.38, p=.46\right.$; VFQ: $\left.\Delta \chi^{2}(1, N=101)=.02, p=.89\right)$ (See Tables 14-16).

The regression analyses investigating the moderating effect of informal support giving while controlling for age, gender, and education, did not find a moderating effect of support giving on the relation between disability or visual functioning and depressive symptoms (ADLs: 
$\Delta R^{2}=.003, \Delta F(1,94)=.79, p=.38 ;$ VFQ: $\left.\Delta R^{2}=.006, \Delta F(1,94)=.65, p=.42\right)$, life satisfaction (ADLs: $\Delta R^{2}=.005, \Delta F(1,94)=.56, p=.46$; VFQ: $\left.\Delta R^{2}=.01, \Delta F(1,94)=.37, p=.54\right)$, reasons for living (ADLs: $\Delta R_{\text {average }}^{2}=.01, \Delta F_{\text {average }}(1,94)=.67, p=.42 ; \mathrm{VFQ}: \Delta R_{\text {average }}^{2}=.01, \Delta F_{\text {average }}$ $(1,94)=1.79, p=.18)$, or suicide ideation (ADLs: $\Delta \chi^{2}(1, N=101)=.58, p=.44 ;$ VFQ: $\Delta \chi^{2}$ $(1, N=101)=2.08, p=.15)($ See Tables 17-19).

Within the models testing the interaction between formal support giving and measures of disability, the number of hours volunteered did not moderate the relation between disability or visual functioning and depressive symptoms (ADLs: $\Delta R^{2}=.001, \Delta F(1,94)=.03, p=.74$; VFQ: $\left.\Delta R^{2}=.0001, \Delta F(1,94)=.03, p=.86\right)$, life satisfaction $\left(\mathrm{ADLs}: \Delta R^{2}=.003, \Delta F(1,94)=.29, p=\right.$ .59 ; VFQ: $\left.\Delta R^{2}=.00, \Delta F(1,94)=.02, p=.89\right)$, reasons for living (ADLs: $\Delta R_{\text {average }}^{2}=.01$, $\left.\Delta F_{\text {average }}(1,94)=1.59, p=.21 ; \mathrm{VFQ}: \Delta R_{\text {average }}^{2}=.02, \Delta F_{\text {average }}(1,94)=2.40, p=.12\right)$, or suicide ideation (ADLs: $\Delta \chi^{2}(1, N=101)=1.18, p=.28$; VFQ: $\left.\Delta \chi^{2}(1, N=101)=3.35, p=.07\right)($ See Tables 20-22). Similarly, volunteer status and the number of volunteer organizations did not moderate the relation between disability and mental health (See Tables 23-28).

The second exploratory question assessed the mediating-indirect model of giving informal support, volunteer behavior, and perceived satisfaction with support received form others within the relation between disability and depressive symptoms, suicide ideation, reasons for living, and life satisfaction. There was a small indirect effect of both measures of disability on reasons for living through the intervening variable, volunteer hours (See Table 29). The number of hours an individual volunteered during the past twelve months was a significant intervening variable within the relation between general disability and reasons for living, $R^{2}=$ $.18, F(5,91)=4.11, p=.03$. Participants with fewer limitations in ADLs reported more hours of volunteer activity. More hours spent volunteering during the past year was related to higher levels of reasons for living endorsed by the participants. Volunteer hours was also an 
intervening variable within the relation between visual functioning and reasons for living, $R^{2}=$ $.19, F(5,91)=4.12, p=.03$. Higher levels of visual functioning were related to more reported hours volunteered. Participants reporting higher number of hours volunteered also reported higher levels of reasons for living. The number of volunteer organizations also had a significant, but small, intervening effect in the same manner as volunteer hours within the relation between both measures of disability and reasons for living (ADLs: $R^{2}=.19, F(5,91)=4.33, p=.001$; VFQ: $\left.R^{2}=.19, F(5,91)=4.30, p=.002\right)($ See Table 30$)$. The number of volunteer hours did not have a significant intervening effect on the relation between measures of disability and depressive symptoms (ADLs: $R^{2}=.15, F(5,95)=3.56, p=.008$; VFQ: $R^{2}=.09, F(5,95)=1.87$, $p=.11)$, life satisfaction $\left(\mathrm{ADLs}: R^{2}=.11, F(5,95)=2.36, p=.05 ; \mathrm{VFQ}: R^{2}=.16, F(5,95)=\right.$ $3.72, p=.004)$, or suicide ideation $\left(\mathrm{ADLs}: \chi^{2}(5, N=101)=6.62, p=.05\right.$; VFQ: $\chi^{2}(5, N=101)$ $=9.92, p=.05)$. An intervening effect on the relation between disability and depressive symptoms, life satisfaction, or suicide ideation was not found for the number of volunteer organizations (See Table 30).

There was a small, but significant, indirect effect of visual functioning on depressive symptoms through the intervening variable, satisfaction with support received, $R^{2}=.12, F(5,95)$ $=2.48, p=.04$ (See Table 31). Individuals with higher visual functioning also reported more satisfaction with the support received. Better satisfaction with support was related to fewer depressive symptoms. Further, visual functioning had a small, but significant indirect effect on reasons for living through satisfaction with support, $R^{2}=.16, F(5,91)=4.36, p=.001$. Higher visual functioning was related to higher reported perceived quality of support, which in turn was related to higher levels of reasons for living. Satisfaction with support received did not have a significant intervening effect on the relation between general disability and depressive symptoms, $R^{2}=.19, F(5,95)=4.45, p=.001$, or reasons for living, $R^{2}=.18, F(5,91)=4.06, p$ 
$=.002$. The satisfaction with support received did not have a significant intervening effect on the relation between measures of disability and life satisfaction (ADLs: $R^{2}=.12, F(5,95)=3.12, p=$ .04 ; VFQ: $\left.R^{2}=.18, F(5,95)=4.14, p=.002\right)$ or suicide ideation $\left(\right.$ ADLs: $\chi^{2}(5, N=101)=$ 13.42, $p=.04$; VFQ: $\left.\chi^{2}(5, N=101)=14.75, p=.02\right)$.

There was no significant intervening effect of informal support giving on either the relation between measures of disability and depressive symptoms (ADLs: $R^{2}=.16, F(5,95)=$ $3.68, p=.004$; VFQ: $\left.R^{2}=.08, F(5,95)=1.56, p=.18\right)$, life satisfaction (ADLs: $R^{2}=.11, F$ $(5,95)=2.37, p=.04$; VFQ: $\left.R^{2}=.16, F(5,95)=3.76, p=.004\right)$, reasons for living (ADLs: $R^{2}=$ $.15, F(5,91)=3.23, p=.02$; VFQ: $\left.R^{2}=.16, F(5,91)=3.59, p=.009\right)$, or suicide ideation ADLs: $\chi^{2}(5, N=101)=110.63, p=.01$; VFQ: $\left.\chi^{2}(5, N=101)=14.45, p=.001\right)$ (See Table $32)$.

\section{Discussion}

This study had several significant findings. Informal support giving was a significant predictor of the presence of suicide ideation such that higher reports of giving support to others were associated with a lower risk of endorsing suicidal ideation. There are several possibilities that may explain why informal support giving may decrease the risk for suicide ideation.

Providing support may decrease a sense of over benefiting within a relationship, which has been found to be related to a decrease in self-perceived burden (McPherson et al., 2010). A sense of burden has been found to be significantly related to an increased risk for suicidal ideation (Jahn \& Cukrowicz, 2011; Van Orden et al., 2010). A sense of obligation to either family or friends has also been found to be related to less severe suicidal ideation (Britton et al., 2008); the measurement of support given to family or friends may be capturing an aspect of this perceived obligation. Finally, providing support may increase a person's sense of social integration and decrease loneliness, which are significant predictors of suicide risk (Beautrais, 2002). As this is 
the first study to investigate the relation between informal support giving and suicide risk, more research is needed to replicate this result in a visually impaired population and other older adult populations in order to address these questions.

Another important finding of this study demonstrated that the number of volunteer hours a person reports engaging in over the past year was a significant predictor of reasons for living, but was not a significant predictor of suicidal ideation. Being a volunteer and the number of hours volunteered were related to an increase in levels of reasons for living. This suggests that while volunteer behavior does not have a direct impact on suicide ideation, it may indirectly decrease suicide risk via its positive impact on a protective factor against suicide. The measure of number of different types of volunteer organizations the person reported being engaged with during the past year was not significantly related to reasons for living. Although the number of different types of organizations may be one measure of volunteer activity (i.e., the more types of groups volunteered with may indicate more overall volunteer activity) it may also be measuring another component of volunteer behavior, like motivation, or may have a restricted range.

Volunteer activity partially explained the indirect relation between greater disability and lower levels of reasons for living, such that higher levels of disability reported was associated with fewer number of volunteer hours and fewer number of types of organizations; the lower levels of volunteer hours and volunteer organizations were associated with lower levels of reasons for living. However, it is important to note the relations between both measures of disability and reasons for living were nonsignficant. Mathieu and Taylor (2006) distinguishes between a mediating effect, in which the intervening variable explains the relation between the independent and dependent variables, and an indirect effect, in which an intervening variable is impacted by the independent variable, and subsequently has an effect on the dependent variable. An indirect effect provides information on how the intervening variable impacts the outcome 
through its relation with other variables and does not necessitate a significant relation between the independent and dependent variable (Hayes, 2009; Mathieu \& Taylor, 2006). A nonsignficant pathway between the measures of general disability and reasons for living may also suggest there may be additional mediating variables not accounted for within this model that act as suppressor variables (Hayes, 2009). These results illustrate one method by which disability may confer greater suicide risk as it curtails volunteer activity, which in turn is related to lower levels of reasons for living. However, these results do not support a conclusion that volunteer activity mediated the relation between disability and reasons for living.

It is notable that volunteering was an intervening variable within the relation between disability and reasons for living, but informal support giving to others did not. One explanation for the lack of significant results is that this study was underpowered to detect a small intervening effect of informal support giving on mental health within the mediating model. However, these results may also indicate that there may be a particular quality of volunteer behavior that differentiates it from providing support to family or friends. For example, the motivations behind volunteer behavior may be different from the motivations behind giving support. The driving motivation to engage in volunteer behavior moderated the relation between volunteer behavior and mortality (Konrath, Fuhrel-Forbis, Lou, \& Brown, 2012). Individuals who express volunteer motivations related to valuing helping/showing compassion towards others had a lower mortality rate over four years, compared to individuals who expressed more self-oriented volunteer motivations (e.g., learning, distraction from personal troubles, improving self-esteem). It is unclear whether this differential effect of motivation driving the behavior would also be found in mental health outcomes or if it would distinguish between informal and formal giving behavior. 
Satisfaction with support received from others was a significant predictor of depressive symptoms, suicide ideation, and reasons for living. Individuals reporting more satisfaction with the support received from others also reported fewer depressive symptoms, higher levels of reasons for living, and lower levels of suicide ideation. These results support the literature connecting satisfaction with support and depression and suicide risk, thus strengthening the evidence for the importance of good quality of support in the mental health of older adults (Duberstein, Conwell, Conner, Eberly, Evinger, et al., 2004; Jang et al., 2002; Taylor \& Lynch, 2004). Feeling that one's support from family and friends is adequate most likely contributes to a sense of social integration and decreases a sense of loneliness, both of which lead to a lower suicide risk (Rubenowitz et al., 2001; Van Orden et al., 2010). Further, the relation between satisfaction with support and reasons for living is interesting as it suggests one possible mechanism by which satisfaction with support decreases older adults' suicide risk. Increasing a person's perception they are receiving satisfactory support may also be increasing the protective factors against suicide risk.

Satisfaction with support received from others buffered the effects of disability on life satisfaction. Individuals with higher rates of disability and lower levels of satisfaction with support reported lower levels of life satisfaction compared with individuals with higher rates of disability and higher levels of perceived quality of support. This relation was consistent across a broad measure of disability and a measure of visual functioning. For individuals encountering significant impairments in functioning, their cognitive appraisal of the overall quality of life may be influenced by their assessment of whether the support received adequately met their needs (i.e., not too much or too little). Within this study, individuals who expressed dissatisfaction with support tended to endorse wanting more support. This finding speaks to the importance of targeting the individual's expectations regarding the support they receive and the individuals' 
skills related to requesting more support, as well as helping family and friends change how they provide support when disability is present.

Finally, satisfaction with support received also had a small intervening effect on the relation between visual functioning and depressive symptoms. Higher rate of visual functioning was related to lower levels of depressive symptoms. This relation was partially explained by the relation between higher rates of visual functioning and better perceived quality of support and the relation between higher satisfaction with support and lower levels of depressive symptoms. As there was a significant total effect between visual functioning and depressive symptoms, these results suggest satisfaction with support received may partially mediate the relation between visual functioning and depressive symptoms. Satisfaction with support received also had a small intervening effect on the relation between visual functioning and reasons for living, such that higher levels of visual functioning were related to higher levels of satisfaction with support and subsequently to higher levels of reasons for living. The intervening effect of satisfaction with support on depressive symptoms is aligned with previous literature (Newsom \& Schulz, 1996; Taylor \& Lynch, 2004). A mediating effect could not be detected in these results, as there was not a significant pathway between visual functioning and reasons for living. The intervening effect of perceived satisfaction with support on reasons for living through the relation between visual functioning and satisfaction with support is interesting as it further suggests how disability decreases in functioning increases suicide risk in older adults. The increased unmet need or unwanted support that may come with increasing impairment in activities of daily living may lead to a disengagement from reasons for living and increase a sense of distress. It is unclear why these intervening effects were not significant when using a measure of general disability. One explanation may be the non-normal distribution of general disability resulting in a type II error. Further, this study may have been underpowered to detect a 
small intervening effect of satisfaction with support on mental health within the relation between general disability and mental health. This finding could also indicate that an older adult may react differently when confronted with visual related limitations compared to other disablement processes.

This study also had several nonsignficant results that are important to note. Informal support giving was not a significant predictor of depressive symptoms, reasons for living, or life satisfaction. The lack of results may be due to the low rate of depressive symptoms in this study; however, this result also supports the previous literature that has not found a significant relation between giving and depression (Krause et al., 1992; Liang et al., 2001; Reinhardt, 2001). Further, small effects between informal support giving and depressive symptoms, reasons for living, or life satisfaction may not have been detected due to this study's low power. Another explanation for the lack of results may be that the measure of giving support captured types of support giving behaviors that also place strain on the older adult, such as providing extensive care to grandchildren (Fuller-Thomson \& Minkler, 2000) or providing care to a spouse experiencing significant health problems or cognitive impairment (Beach, Schulz, Yee, \& Jackson, 2000). Although these support giving behaviors may positively impact constructs that decrease suicide risk, like increasing a sense of responsibility or a decreasing the sense of being a burden to others, the behaviors may also increase stain, stress, or a sense of being burdened, resulting in the differential relation between depression and suicide ideation.

Volunteer behavior did not predict depressive symptoms, life satisfaction, or suicide ideation. These results may seem contradictory to the previous literature that has found significant relations between volunteer behavior, depression and life satisfaction (Y Li, 2007; Y. Li \& Ferraro, 2005; Lum \& Lightfoot, 2005; Morrow-Howell et al., 2003; Wheeler et al., 1998; Wu et al., 2005). However, a large number of these studies were longitudinal. The beneficial 
effects of current volunteer behavior may present itself at a later time in the future or beneficial effects may be seen over sustained volunteer activity. Additionally, the low levels of depressive symptoms in the present study may have limited the study's ability to find a relation between volunteer behavior and depressive symptoms. The lack of significant results may have also been due to the low power of this study to detect small effects.

Satisfaction with support was not directly related to life satisfaction. This also contradicts the previous literature that found a direct relation between satisfaction with support and life satisfaction in older adults (Berg et al., 2006; Reinhardt, 2001). It is possible that the direct relation between satisfaction with support and life satisfaction is present but relatively small. The measure used in this study to assess satisfaction with support assessed the presence of too much or too little support received. Overall, the perception of support received was relatively positive, with most individuals reporting satisfaction with the tangible, informational, and emotional support received from family, friends, and neighbors. Of the individuals who expressed some dissatisfaction with the support received, most expressed a desire for more support, suggesting participants were more likely to experience unmet needs rather than experiencing a negative reaction to support received as has been found in other studies (Newsom \& Schulz, 1998). Individuals who experience a negative reaction to support received, compared to individuals who experience unmet needs, may be more likely to experience a sense being a burden and subsequently decreased life satisfaction. Other forms of cognitive appraisals of support received, like the presence of critical messages, fights, or other negative social behaviors, may also have a stronger relation to life satisfaction and well-being (S. L. Brown \& Vinokur, 2003; Newsom et al., 2005).

This study also set out to explore the relation between giving support to others and satisfaction with support received from others. In contrast to previous literature (Ko \& Lewis, 
2011; Krause, 1995), this study demonstrated no relation between giving support and the satisfaction with support received from others. Interestingly, the total amount of support received from others also did not significantly predict perceived quality of support. Several possible explanations may explain the lack of a result in this study. The satisfaction with support received measure was not normally distributed and had low internal consistency; this may have adversely impacted its ability to measure satisfaction with support resulting in an increased likelihood of a type II error. The previous studies finding a relation between providing support and satisfaction with support also utilized different populations, such as older adults not at increased risk for disability (Krause, 1995) or caregiving spouses (Kuijer et al., 2004). For older adults at risk for visual impairment there may be more important factors related to the satisfaction with support received than the amount of support they give to others or the amount of support they receive. Further, the relation between giving support and satisfaction with support received may vary depending on who is giving and receiving the support. For example, giving support to a spouse may be more important to the perception of the support received from the spouse (Ko \& Lewis, 2011) compared to other types of relationships. More research is needed in this area to understand better the relation between satisfaction with support received and giving support.

Informal and formal support giving behaviors did not modify the relation between disability and any mental health outcomes. This suggests the amount of support giving behaviors did not produce differential effects on mental health in older adults with and without disability. The satisfaction with support received also did not buffer the negative effects of disability on depressive symptoms, suicide risk, and reasons for living, lending support for the hypothesis that satisfaction with support has a direct effect, rather than a buffering effect, on these mental health outcomes (Jang et al., 2002). 
Finally, informal support giving did not mediate the relation between any mental health outcome and disability. Formal support giving did not mediate the relation between disability and depressive symptoms, suicide ideation, or life satisfaction. This suggests giving behaviors are more likely to have direct effect on depressive symptoms, suicide ideation, and life satisfaction rather than a mediating or moderating effect. Additionally, satisfaction with support received from others did not mediate the relation between disability and life satisfaction. Although there has been evidence of a mediating effect of satisfaction with support on life satisfaction (Newsom \& Schulz, 1996), this study's results suggest satisfaction with support played a moderating role in the relation between disability and life satisfaction, not a mediating role.

Several conclusions can be drawn from this study. The direct effects model of informal support giving on suicide ideation was supported. Volunteer behavior had a direct effect on reasons for living. Satisfaction with support received from others had a direct effect on depressive symptoms, suicide ideation, and reasons for living. Satisfaction with support also moderated the relation between all measures of disability and life satisfaction. Volunteer behavior had a small intervening effect on reasons for living through its relations with general disability and visual functioning, but did not mediate the relation between disability and reasons for living. Satisfaction with support partially mediated the relation between visual functioning and depression and had an intervening effect on the reasons for living through its relation with visual functioning.

The lack of a direct effect of informal support giving on satisfaction with support received suggests that within a sample of older adults with vision related diagnoses, providing support or maintaining a balance of give and take within a relationship was not influential in how the individual perceived their social support. The lack of a moderating or mediating role for 
support giving behaviors on the relation between disability and depressive symptoms or life satisfaction suggests that individuals were not necessarily experiencing burden due to these giving behaviors. Further, the lack of a moderating effect suggests that activity promotion that comes from support giving behaviors may not be more salient for older adults at risk for a decrease in behavioral activation due to disability. In this study, individuals with and without disability did not experience significant changes in depressive symptoms or life satisfaction due to support giving behaviors.

\section{Limitations}

There are several limitations to this study. Measurement of social support is multifaceted in nature and the selection of only a small number of those facets may have influenced the results of this study. The measure of satisfaction with support only assessed the presence of too much or too little of tangible, emotional, and informal support from family and friends. The perception of negative social interactions, such as critical messages or unsympathetic behavior, was not measured in this study. Further, the measures of satisfaction with support received, support received from others, support given to others did not assess the social interactions with friends and family separately. Nevertheless, the use of these specific areas of social support suggests which facets of social support may have potential for future research.

The use of self-reported level of support given to others over a one year period and not a measure of the daily acts of support exchange may be a limitation as it is not possible to determine whether the participants over reported or under reported supportive behaviors. Nevertheless, the use of the perception of support giving is consistent with the literature that suggests that it is not the actual amount of support exchange, but rather the perception of the interactions with the network that is related to mental health outcomes (Cohen \& Wills, 1985). 
Additionally, the measure of satisfaction with support received from others may not have adequately measured the intended construct as evidenced by the low Cronbach's alpha and nonnormal distribution increasing the risk of type I or type II errors. The low number of items include in this measure may have adversely effected the internal consistency. As the items were measuring satisfaction with the adequacy of three different types of support received, the combined total score may have been measuring three different constructs of satisfaction with support leading to low internal consistency. A measure with additional items assessing adequacy of social support may help improve the overall measurement of perceived quality of support.

Overall, this sample of older adults with vision related diagnoses had a low rate of depressive symptoms compared to other samples using community dwelling older adults and visually impaired older adults (Djernes, 2006; Evans et al., 2007). Additionally, this sample had a low rate of suicide ideation compared to other samples of visually impaired individuals (Waern et al., 2002; Waern et al., 2003). These lower rates may have limited this study's ability to detect significant relations between support variables, depressive symptoms, and the presence of suicide risk. Nevertheless, several significant findings were detected. Further limiting this study's ability to detect significant but small effects is the low power. A sample size of 101 was not sufficient to detect small effects, suggesting nonsignficant results be interpreted cautiously.

The recruitment of participants from West Virginia resulted in a predominantly white sample, which limits external validity. Nevertheless, in 2010 West Virginia had a death by suicide rate of 18.21 per 100,000 for adults over the age of 60 compared to the national rate of 15.10 per 100,000 in older adults over the age of 60 (Centers for Disease Control, 2010). Further, older white men have the highest rate of death by suicide (31.31 per 100,000 in 2010). This suggests that understanding suicide risk and protective factors in West Virginia and within a primarily white sample with $44 \%$ male participants may be particularly salient. The use of only 
participants selected due to their risk for visual disability also limits the external validity to other forms of impairment that may take a different disablement trajectory compared to visual related impairments (Taylor \& Lynch, 2011). However, due to the relation between visual impairment, depression, and suicide, it is important to expand the understanding of factors that can help this population decrease their risk for suicide and poor mental health outcomes.

Another limitation of the study is the cross-sectional design, which precludes distinguishing cause and effect relations between giving support, perception of support, and mental health. Depression may influence a person's sense of how much support they give to others, or older adults with less depression may be generally more likely to maintain activity, like giving support or volunteering. Although there may be either reverse or bidirectional causation, there is evidence that giving support and volunteer activity precede changes in mental health (Y Li, 2007; Lum \& Lightfoot, 2005; Morrow-Howell et al., 2003; Musick \& Wilson, 2003). Additionally, the cross-sectional nature of this study limits the ability to make directional conclusions regarding the meditational models of support. There has been limited evidence regarding the role support giving behavior plays in the relation between disability and mental health, cross-sectional evidence, as found in this study, helps provide a foundation for modeling the role of social exchanges in future longitudinal studies.

\section{Conclusion and Future Directions}

This study is unique in its investigation of support giving behaviors and suicide risk. The direct effect of informal support giving on suicide ideation and the direct and indirect effect of volunteer behavior on reasons for living suggests two possible avenues that can be targeted to decrease suicide risk and elevate protective factors in older adults. Satisfaction with support also had a direct effect on depressive symptoms and suicide ideation as well as a direct and indirect effect on reasons for living. Further, satisfaction with support was related to better life 
satisfaction in individuals with higher rates of disability. Helping individuals experiencing disability improve their satisfaction with support may also help lower the risk for depression, and subsequently suicide risk, while elevating overall well-being and protective factors against suicide. These results provide a deeper understanding of how social exchanges can influence well-being and suicide risk in older adults within the context of disability.

As evident by the rate of volunteer and informal support giving behaviors within this sample, visual disability does not prevent individuals from engaging in these behaviors. Many of the activities reported as volunteer behavior, such as cooking dinners or visiting hospitals, as well as the informal support behavior, like giving advice or listening to someone's troubles, can be accomplished with limited vision or with the aid of assisted technology devices. Additionally, the relation between volunteer behavior and a person's value systems may be important for rehabilitation, as values such as religiosity have been found to be important in the adaptation process (Yampolsky, Wittich, Webb, \& Overbury, 2008). Vision rehabilitation could incorporate interventions designed to increase support giving behavior and satisfaction with support received from others in order to decrease the risk for depression or suicide and improve the well-being of older adults with visual impairment. Although older adults and older adults with vision impairment do report some declines in support giving behavior compared to younger adults, this study provides evidence that these behaviors are not incompatible with disability or vision impairment. Older adults are capable of engaging in both informal and formal support giving and the declines in support giving makes these areas of social support a feasible target for intervention.

There are several directions in which future studies can continue to advance this research. As mentioned above, a significant limitation to this study is the cross-sectional design. Longitudinal studies are important in illuminating causal relations between support giving and 
mental health. While this study did not find a relation between volunteer behavior and depression, previous studies using longitudinal designs have found a positive relation, suggesting the effect may not be detected via cross-sectional data. Further, cross-sectional self-report studies limit the ability to make conclusions regarding the clinical utility of targeting these behaviors. Intervention studies would allow researchers to investigate whether the positive benefits of giving support translates into positive and meaningful changes in clinical outcomes. Additionally, this study suggests that relations between support giving behaviors and mental health outcomes may be small; future studies should account for the need for larger samples in order to achieve sufficient power to detect significant but small pathways.

This study was a preliminary investigation of support giving behaviors and thus used a broad measure of informal support giving; future studies should continue to expand on this construct in order to understand better the nuances of support giving. For example, future studies could assess support giving behaviors within different types of relations (e.g., family, friends, and neighbors) as one study has reported differential effects of giving support to family versus friends on life satisfaction (Reinhardt, 2001). Additionally, incorporating measures that assess other components within the satisfaction with support giving (e.g., perceived inadequacies in support giving, obligation to provide support, sense of burden when providing support) may help the understanding of both the positive aspects of support giving as well as potential negative aspects. Britton et al. (2008) reported an interactive effect between family responsibility, hopelessness, and suicidal ideation, such that a sense of family responsibility strengthened the relation between hopelessness and suicidal ideation. This result may be reflecting the perception that the older adults are unable to provide support, despite feeling a sense of obligation. These additional appraisals of informal support giving behaviors may explain the lack of a relation between support giving behavior and depressive symptoms and the presence of a relation 
between support giving and suicide ideation. Including measures of support giving behaviors, the perception of ability to give support, and family obligation may help explain these findings. The construct of volunteer behavior should also be expanded upon in future research. This research investigated volunteer status, the number of hours and the number of different types of organizations. However, it is unclear whether the number of different types of organizations reflects volunteer activity level or a different facet of volunteering, such as diversity of interest or a person's personal values. Volunteer behavior may also encompass other facets beyond social exchanges, such as religiosity, that may have resulted in its beneficial effects. Measures of volunteer motivation and perceived benefits of volunteering may help broaden the understanding of the positive benefits of volunteer behavior.

The relation between giving support, suicide risk, and protective factors opens up interesting areas for future research. Giving support may decrease suicide risk by decreasing the sense of burden a person may feel towards family and friends, increasing social integration, increasing a person's sense of responsibility to others, or increasing a person's engagement with value driven behavior. Including measures of self-perceived burden, familial obligation, and social integration can help illuminate the ways giving support to others confers decreased suicide risk.

As discussed above, this study is limited in its generalization to older adults with vision related diagnoses. Other disablement processes, such as a high level of stable disability that can come with conditions like hip fractures or stroke, might exhibit different relations between giving support and mental health. Further, the timing of disability onset may also influence the relative importance of support giving behaviors. Individuals are more likely to experience depression at the onset of disability (Yang \& George, 2005) and the importance of support giving behavior may be more salient at that time. Additionally, giving informal and formal support may 
be an important factor in reducing suicide risk in older adults not characterized by disability. Giving support may decrease suicide risk in older adults without physical impairments but who are experiencing other risk factors such as substance abuse. Investigating these relations in community dwelling older adults as well as in older adults with alternative risk factors for suicide will increase the generalizability of this study's results from this study and broaden the understanding of how social exchanges impact suicide risk in older adults.

This study makes an important contribution to the literature through its evaluation of support giving behaviors within a sample of older adults at risk for functional disability. The significant relations between giving behaviors, suicide risk, and protective factors as well as the significant relations between satisfaction with support on depression and well-being present several potential areas for treatment and improved vision rehabilitation. This knowledge contributes to the foundation for the development of prevention programs that utilize support exchanges to decrease adverse mental health outcomes and improve well-being in older adults with vision related diagnoses. 


\section{Works Cited}

Antonucci, T. C., \& Akiyama, H. (1987). Social networks in adult life and a preliminary examination of the convoy model. Journal of Gerontology, 42(5), 519-527.

Areán, P. A., \& Ayalon, L. (2005). Assessment and Treatment of Depressed Older Adults in Primary Care. Clinical Psychology: Science and Practice, 12(3), 321-335. doi: 10.1093/clipsy/bpi034

Awata, S., Seki, T., Koizumi, Y., Sato, S., Hozawa, A., Omori, K., . . Tsuji, I. (2005). Factors associated with suicidal ideation in an elderly urban Japanese population: A communitybased, cross-sectional study. Psychiatry and clinical neurosciences, 59(3), 327-336. doi: 10.1111/j.1440-1819.2005.01378.x

Bandura, A. (1977). Self-efficacy: Toward a unifying theory of behavioral change. Psychological review, 84(2), 191-215. doi: 10.1037/0033-295X.84.2.191

Beach, S. R., Schulz, R., Yee, J. L., \& Jackson, S. (2000). Negative and positive health effects of caring for a disabled spouse: Longitudinal findings from the Caregiver Health Effects Study. Psychology and Aging, 15(2), 259-271. doi: 10.1037/0882-7974.15.2.259

Beautrais, A. L. (2002). A case control study of suicide and attempted suicide in older adults. Suicide and Life-Threatening Behavior, 32(1), 1-9. doi: 10.1521/suli.32.1.1.22184

Beck, A. T., Kovacs, M., \& Weissman, A. (1979). Assessment of suicidal intention: The Scale for Suicide Ideation. Journal of consulting and clinical psychology, 47(2), 343-352. doi: 10.1037/0022-006X.47.2.343

Beck, A. T., \& Steer, R. A. (1991). Manual for Beck Scale for Suicidal Ideation.

Berg, A. I., Hassing, L. B., McClearn, G. E., \& Johansson, B. (2006). What matters for life satisfaction in the oldest-old? Aging \& Mental Health, 10(3), 257-264. doi: $10.1080 / 13607860500409435$ 
Berkman, L. F., Glass, T., Brissette, I., \& Seeman, T. E. (2000). From social integration to health: Durkheim in the new millennium. Social science \& medicine, 51(6), 843-857. doi: $10.1016 / \mathrm{S} 0277-9536(00) 00065-4$

Bierman, A., \& Statland, D. (2010). Timing, social support, and the effects of physical limitations on psychological distress in late life. The Journals of Gerontology: Series B: Psychological Sciences and Social Sciences, 65B(5), 631-639. doi: $10.1093 /$ geronb/gbp 128

Boerner, K., \& Reinhardt, J. P. (2003). Giving While in Need: Support Provided by Disabled Older Adults. The Journals of Gerontology: Series B: Psychological Sciences and Social Sciences, 58B(5), S297-S304. doi: 10.1093/geronb/58.5.S297

Borg, C., Hallberg, I. R., \& Blomqvist, K. (2006). Life satisfaction among older people (65+) with reduced self-care capacity: The relationship to social, health and financial aspects. Journal of Clinical Nursing, 15(5), 607-618. doi: 10.1111/j.1365-2702.2006.01375.x

Bornman, J. (2004). The World Health Organisation's terminology and classification: Application to severe disability. Disability and Rehabilitation: An International, Multidisciplinary Journal, 26(3), 182-188. doi: 10.1080/09638280410001665218

Bradley, M. J. (2006). Quality of life in age-related macular degeneration: a review of the literature. Health And Quality Of Life Outcomes, 4, 97-97.

Brault, M. W. (2012). Americans With Disabilities: 2010 (Vol. P70-131, pp. P70-131). Washington, DC: U.S. Census Bureau.

Bravell, M. E., Zarit, S. H., \& Johansson, B. (2011). Self-reported activities of daily living and performance-based functional ability: A study of congruence among the oldest old. European Journal of Ageing, 8(3), 199-209. doi: 10.1007/s 10433-011-0192-6 
Britton, P. C., Duberstein, P. R., Conner, K. R., Heisel, M. J., Hirsch, J. K., \& Conwell, Y. (2008). Reasons for living, hopelessness, and suicide ideation among depressed adults 50 years or older. The American Journal of Geriatric Psychiatry, 16(9), 736-741. doi: 10.1097/JGP.0b013e31817b609a

Brown, E. (2007). Care recipients' psychological well-being: The role of sense of control and caregiver type. Aging \& Mental Health, 11(4), 405-414. doi:

$10.1080 / 13607860600963570$

Brown, R., \& Barrett, A. E. (2011). Visual impairment and quality of life among older adults: An examination of explanations for the relationship. The Journals of Gerontology: Series B: Psychological Sciences and Social Sciences, 66B(3), 364-373. doi: 10.1093/geronb/gbr015

Brown, S., Brown, R. M., House, J. S., \& Smith, D. M. (2008). Coping with spousal loss: Potential buffering effects of self-reported helping behavior. Personality and Social Psychology Bulletin, 34(6), 849-861. doi: 10.1177/0146167208314972

Brown, S., Nesse, R. M., Vinokur, A. D., \& Smith, D. M. (2003). Providing social support may be more beneficial than receiving it: Results from a prospective study of mortality. Psychological Science, 14(4), 320-327. doi: 10.1111/1467-9280.14461

Brown, S. L., \& Vinokur, A. D. (2003). The Interplay Among Risk Factors for Suicidal Ideation and Suicide: The Role of Depression, Poor Health, and Loved Ones' Messages of Support and Criticism. American Journal of Community Psychology, 32(1-2), 131-141. doi: 10.1023/A:1025659210192

Bruce, M. L. (2001). Depression and disability in late life: Directions for future research. The American Journal of Geriatric Psychiatry, 9(2), 102-112. doi: 10.1176/appi.ajgp.9.2.102 
Caine, E. D., \& Conwell, Y. (2001). Suicide in the elderly. International Clinical Psychopharmacology, 16(Suppl2), S25-S30. doi: 10.1097/00004850-200103002-00005

Campbell, V. A., Crews, J. E., Moriarty, D. G., Zack, M. M., \& Blackman, D. K. (1999).

Surveillance for sensory impairment, activity limitation, and health-related quality of life among older adults--United States, 1993-1997. MMWR.CDC Surveillance Summaries: Morbidity And Mortality Weekly Report.CDC Surveillance Summaries / Centers For Disease Control, 48(8), 131-156.

Centers for Disease Control. (2010). Web-based Injury Statistics Query and Reporting System (WISQARS) (online). Retrieved November 15, 2012 http://webappa.cdc.gov/sasweb/ncipc/mortrate10_us.html

Chen, C. (2001). Aging and life satisfaction. Social Indicators Research, 54(1), 57-79. doi: 10.1023/A:1007260728792

Cheng, S.-T., Lee, C. K. L., \& Chow, P. K.-Y. (2010). Social support and psychological wellbeing of nursing home residents in Hong Kong. International Psychogeriatrics, 22(7), 1185-1190. doi: 10.1017/S1041610210000220

Chwalisz, K., \& Vaux, A. (2000). Social support and adjustment to disability. In R. G. Frank \& T. R. Elliott (Eds.), Handbook of rehabilitation psychology (pp. 537-552). Washington, DC US: American Psychological Association.

Clemons, T. E., Chew, E. Y., Bressler, S. B., \& McBee, W. (2003). National Eye Institute Visual Function Questionnaire in the Age-Related Eye Disease Study (AREDS): AREDS Report No. 10. Archives Of Ophthalmology, 121(2), 211-217.

Cohen, S. (1988). Psychosocial models of the role of social support in the etiology of physical disease. Health Psychology, 7(3), 269-297. doi: 10.1037/0278-6133.7.3.269 
Cohen, S. (2004). Social Relationships and Health. American Psychologist, 59(8), 676-684. doi: 10.1037/0003-066X.59.8.676

Cohen, S., \& Wills, T. A. (1985). Stress, social support, and the buffering hypothesis. Psychological bulletin, 98(2), 310-357. doi: 10.1037/0033-2909.98.2.310

Conwell, Y., Duberstein, P. R., Hirsch, J. K., Conner, K. R., Eberly, S., \& Caine, E. D. (2010). Health status and suicide in the second half of life. International journal of geriatric psychiatry, 25(4), 371-379. doi: 10.1002/gps.2348

Davis, C., Lovie-Kitchin, J., \& Thompson, B. (1995). Psychosocial adjustment to age-related macular degeneration. Journal of Visual Impairment \& Blindness, 89(1), 16-27.

Diener, E., Emmons, R. A., Larsen, R. J., \& Griffin, S. (1985). The Satisfaction With Life Scale. Journal of Personality Assessment, 49(1), 71-75. doi: 10.1207/s15327752jpa4901_13

Djernes, J. K. (2006). Prevalence and predictors of depression in populations of elderly: A review. Acta Psychiatrica Scandinavica, 113(5), 372-387. doi: 10.1111/j.16000447.2006.00770.x

Dreer, L. E., Elliott, T. R., Fletcher, D. C., \& Swanson, M. (2005). Social Problem-Solving Abilities and Psychological Adjustment of Persons in Low Vision Rehabilitation. Rehabilitation Psychology, 50(3), 232-238. doi: 10.1037/0090-5550.50.3.232

Duberstein, P. R., Conwell, Y., Conner, K. R., Eberly, S., \& Caine, E. D. (2004). Suicide at 50 years of age and older: Perceived physical illness, family discord and financial strain. Psychological medicine, 34(1), 137-146. doi: 10.1017/S0033291703008584

Duberstein, P. R., Conwell, Y., Conner, K. R., Eberly, S., Evinger, J. S., \& Caine, E. D. (2004). Poor social integration and suicide: Fact or artifact? A case-control study. Psychological medicine, 34(7), 1331-1337. doi: 10.1017/S0033291704002600

Durkheim, E. (1951). Suicide: A study in sociology. New York: The Free Press. 
Dyeson, T. B. (2000). Burden self-image: A mediating variable of depressive symptoms among chronically ill care recipients. Journal of Gerontological Social Work, 33(1), 17-33. doi: 10.1300/J083v33n01_03

Eaton, W. W., Smith, C., Ybarra, M., Muntaner, C., \& Tien, A. (2004). Center for Epidemiologic Studies Depression Scale: Review and Revision (CESD and CESD-R). In M. E. Maruish (Ed.), The use of psychological testing for treatment planning and outcomes assessment: Volume 3: Instruments for adults (3rd ed) (pp. 363-377). Mahwah, NJ US: Lawrence Erlbaum Associates Publishers.

Edelstein, B. A., Heisel, M. J., McKee, D. R., Martin, R. R., Koven, L. P., Duberstein, P. R., \& Britton, P. C. (2009). Development and psychometric evaluation of the Reasons for Living_-Older Adults Scale: A Suicide Risk Assessment Inventory. The Gerontologist, 49(6), 736-745. doi: 10.1093/geront/gnp052

Enkvist, Å., Ekström, H., \& Elmståhl, S. (2012). What factors affect life satisfaction (LS) among the oldest-old? Archives of Gerontology and Geriatrics, 54(1), 140-145. doi: 10.1016/j.archger.2011.03.013

Evans, J. R., Fletcher, A. E., \& Wormald, R. P. (2007). Depression and anxiety in visually impaired older people. Ophthalmology, 114(2), 283-288.

Fauth, E. B., Gerstorf, D., Ram, N., \& Malmberg, B. (2012). Changes in depressive symptoms in the context of disablement processes: Role of demographic characteristics, cognitive function, health, and social support. The Journals of Gerontology: Series B:

Psychological Sciences and Social Sciences, 67B(2), 167-177. doi: 10.1093/geronb/gbr078 
Femia, E. E., Zarit, S. H., \& Johansson, B. (2001). The disablement process in very late life: A study of the oldest-old in Sweden. The Journals of Gerontology: Series B: Psychological Sciences and Social Sciences, 56B(1), P12-P23. doi: 10.1093/geronb/56.1.P12

Finger, R. P., Fleckenstein, M., Holz, F. G., \& Scholl, H. P. N. (2008). Quality of life in agerelated macular degeneration: A review of available vision-specific psychometric tools. Quality of Life Research: An International Journal of Quality of Life Aspects of Treatment, Care \& Rehabilitation, 17(4), 559-574. doi: 10.1007/s11136-008-9327-4

Forsell, Y., Jorm, A. F., \& Winblad, B. (1997). Suicidal thoughts and associated factors in an elderly population. Acta Psychiatrica Scandinavica, 95(2), 108-111. doi: 10.1111/j.16000447.1997.tb00382.x

Fremouw, W., McCoy, K., Tyner, E. A., \& Musick, R. (2009). Suicidal Older Adult ProtocolSOAP. In J. B. Allen, E. M. Wolf \& L. VandeCreek (Eds.), Innovations in clinical practice: A 21st century sourcebook, Vol 1 (pp. 203-212). Sarasota, FL US: Professional Resource Press/Professional Resource Exchange.

Fuller-Thomson, E., \& Minkler, M. (2000). The mental and physical health of grandmothers who are raising their grandchildren. Journal of Mental Health and Aging, 6(4), 311-323.

Gale, C. R., Sayer, A. A., Cooper, C., Dennison, E. M., Starr, J. M., Whalley, L. J., . . Deary, I. J. (2011). Factors associated with symptoms of anxiety and depression in five cohorts of community-based older people: The HALCyon (Healthy Ageing across the Life Course) Programme. Psychological medicine, 41(10), 2057-2073. doi:

$10.1017 / \mathrm{S} 0033291711000195$

Gatz, M., Reynolds, C., Nikolic, J., Lowe, B., Karel, M., \& Pedersen, N. (1995). An empirical test of telephone screening to identify potential dementia cases. International Psychogeriatrics, 7(3), 429-438. doi: 10.1017/S1041610295002171 
Gatz, M., Reynolds, C. A., John, R., Johansson, B., Mortimer, J. A., \& Pedersen, N. L. (2002). Telephone screening to identify potential dementia cases in a population-based sample of older adults. International Psychogeriatrics, 14(3), 273-289. doi: $10.1017 / \mathrm{S} 1041610202008475$

Good, G. A. (2008). Life satisfaction and quality of life of older New Zealanders with and without impaired vision: A descriptive, comparative study. European Journal of Ageing, 5(3), 223-231. doi: 10.1007/s10433-008-0087-3

Greenfield, E. A., \& Marks, N. F. (2004). Formal volunteering as a protective factor for older adults' psychological well-being. Journals of Gerontology: Series B: Psychological Sciences and Social Sciences(5), S258.

Gwozdz, W., \& Sousa-Poza, A. (2010). Ageing, health and life satisfaction of the oldest old: An analysis for Germany. Social Indicators Research, 97(3), 397-417. doi: 10.1007/s11205009-9508-8

Haber, M. G., Cohen, J. L., Lucas, T., \& Baltes, B. B. (2007). The relationship between selfreported received and perceived social support: A meta-analytic review. American Journal of Community Psychology, 39(1-2), 133-144. doi: 10.1007/s10464-007-9100-9

Hayes, A. F. (2009). Beyond Baron and Kenny: Statistical mediation analysis in the new millennium. Communication Monographs, 76(4), 408-420. doi: $10.1080 / 03637750903310360$

Hayes, A. F. (2012). A versatile computational tool for observed variable mediation, moderation, and conditional process modeling [White Paper]. Retrieved September 30, 2012, from http://www.afhayes.com/public/process2012.pdf

Haynie, D. A., Berg, S., Johansson, B., Gatz, M., \& Zarit, S. H. (2001). Symptoms of depression in the oldest old: A longitudinal study. The Journals of Gerontology: Series B: 
Psychological Sciences and Social Sciences, 56B(2), P111-P118. doi:

10.1093/geronb/56.2.P111

Herzog, A. R., \& House, J. S. (1991). Productive activities and aging well. Generations: Journal of the American Society on Aging, 15(1), 49-54.

Heyl, V., \& Wahl, H.-W. (2001). Psychosocial adaptation to age-related vision loss: A six-year perspective. Journal of Visual Impairment \& Blindness, 95(12), 739-748.

Holladay, J. T. (1997). Proper method for calculating average visual acuity. Journal Of Refractive Surgery (Thorofare, N.J.: 1995), 13(4), 388-391.

Horowitz, A., Brennan, M., \& Reinhardt, J. P. (2005). Prevalence and Risk Factors for SelfReported Visual Impairment Among Middle-Aged and Older Adults. Research on aging, 27(3), 307-326. doi: 10.1177/0164027504274267

Horowitz, A., Reinhardt, J. P., \& Boerner, K. (2005). The effect of rehabilitation on depression among visually disabled older adults. Aging \& Mental Health, 9(6), 563-570. doi: $10.1080 / 13607860500193500$

Horowitz, A., Reinhardt, J. P., Boerner, K., \& Travis, L. A. (2003). The influence of health, social support quality and rehabilitation on depression among disabled elders. Aging \& Mental Health, 7(5), 342-350. doi: 10.1080/1360786031000150739

Horowitz, A., Reinhardt, J. P., \& Kennedy, G. J. (2005). Major and Subthreshold Depression Among Older Adults Seeking Vision Rehabilitation Services. The American Journal of Geriatric Psychiatry, 13(3), 180-187. doi: 10.1176/appi.ajgp.13.3.180

House, J. (1997). Americans' changing lives: Waves I and II, 1986 and 1989 [computer file]. ICPSR version. 
Hsu, H.-C. (2012). Trajectories and covariates of life satisfaction among older adults in Taiwan. Archives of Gerontology and Geriatrics, 55(1), 210-216. doi: 10.1016/j.archger.2011.08.011

Huang, C. Q., Dong, B. R., Lu, Z. C., Yue, J. R., \& Liu, Q. X. (2010). Chronic diseases and risk for depression in old age: a meta-analysis of published literature. Ageing Research Reviews, 9(2), 131-141.

Hunter, K. I., \& Linn, M. W. (1980). Psychosocial differences between elderly volunteers and non-volunteers. The International Journal of Aging \& Human Development, 12(3), 205213. doi: 10.2190/0H6V-QPPP-7JK4-LR38

Hunter, K. I., Linn, M. W., \& Harris, R. (1981). Characteristics of high and low self-esteem in the elderly. The International Journal of Aging \& Human Development, 14(2), 117-126. doi: 10.2190/BGVM-2X68-PPFQ-EYV8

Jahn, D. R., \& Cukrowicz, K. C. (2011). The impact of the nature of relationships on perceived burdensomeness and suicide ideation in a community sample of older adults. Suicide and Life-Threatening Behavior, 41(6), 635-649. doi: 10.1111/j.1943-278X.2011.00060.x

Jang, Y., Haley, W. E., Small, B. J., \& Mortimer, J. A. (2002). The role of mastery and social resources in the associations between disability and depression in later life. The Gerontologist, 42(6), 807-813. doi: 10.1093/geront/42.6.807

June, A., Segal, D. L., Coolidge, F. L., \& Klebe, K. (2009). Religiousness, social support and reasons for living in African American and European American older adults: An exploratory study. Aging \& Mental Health, 13(5), 753-760. doi: $10.1080 / 13607860902918215$ 
Kaplan, M. S., McFarland, B. H., Huguet, N., \& Newsom, J. T. (2007). Physical illness, functional limitations, and suicide risk: A population-based study. American Journal of Orthopsychiatry, 77(1), 56-60. doi: 10.1037/0002-9432.77.1.56

Katz, S. (1983). Assessing self-maintenance: Activities of daily living, mobility, and instrumental activities of daily living. Journal of the American Geriatrics Society, 31(12), 721-727.

Kelly, J. S. (1993). Visual impairment among older people. British journal of nursing (Mark Allen Publishing), 2(2), 110-116.

Kessler, R. C., Foster, C., Webster, P. S., \& House, J. S. (1992). The relationship between age and depressive symptoms in two national surveys. Psychology and Aging, 7(1), 119-126. doi: 10.1037/0882-7974.7.1.119

Kim, J., \& Pai, M. (2010). Volunteering and trajectories of depression. Journal of aging and health, 22(1), 84-105. doi: 10.1177/0898264309351310

Kinne, S., Patrick, D. L., \& Doyle, D. L. (2004). Prevalence of secondary conditions among people with disabilities. American Journal of Public Health, 94(3), 443-445.

Kissane, M., \& McLaren, S. (2006). Sense of belonging as a predictor of reasons for living in older adults. Death studies, 30(3), 243-258. doi: 10.1080/07481180500493401

Ko, L. K., \& Lewis, M. A. (2011). The role of giving and receiving emotional support in depressive symptomatology among older couples: An application of the actor-partner interdependence model. Journal of Social and Personal Relationships, 28(1), 83-99. doi: $10.1177 / 0265407510387888$

Konrath, S., Fuhrel-Forbis, A., Lou, A., \& Brown, S. (2012). Motives for volunteering are associated with mortality risk in older adults. Health Psychology, 31(1), 87-96. doi: $10.1037 / \mathrm{a} 0025226$ 
Krause, N. (1990). Satisfaction with social support and changes in functional disability through time. In H. Giles, N. Coupland \& J. M. Wiemann (Eds.), Communication, health and the elderly (pp. 29-44). Manchester England: Manchester University Press.

Krause, N. (1995). Negative interaction and satisfaction with social support among older adults. The Journals of Gerontology: Series B: Psychological Sciences and Social Sciences, 50B(2), P59-P73. doi: 10.1093/geronb/50B.2.P59

Krause, N. (1999). Assessing change in social support during late life. Research on aging, 21(4), 539-569. doi: 10.1177/0164027599214002

Krause, N. (2011). Neighborhood conditions and helping behavior in late life. Journal of Environmental Psychology, 31(1), 62-69. doi: 10.1016/j.jenvp.2010.11.003

Krause, N., \& Hayward, R. D. (2012). Religion, meaning in life, and change in physical functioning during late adulthood. Journal of Adult Development, 19(3), 158-169. doi: $10.1007 / \mathrm{s} 10804-012-9143-5$

Krause, N., Herzog, A. R., \& Baker, E. (1992). Providing support to others and well-being in later life. Journals of Gerontology, 47(5), P300-P311.

Krause, N., \& Markides, K. S. (1990). Measuring social support among older adults. The International Journal of Aging \& Human Development, 30(1), 37-53.

Kuchibhatla, M. N., Fillenbaum, G. G., Hybels, C. F., \& Blazer, D. G. (2012). Trajectory classes of depressive symptoms in a community sample of older adults. Acta Psychiatrica Scandinavica, 125(6), 492-501. doi: 10.1111/j.1600-0447.2011.01801.x

Kuijer, R. G., Buunk, B. P., De Jong, G. M., Ybema, J. F., \& Sanderman, R. (2004). Effects of a Brief Intervention Program for Patients with Cancer and Their Partners on Feelings of Inequity, Relationship Quality and Psychological Distress. Psycho-oncology, 13(5), 321334. doi: 10.1002/pon.749 
La Grow, S., Yeung, P., Towers, A., Alpass, F., \& Stephens, C. (2011). Determinants of the overall quality of life of older persons who have difficulty seeing: The importance of the ability to get around. Journal of Visual Impairment \& Blindness, 105(10), 720-730.

LeBrasseur, N. K., Sayers, S. P., Ouellette, M. M., \& Fielding, R. A. (2006). Muscle impairments and behavioral factors mediate functional limitations and disability following stroke. Physical Therapy, 86(10), 1342-1350.

Lenze, E. J., Rogers, J. C., Martire, L. M., Mulsant, B. H., Rollman, B. L., Dew, M. A., . . . Reynolds, C. F. I., II. (2001). The association of late-life depression and anxiety with physical disability: A review of the literature and prospectus for future research. The American Journal of Geriatric Psychiatry, 9(2), 113-135. doi: 10.1176/appi.ajgp.9.2.113

Leveille, S. G., Penninx, B. W. J. H., Melzer, D., Izmirlian, G., \& Guralnik, J. M. (2000). Sex differences in the prevalence of mobility disability in old age: The dynamics of incidence, recovery, and mortality. The Journals of Gerontology: Series B: Psychological Sciences and Social Sciences, 55B(1), S41-S50.

Lewinsohn, P. M., Seeley, J. R., Roberts, R. E., \& Allen, N. B. (1997). Center for Epidemiologic Studies Depression Scale (CES-D) as a screening instrument for depression among community-residing older adults. Psychology and Aging, 12(2), 277-287. doi: $10.1037 / 0882-7974.12 .2 .277$

Li, T., Fok, H. K., \& Fung, H. H. (2011). Is reciprocity always beneficial? Age differences in the association between support balance and life satisfaction. Aging \& Mental Health, 15(5), 541-547. doi: 10.1080/13607863.2010.551340

Li, X., Wang, W., Gao, Q., Wu, L., Luo, Y., Tang, Z., \& Guo, X. (2012). The trajectories and correlation between physical limitation and depression in elderly residents of Beijing, 1992-2009. PLoS ONE, 7(8). 
Li, Y. (2007). Recovering from spousal bereavement in later life: Does volunteer participation play a role. The Journals of Gerontology: Series B: Psychological Sciences and Social Sciences, 62B(4), S257-S266. doi: 10.1093/geronb/62.4.S257

Li, Y., \& Ferraro, K. F. (2005). Volunteering and Depression in Later Life: Social Benefit or Selection Processes? Journal of Health and Social Behavior, 46(1), 68-84. doi: $10.1177 / 002214650504600106$

Liang, J., Krause, N. M., \& Bennett, J. M. (2001). Social exchange and well-being: Is giving better than receiving? Psychology and Aging, 16(3), 511-523. doi: 10.1037/08827974.16.3.511

Linehan, M. M., Goodstein, J. L., Nielsen, S. L., \& Chiles, J. A. (1983). Reasons for staying alive when you are thinking of killing yourself: The Reasons for Living Inventory. Journal of consulting and clinical psychology, 51(2), 276-286. doi: 10.1037/0022006X.51.2.276

Lowenstein, A., Katz, R., \& Gur-Yaish, N. (2007). Reciprocity in parent-child exchange and life satisfaction among the elderly: A cross-national perspective. Journal of Social Issues, 63(4), 865-883.

Lum, T. Y., \& Lightfoot, E. (2005). The Effects of Volunteering on the Physical and Mental Health of Older People. Research on aging, 27(1), 31-55. doi: $10.1177 / 0164027504271349$

Lyness, J. M., Noel, T. K., Cox, C., King, D. A., Conwell, Y., \& Caine, E. D. (1997). Screening for depression in elderly primary care patients. A comparison of the Center for Epidemiologic Studies-Depression Scale and the Geriatric Depression Scale. Archives Of Internal Medicine, 157(4), 449-454. 
MacKinnon, D. P., Lockwood, C. M., Hoffman, J. M., West, S. G., \& Sheets, V. (2002). A comparison of methods to test mediation and other intervening variable effects. Psychological methods, 7(1), 83-104. doi: 10.1037/1082-989X.7.1.83

Mangione, C. M., Lee, P. P., Gutierrez, P. R., Spritzer, K., Berry, S., \& Hays, R. D. (2001). Development of the 25-item National Eye Institute Visual Function Questionnaire. Archives Of Ophthalmology, 119(7), 1050-1058.

Mathieu, J. E., \& Taylor, S. R. (2006). Clarifying conditions and decision points for mediational type inferences in Organizational Behavior. Journal of Organizational Behavior, 27(8), 1031-1056. doi: 10.1002/job.406

McDonnall, M. C. (2009). Risk factors for depression among older adults with dual sensory loss. Aging \& Mental Health, 13(4), 569-576. doi: 10.1080/13607860902774410

McDonnall, M. C. (2011). The effect of productive activities on depressive symptoms among older adults with dual sensory loss. Research on aging, 33(3), 234-255. doi:

\section{$10.1177 / 0164027511399106$}

McDowell, I. (2010). Measures of self-perceived well-being. Journal of psychosomatic research, 69(1), 69-79. doi: 10.1016/j.jpsychores.2009.07.002

McLaren, S., Gomez, R., Bailey, M., \& Van Der Horst, R. K. (2007). The Association of Depression and Sense of Belonging with Suicidal Ideation Among Older Adults: Applicability of resiliency models. Suicide and Life-Threatening Behavior, 37(1), 89102. doi: $10.1521 /$ suli.2007.37.1.89

McPherson, C. J., Wilson, K. G., Chyurlia, L., \& Leclerc, C. (2010). The balance of give and take in caregiver-partner relationships: An examination of self-perceived burden, relationship equity, and quality of life from the perspective of care recipients following stroke. Rehabilitation Psychology, 55(2), 194-203. doi: 10.1037/a0019359 
Meeks, S., \& Murrell, S. A. (2001). Contribution of education to health and life satisfaction in older adults mediated by negative affect. Journal of aging and health, 13(1), 92-119. doi: $10.1177 / 089826430101300105$

Miller, I. W., Norman, W. H., Bishop, S. B., \& Dow, M. G. (1986). The Modified Scale for Suicidal Ideation: Reliability and validity. Journal of consulting and clinical psychology, 54(5), 724-725. doi: 10.1037/0022-006X.54.5.724

Morrow-Howell, N., Hinterlong, J., Rozario, P. A., \& Tang, F. (2003). Effects of volunteering on the well-being of older adults. The Journals of Gerontology: Series B: Psychological Sciences and Social Sciences, 58B(3), S137-S145. doi: 10.1093/geronb/58.3.S137

Morrow-Howell, N., Hong, S.-I., McCrary, S., \& Blinne, W. (2012). Changes in activity among older volunteers. Research on aging, 34(2), 174-196. doi: 10.1177/0164027511419371

Musick, M. A., \& Wilson, J. (2003). Volunteering and depression: The role of psychological and social resources in different age groups. Social science \& medicine, 56(2), 259-269. doi: $10.1016 / \mathrm{S} 0277-9536(02) 00025-4$

Newsom, J. T. (1999). Another side to caregiving: Negative reactions to being helped. Current Directions in Psychological Science, 8(6), 183-187. doi: 10.1111/1467-8721.00043

Newsom, J. T., Nishishiba, M., Morgan, D. L., \& Rook, K. S. (2003). The Relative Importance of Three Domains of Positive and Negative Social Exchanges: A Longitudinal Model With Comparable Measures. Psychology and Aging, 18(4), 746-754. doi: 10.1037/08827974.18.4.746

Newsom, J. T., Rook, K. S., Nishishiba, M., Sorkin, D. H., \& Mahan, T. L. (2005). Understanding the relative importance of positive and negative social exchanges: Examining specific domains and appraisals. The Journals of Gerontology: Series B: 
Psychological Sciences and Social Sciences, 60B(6), P304-P312. doi:

10.1093/geronb/60.6.P304

Newsom, J. T., \& Schulz, R. (1996). Social support as a mediator in the relation between functional status and quality of life in older adults. Psychology and Aging, 11(1), 34-44. doi: 10.1037/0882-7974.11.1.34

Newsom, J. T., \& Schulz, R. (1998). Caregiving from the recipient's perspective: Negative reactions to being helped. Health Psychology, 17(2), 172.

Nosek, M. A., Hughes, R. B., Petersen, N. J., Taylor, H. B., Robinson-Whelen, S., Byrne, M., \& Morgan, R. (2006). Secondary conditions in a community-based sample of women with physical disabilities over a 1-year period. Archives of Physical Medicine and Rehabilitation, 87(3), 320-327.

Okun, M. A., August, K. J., Rook, K. S., \& Newsom, J. T. (2010). Does volunteering moderate the relation between functional limitations and mortality? Social science \& medicine, 7l(9), 1662-1668. doi: 10.1016/j.socscimed.2010.07.034

Owen, C. G., Rudnicka, A. R., Smeeth, L., Evans, J. R., Wormald, R. P. L., \& Fletcher, A. E. (2006). Is the NEI-VFQ-25 a useful tool in identifying visual impairment in an elderly population? BMC Ophthalmology, 6, 24-24.

Oxman, T. E., \& Berkman, L. F. (1990). Assessment of social relationships in elderly patients. International journal of psychiatry in medicine, 20(1), 65-84. doi: 10.2190/G6CXYCGL-HAB3-8BMC

Parkinson, L., Warburton, J., Sibbritt, D., \& Byles, J. (2010). Volunteering and older women: Psychosocial and health predictors of participation. Aging \& Mental Health, 14(8), 917927. doi: $10.1080 / 13607861003801045$ 
Pavot, W., \& Diener, E. (2008). The Satisfaction With Life Scale and the emerging construct of life satisfaction. The Journal of Positive Psychology, 3(2), 137-152. doi: $10.1080 / 17439760701756946$

Pearlin, L. I., Menaghan, E. G., Lieberman, M. A., \& Mullan, J. T. (1981). The stress process. Journal of Health and Social Behavior, 22(4), 337-356. doi: 10.2307/2136676

Penning, M. J., \& Strain, L. A. (1994). Gender differences in disability, assistance, and subjective well-being in later life. Journals of Gerontology, 49(4), S202-S208.

Piliavin, J. A., \& Siegl, E. (2007). Health benefits of volunteering in the Wisconsin Longitudinal Study. Journal of Health and Social Behavior, 48(4), 450.

Pinquart, M., \& Pfeiffer, J. P. (2011). Psychological well-being in visually impaired and unimpaired individuals: A meta-analysis. British Journal of Visual Impairment, 29(1), 27-45. doi: 10.1177/0264619610389572

Pirkis, J., Burgess, P., \& Dunt, D. (2000). Suicidal ideation and suicide attempts among Australian adults. Crisis: The Journal of Crisis Intervention and Suicide Prevention, 21(1), 16-25. doi: 10.1027//0227-5910.21.1.16

Preacher, K. J., \& Hayes, A. F. (2004). SPSS and SAS procedures for estimating indirect effects in simple mediation models. Behavior Research Methods, Instruments \& Computers, 36(4), 717-731. doi: 10.3758/BF03206553

Preacher, K. J., \& Hayes, A. F. (2008). Asymptotic and resampling strategies for assessing and comparing indirect effects in multiple mediator models. Behavior Research Methods, 40(3), 879-891. doi: 10.3758/BRM.40.3.879

Préville, M., Hébert, R., Boyer, R., Bravo, G., \& Seguin, M. (2005). Physical health and mental disorder in elderly suicide: A case-control study. Aging \& Mental Health, 9(6), 576-584. doi: 10.1080/13607860500192973 
Pruchno, R. A., Burant, C. J., \& Peters, N. D. (1997). Understanding the well-being of care receivers. The Gerontologist, 37(1), 102-109. doi: 10.1093/geront/37.1.102

Reinhardt, J. P. (1996). The importance of friendship and family support in adaptation to chronic vision impairment. The Journals of Gerontology: Series B: Psychological Sciences and Social Sciences, 51B(5), P268-P278. doi: 10.1093/geronb/51B.5.P268

Reinhardt, J. P. (2001). Effects of positive and negative support received and provided on adaptation to chronic visual impairment. Applied Developmental Science, 5(2), 76-85. doi: 10.1207/S1532480XADS0502_3

Rook, K. S., \& Sorkin, D. H. (2003). Fostering social ties through a volunteer role: Implications for older-adults' psychological health. International Journal of Aging \& Human Development, 57(4), 313.

Rowe, J. L., Conwell, Y., Schulberg, H. C., \& Bruce, M. L. (2006). Social Support and Suicidal Ideation in Older Adults Using Home Healthcare Services. The American Journal of Geriatric Psychiatry, 14(9), 758-766. doi: 10.1097/01.JGP.0000218324.78202.25

Rubenowitz, E., Waern, M., Wilhelmson, K., \& Allebeck, P. (2001). Life events and psychosocial factors in elderly suicides-A case-control study. Psychological medicine, 31(7), 1193-1202. doi: 10.1017/S0033291701004457

Rudd, M. D., \& Rajab, M. H. (1995). Use of the Modified Scale for Suicidal Ideation with suicide ideators and attempters. Journal of clinical psychology, 51(5), 632-635. doi: 10.1002/1097-4679(199509)51:5<632::AID-JCLP2270510508>3.0.CO;2-N

Russell, D., Turner, R. J., \& Joiner, T. E. (2009). Physical disability and suicidal ideation: A community-based study of risk/protective factors for suicidal thoughts. Suicide and LifeThreatening Behavior, 39(4), 440-451. doi: 10.1521/suli.2009.39.4.440 
Ryff, C. D. (1989). Happiness is everything, or is it? Explorations on the meaning of psychological well-being. Journal of personality and social psychology, 57(6), 10691081. doi: 10.1037/0022-3514.57.6.1069

Sarid, O., Melzer, I., Kurz, I., Shahar, D. R., \& Ruch, W. (2010). The effect of helping behavior and physical activity on mood states and depressive symptoms of elderly people. Clinical Gerontologist: The Journal of Aging and Mental Health, 33(4), 270-282. doi: $10.1080 / 07317115.2010 .502105$

SAS for Windows (9.3) [Computer Software]. Cary, NC: SAS Institute Inc.

Segal, D. L., Lebenson, S., \& Coolidge, F. L. (2008). Global self-rated health status predicts reasons for living among older adults. Clinical Gerontologist: The Journal of Aging and Mental Health, 31(4), 122-132. doi: 10.1080/07317110802144006

Shaw, B. A., Krause, N., Liang, J., \& Bennett, J. (2007). Tracking changes in social relations throughout late life. The Journals of Gerontology: Series B: Psychological Sciences and Social Sciences, 62B(2), S90-S99. doi: 10.1093/geronb/62.2.S90

Social Security Administration. (2008). Disability Evaluation Under Social Security: 2.00 Special Senses and Speech: Social Security Adminstration.

Szanto, K., Dombrovski, A. Y., Sahakian, B. J., Mulsant, B. H., Houck, P. R., Reynolds, C. F. I., II, \& Clark, L. (2012). Social emotion recognition, social functioning, and attempted suicide in late-life depression. The American Journal of Geriatric Psychiatry, 20(3), 257265. doi: 10.1097/JGP.0b013e31820eea0c

Tabachnick, B. G., \& Fidell, L. S. (2007). Cleaning up your act: Screening Data Prior to Analysis Using multivariate statistics (5th ed.). (pp. 60-116). Boston, MA: Allyn \& Bacon/Pearson Education. 
Tan, E. J., Rebok, G. W., Yu, Q., Frangakis, C. E., Carlson, M. C., Wang, T., . . Fried, L. P. (2009). The long-term relationship between high-intensity volunteering and physical activity in older African American women. The Journals of Gerontology: Series B: Psychological Sciences and Social Sciences, 64B(2), 304-311. doi: 10.1093/geronb/gbn023

Taylor, M. G., \& Lynch, S. M. (2004). Trajectories of Impairment, Social Support, and Depressive Symptoms in Later Life. The Journals of Gerontology: Series B: Psychological Sciences and Social Sciences, 59B(4), S238-S246. doi: 10.1093/geronb/59.4.S238

Taylor, M. G., \& Lynch, S. M. (2011). Cohort differences and chronic disease profiles of differential disability trajectories. The Journals of Gerontology: Series B: Psychological Sciences and Social Sciences, 66B(6), 729-738. doi: 10.1093/geronb/gbr104

Thoits, P. A., \& Hewitt, L. N. (2001). Volunteer work and well-being. Journal of Health and Social Behavior, 42(2), 115-131. doi: 10.2307/3090173

Turvey, C. L., Conwell, Y., Jones, M. P., Phillips, C., Simonsick, E., Pearson, J. L., \& Wallace, R. (2002). Risk factors for late-life suicide: A prospective community-based study. American Journal of Geriatric Psychiatry, 10(4), 398.

U.S. Bureau of Labor Statistics. (2012). Volunteering in the United States- 2011. United States Bureau of Labor.

Uchino, B. N. (2006). Social Support and Health: A Review of Physiological Processes Potentially Underlying Links to Disease Outcomes. Journal of Behavioral Medicine, 29(4), 377-387. doi: 10.1007/s10865-006-9056-5 
Van Orden, K. A., Witte, T. K., Cukrowicz, K. C., Braithwaite, S. R., Selby, E. A., \& Joiner, T. E., Jr. (2010). The interpersonal theory of suicide. Psychological review, 117(2), 575600. doi: $10.1037 / \mathrm{a} 0018697$

Van Willigen, M. (2000). Differential benefits of volunteering across the life course. The Journals of Gerontology: Series B: Psychological Sciences and Social Sciences, 55B(5), S308-S318. doi: 10.1093/geronb/55.5.S308

Vaux, A. (1988). Social support: Theory, research, and intervention. In A. Vaux (Ed.), Social support: Theory, research, and intervention (pp. 92-132). New York, NY England: Praeger Publishers.

Verbrugge, L. M., \& Jette, A. M. (1994). The Disablement Process. Social science \& medicine, 38(1), 1-14. doi: 10.1016/0277-9536(94)90294-1

Waddell, E. L., \& Jacobs-Lawson, J. M. (2010). Predicting positive well-being in older men and women. The International Journal of Aging \& Human Development, 70(3), 181-197. doi: 10.2190/AG.70.3.a

Waern, M., Rubenowitz, E., Runeson, B., Skoog, I., Wilhelmson, K., \& Allebeck, P. (2002). Burden of illness and suicide in elderly people: Case-control study. BMJ: British Medical Journal, 324(7350). doi: 10.1136/bmj.324.7350.1355

Waern, M., Rubenowitz, E., \& Wilhelmson, K. (2003). Predictors of Suicide in the Old Elderly. Gerontology, 49(5), 328-334. doi: 10.1159/000071715

Wallsten, S. M., Tweed, D. L., Blazer, D. G., \& George, L. K. (1999). Disability and depressive symptoms in the elderly: The effects of instrumental support and its subjective appraisal. The International Journal of Aging \& Human Development, 48(2), 145-159. doi: 10.2190/E48R-W561-V7RG-LL8D 
Walster, E., Berscheid, E., \& Walster, G. W. (1973). New directions in equity research. Journal of personality and social psychology, 25(2), 151-176. doi: 10.1037/h0033967

Walter, C., Humble, H., Althouse, R., \& Odom, J. V. (2005). A comparison of low vision patients from a clinic and a random sample of West Virginians: Demographics; treatment patterns; vision problems; and activities of daily living. Vision 2005 Proceedings of the International Congress held between 4 and 7 April 2005 in London, UK, 1282(0), 462465. doi: 10.1016/j.ics.2005.05.060

Warner, L. M., Schüz, B., Wurm, S., Ziegelmann, J. P., \& Tesch-Römer, C. (2010). Giving and taking-Differential effects of providing, receiving and anticipating emotional support on quality of life in adults with multiple illnesses. Journal of Health Psychology, 15(5), 660670. doi: $10.1177 / 1359105310368186$

Warr, P., Butcher, V., \& Robertson, I. (2004). Activity and psychological well-being in older people. Aging \& Mental Health, 8(2), 172-183. doi: 10.1080/13607860410001649662

Wethington, E., Moen, P., Glasgow, N., \& Pillemer, K. (2000). Multiple roles, social integration, and health. In K. Pillemer, P. Moen, E. Wethington \& N. Glasgow (Eds.), Social integration in the second half of life (pp. 48-71). Baltimore, MD US: Johns Hopkins University Press.

Wheeler, J. A., Gorey, K. M., \& Greenblatt, B. (1998). The beneficial effects of volunteering for older volunteers and the people they serve: A meta-analysis. The International Journal of Aging \& Human Development, 47(1), 69-79. doi: 10.2190/VUMP-XCMF-FQYU-V0JH

Wiktorsson, S., Runeson, B., Skoog, I., Östling, S., \& Waern, M. (2010). Attempted suicide in the elderly: Characteristics of suicide attempters 70 years and older and a general population comparison group. The American Journal of Geriatric Psychiatry, 18(1), 5767. doi: 10.1097/JGP.0b013e3181bd1c13 
Williamson, G. M. (1998). The central role of restricted normal activities in adjustment to illness and disability: A model of depressed affect. Rehabilitation Psychology, 43(4), 327-347. doi: $10.1037 / 0090-5550.43 .4 .327$

Wolff, J. L., \& Agree, E. M. (2004). Depression Among Recipients of Informal Care: The Effects of Reciprocity, Respect, and Adequacy of Support. The Journals of Gerontology: Series B: Psychological Sciences and Social Sciences, 59B(3), S173-S180. doi: 10.1093/geronb/59.3.S173

Wu, A. M. S., Tang, C. S. K., \& Yan, E. C. W. (2005). Post-retirement voluntary work and psychological functioning among older Chinese in Hong Kong. Journal of CrossCultural Gerontology, 20(1), 27-45. doi: 10.1007/s10823-005-3796-5

Yampolsky, M. A., Wittich, W., Webb, G., \& Overbury, O. (2008). The Role of Spirituality in Coping with Visual Impairment. Journal of Visual Impairment and Blindness, 102(1), 2839.

Yang, Y. (2006). How does functional disability affect depressive symptoms in late life? The role of perceived social support and psychological resources. Journal of Health and Social Behavior, 47(4), 355-372. doi: 10.1177/002214650604700404

Yang, Y., \& George, L. K. (2005). Functional Disability, Disability Transitions, and Depressive Symptoms in Late Life. Journal of aging and health, 17(3), 263-292. doi:

\section{$10.1177 / 0898264305276295$}

Yuen, H. K. (2002). Impact of an Altruistic Activity on Life Satisfaction in Institutionalized Elders: A Pilot Study. Physical \& Occupational Therapy in Geriatrics, 20(3), 125.

Zeiss, A. M., Lewinsohn, P. M., Rohde, P., \& Seeley, J. R. (1996). Relationship of physical disease and functional impairment to depression in older people. Psychology and Aging, 11(4), 572-581. doi: 10.1037/0882-7974.11.4.572 
Table 1.

Descriptive Characteristics of Participants with Possible Cognitive Impairment

\begin{tabular}{|c|c|c|c|}
\hline & $\begin{array}{l}\text { Frequency } \\
\text { (Percentage) }\end{array}$ & Mean & $\begin{array}{l}\text { Standard } \\
\text { deviation }\end{array}$ \\
\hline Age & & 78.55 & 8.16 \\
\hline Tele Score & & 12.75 & 1.82 \\
\hline \multicolumn{4}{|l|}{ Sex } \\
\hline Female & $12(60.0)$ & & \\
\hline Male & $8(40.0)$ & & \\
\hline \multicolumn{4}{|l|}{ Race } \\
\hline Caucasian & $18(90.0)$ & & \\
\hline African-American & $1(5.0)$ & & \\
\hline Native American & $1(5.0)$ & & \\
\hline \multicolumn{4}{|c|}{ Marital Status } \\
\hline Married & $10(50.0)$ & & \\
\hline Separated & $1(5.0)$ & & \\
\hline Divorced & $2(10.0)$ & & \\
\hline Widowed & $7(35.0)$ & & \\
\hline \multicolumn{4}{|l|}{ Education } \\
\hline Less than high school & $4(20.0)$ & & \\
\hline High school & $7(35.0)$ & & \\
\hline GED & $2(10.0)$ & & \\
\hline Some college & $4(20.0)$ & & \\
\hline College degree & $3(15.0)$ & & \\
\hline \multicolumn{4}{|l|}{ Occupation status } \\
\hline Homemaker & $1(5.0)$ & & \\
\hline Retired & $16(80.0)$ & & \\
\hline Disabled & $3(15.0)$ & & \\
\hline \multicolumn{4}{|l|}{ Income } \\
\hline Less than 10,000 & $2(10.0)$ & & \\
\hline $10,000-14,999$ & $4(20.0)$ & & \\
\hline $15,000-24,999$ & $3(15.0)$ & & \\
\hline $25,000-34,999$ & $4(20.0)$ & & \\
\hline $35,000-49,999$ & $1(5.0)$ & & \\
\hline $100,000-149,999$ & $1(5.0)$ & & \\
\hline Don't know & $5(25)$ & & \\
\hline
\end{tabular}

Note. $n=20$ 
Table 2 .

Descriptive Characteristics of Participants Who Completed the Interview

\begin{tabular}{|c|c|c|c|}
\hline & Frequency (Percentage) & Mean & Standard deviation \\
\hline Age & & 73.48 & 8.07 \\
\hline Tele & & 16.66 & 1.14 \\
\hline Female & $56(55.45)$ & & \\
\hline Male & $44(44.55)$ & & \\
\hline Caucasian & $93(92.08)$ & & \\
\hline African-American & $2(1.98)$ & & \\
\hline Native American & $2(1.98)$ & & \\
\hline Other/Mixed & $4(3.96)$ & & \\
\hline Marital Status & $4(3.96)$ & & \\
\hline Married & $63(62.38)$ & & \\
\hline Live-in partner & $2(1.98)$ & & \\
\hline Divorced & $9(8.91)$ & & \\
\hline Widowed & $23(22.77)$ & & \\
\hline
\end{tabular}

Education

Less than high school $11(10.89)$

High school 33 (32.67)

GED 5 (4.95)

Some college 25 (24.75)

College degree 13 (12.87)

Post college 14 (13.86)

Occupation Status

Working full time $9(8.91)$

Working part time $10(9.90)$

Homemaker 3 (2.97)

Unemployed 1 (.99)

Retired 74 (73.27)

Disabled 4 (3.96)

Income

Less than $10,000 \quad 2(1.98)$

$10,000-14,999 \quad 10(9.90)$

$15,000-24,999 \quad 26(25.74)$

25,000-34,999 12 (11.88)

$35,000-49,999 \quad 14(13.86)$

$50,000-74,999 \quad 13(12.87)$

75,000-99,999 4 (3.96)

$100,000-149,999 \quad 10(9.90)$

$150,000-199,999 \quad 2(1.98)$

200,000 or more $1(.99)$

Don't know 7 (6.93)

Note. $N=101$ 
Table 3.

Correlations Between Study Variables

\begin{tabular}{|c|c|c|c|c|c|c|c|c|c|c|c|c|c|c|c|c|c|c|}
\hline & 1 & 2 & 3 & 4 & 5 & 6 & 7 & 8 & 9 & 10 & 11 & 12 & 13 & 14 & 15 & 16 & 17 & 18 \\
\hline 1. Age & 1 & & & & & & & & & & & & & & & & & \\
\hline 2. Gender & -.05 & 1 & & & & & & & & & & & & & & & & \\
\hline 3. Education & $-.21^{*}$ & .04 & 1 & & & & & & & & & & & & & & & \\
\hline 4. Income & $-.21^{*}$ & .05 & $.33^{* *}$ & 1 & & & & & & & & & & & & & & \\
\hline 5. CESD-R & .10 & -.03 & -.01 & -.07 & 1 & & & & & & & & & & & & & \\
\hline 6. SWLS & .01 & .01 & .13 & .16 & $-.47^{* * * *}$ & 1 & & & & & & & & & & & & \\
\hline 7. Suicide & -.21 & -.11 & -.06 & -.02 & $.93^{* * * *}$ & $-.78^{* * * *}$ & 1 & & & & & & & & & & & \\
\hline 8. RFL-OA ${ }^{\mathrm{a}}$ & $.32^{* *}$ & $-.21^{*}$ & $-.21^{*}$ & $-.21^{*}$ & -.08 & .12 & $-.59^{* * * *}$ & 1 & & & & & & & & & & \\
\hline $\begin{array}{l}\text { 9. Informal } \\
\text { Support }\end{array}$ & $-.30^{* *}$ & .02 & $.23^{*}$ & $.23^{*}$ & .03 & .08 & $-.42^{*}$ & -.15 & 1 & & & & & & & & & \\
\hline $\begin{array}{l}\text { 10. Volunteer } \\
\text { Hrs }\end{array}$ & -.10 & -.07 & $.27^{* * *}$ & $.21^{*}$ & -.18 & .14 & -.34 & .14 & $.31^{* * *}$ & 1 & & & & & & & & \\
\hline $\begin{array}{l}\text { 11. Volunteer } \\
\text { Status }\end{array}$ & -.09 & -.16 & $.28^{*}$ & $.24^{*}$ & -.18 & .20 & - & .22 & $.38^{* * *}$ & $.99^{* * * *}$ & 1 & & & & & & & \\
\hline $\begin{array}{c}\text { 12. Volunteer } \\
\text { Groups }\end{array}$ & -.02 & -.08 & $.28^{* * *}$ & $.28^{* * *}$ & -.13 & .17 & -.19 & .18 & $.22^{*}$ & $.80^{* * * *}$ & $.99^{* * * *}$ & 1 & & & & & & \\
\hline 13.PSR & -.06 & -.10 & .03 & .05 & $-.27^{* * *}$ & $.22^{*}$ & $-.44^{* *}$ & .18 & -.008 & .14 & .13 & .07 & 1 & & & & & \\
\hline $\begin{array}{c}\text { 14. Received } \\
\text { Support }\end{array}$ & .16 & $-.29^{* *}$ & -.01 & -.02 & .16 & -.009 & -.36 & $.31^{* *}$ & $.32^{* *}$ & -.02 & .005 & -.04 & .05 & 1 & & & & \\
\hline 15.ADLs & -.13 & .06 & .11 & .14 & $-.38^{* * * *}$ & $.31^{* *}$ & $-.34^{*}$ & .06 & $.20^{* *}$ & $.38^{* * *}$ & $.44^{* * * *}$ & $.34^{* * * *}$ & .18 & $-.27^{* * *}$ & 1 & & & \\
\hline 16. VFQ & -.11 & .06 & .13 & .14 & $-.25^{* *}$ & $.39^{* * * *}$ & $-.43^{*}$ & .03 & .09 & $.23^{*}$ & .22 & $.26^{* *}$ & $.26^{* *}$ & $-.39^{* * * *}$ & $.59^{* * *}$ & 1 & & \\
\hline 17. Acuity & $.26^{* *}$ & .15 & -.15 & -.14 & $.34^{* * * *}$ & $-.44^{* * * *}$ & $.36^{*}$ & -.04 & -.12 & $-.28^{* *}$ & $-.36^{* * *}$ & $-.26^{* * *}$ & $-.36^{* * * *}$ & .16 & $-.43^{* * * *}$ & $-.52^{* * * *}$ & 1 & \\
\hline $\begin{array}{l}\text { 18. Visual } \\
\text { Field }\end{array}$ & .10 & .09 & -.15 & -.12 & .08 & $-.28^{* *}$ & $.42^{*}$ & -.10 & -.05 & -.22 & $-.27^{*}$ & $-.23^{*}$ & -.001 & .07 & $-.40^{* * *}$ & -.51 & $.26^{* *}$ & 1 \\
\hline
\end{tabular}


Table 3.

Correlations Between Study Variables cont.

Note. $N=101$. Significant correlations are shown in boldface. CESD-R = Center for Epidemiological Studies Depression ScaleRevised, SSWLS = Satisfaction with Life Scale, RFL-OA = Reasons for Living Older Adults, PSR = Perceived satisfaction with support Received, ADLs = Activities of Daily Living Scale, VFQ = Visual Function Questionnaire, Acuity = Acuity in better eye. ${ }^{\mathrm{a}} n=96$ due to missing data.

$* p<.05, * * p<.01, * * * p<.001$. 
Table 4.

Hierarchical Regression of Informal Support Giving as Predictor of Depressive Symptoms and Life Satisfaction

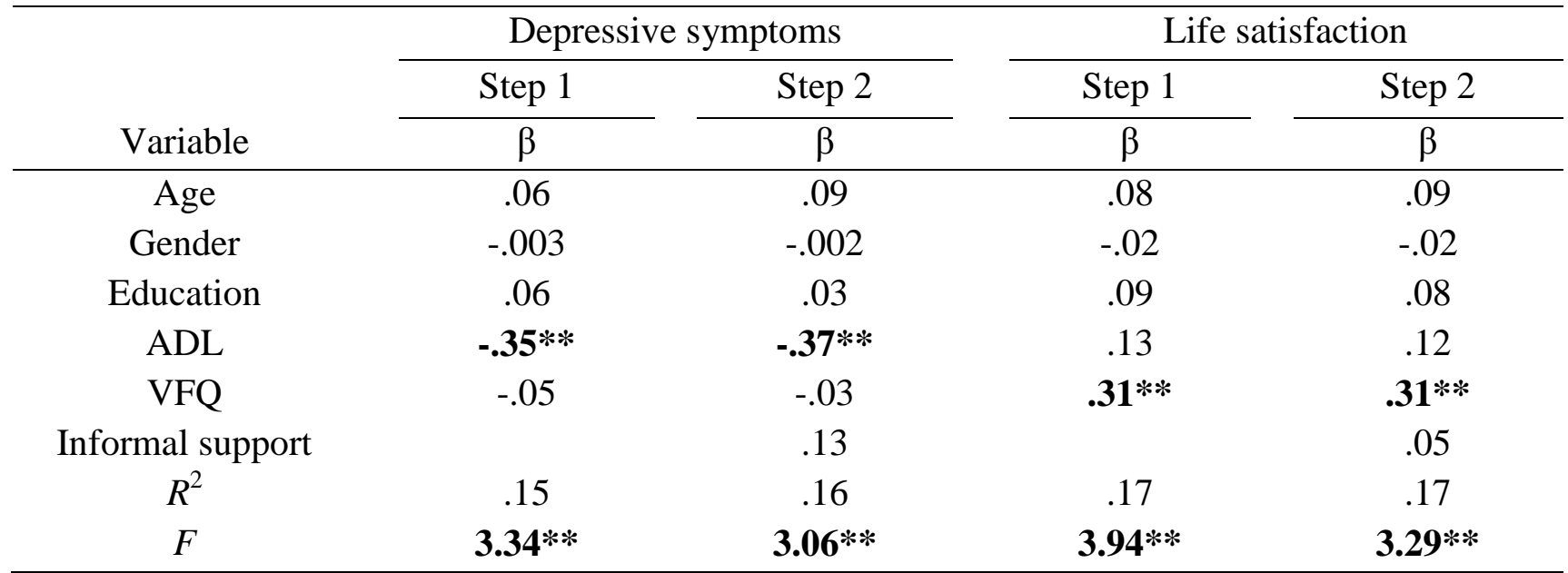

Note. $N=101$. Significant results are shown in boldface. ADLs $=$ Activities of Daily Living Scale, VFQ $=$ Visual Function Questionnaire.

$* p<.05, * * p<.01, * * * p<.001$. 
Table 5.

Hierarchical Regression of Informal Support Giving as Predictor of Reasons for Living

\begin{tabular}{|c|c|c|c|c|c|c|}
\hline \multirow[b]{3}{*}{ Variable } & \multicolumn{6}{|c|}{ Reasons for living } \\
\hline & \multicolumn{3}{|c|}{ Step 1} & \multicolumn{3}{|c|}{ Step 2} \\
\hline & $\mathrm{b}$ & SE & $95 \% \mathrm{CI}$ & $\mathrm{b}$ & SE & $95 \% \mathrm{CI}$ \\
\hline Age & $.02 * *$ & .005 & {$[.01, .03]$} & $.02 * *$ & .59 & {$[.007, .03]$} \\
\hline Gender & -.17 & .10 & {$[-.38, .05]$} & -.17 & .005 & {$[-.38, .05]$} \\
\hline Education & -.07 & .04 & {$[-.16, .01]$} & -.07 & .10 & {$[-.15, .01]$} \\
\hline ADL & .07 & .13 & {$[-.33, .18]$} & .06 & .04 & {$[-.33, .20]$} \\
\hline VFQ & $.006 *$ & .002 & {$[.001, .01]$} & $.006 * *$ & .002 & {$[.002, .01]$} \\
\hline Informal support & & & & -.003 & .006 & {$[-.02, .01]$} \\
\hline$R^{2}$ & .34 & & & .34 & & \\
\hline$F$ & $9.86 * *$ & & & $8.30 * *$ & & \\
\hline
\end{tabular}

Note. $N=101$. Significant results are shown in boldface. ADLs $=$ Activities of Daily Living Scale, VFQ $=$ Visual Function Questionnaire.

$* p<.05, * * p<.01, * * * p<.001$. 
Table 6.

Hierarchical Logistic Regression of Informal Support Giving as Predictor of Suicide Ideation

\begin{tabular}{|c|c|c|c|c|}
\hline \multirow[b]{3}{*}{ Variable } & \multicolumn{2}{|c|}{ Suicide ideation } & & \\
\hline & \multicolumn{2}{|c|}{ Step 1} & \multicolumn{2}{|c|}{ Step 2} \\
\hline & OR & $95 \%$ CI & OR & $95 \% \mathrm{CI}$ \\
\hline Age & .92 & {$[.81,1.05]$} & .87 & {$[.74,1.02]$} \\
\hline Gender & .66 & {$[.10,4.32]$} & .36 & {$[.04,3.59]$} \\
\hline Education & 1.03 & {$[.49,2.17]$} & 1.03 & {$[.48,2.20]$} \\
\hline ADL & .45 & {$[.03,6.49]$} & .94 & {$[.04,22.83]$} \\
\hline VFQ & .96 & {$[.92,1.01]$} & .95 & {$[.90,1.00]$} \\
\hline Informal support & & & .82 & {$[.68, .99]$} \\
\hline$\chi^{2}$ & 8.50 & & $14.45 *$ & \\
\hline
\end{tabular}

Note. $N=101$. Significant results are shown in boldface. ADLs $=$ Activities of Daily Living Scale, VFQ $=$ Visual Function Questionnaire.

$* p<.05, * * p<.01, * * * p<.001$. 
Table 7.

Hierarchical Regressions of Volunteer Behavior as Predictor of Depressive Symptoms and Life Satisfaction

\begin{tabular}{|c|c|c|c|c|}
\hline \multicolumn{5}{|c|}{ Volunteer hours } \\
\hline & \multicolumn{2}{|c|}{ Depressive symptoms } & \multicolumn{2}{|c|}{ Life satisfaction } \\
\hline & Step 1 & Step 2 & Step 1 & Step 2 \\
\hline Variable & $\beta$ & $\beta$ & $\beta$ & $\beta$ \\
\hline Age & .06 & .06 & .08 & .08 \\
\hline Gender & -.003 & -.01 & -.02 & -.02 \\
\hline Education & .06 & .07 & .09 & .08 \\
\hline ADL & $-.35 * *$ & $-.33 *$ & .13 & .12 \\
\hline VFQ & -.05 & -.05 & $.31 * *$ & $.31 * *$ \\
\hline Volunteer hours & & -.05 & & .01 \\
\hline$R^{2}$ & .15 & .15 & .17 & .17 \\
\hline \multirow[t]{4}{*}{$F$} & $3.34 * *$ & $2.80 *$ & $3.94 * *$ & $3.25 * *$ \\
\hline & \multicolumn{4}{|c|}{ Volunteer status } \\
\hline & \multicolumn{2}{|c|}{ Depressive symptoms } & \multicolumn{2}{|c|}{ Life satisfaction } \\
\hline & Step 1 & Step 2 & Step 1 & Step 2 \\
\hline Variable & $\beta$ & $\beta$ & $\beta$ & $\beta$ \\
\hline Age & .06 & .06 & .08 & .08 \\
\hline Gender & -.003 & -.01 & -.02 & -.01 \\
\hline Education & .06 & .06 & .09 & .08 \\
\hline ADL & $-.35 * *$ & $-.34 *$ & .13 & .10 \\
\hline VFQ & -.049 & -.05 & $.31 * *$ & $.31 * *$ \\
\hline Volunteer status & & -.03 & & .06 \\
\hline$R^{2}$ & .15 & .15 & .172 & .174 \\
\hline$F$ & $3.34 * *$ & $2.77 *$ & $3.94 * *$ & $3.31 * *$ \\
\hline$\Delta R^{2}$ & & .001 & & .003 \\
\hline$\Delta F$ & & .08 & & .31 \\
\hline
\end{tabular}


Table 7.

Hierarchical Regressions of Volunteer Behavior as Predictor of Depressive Symptoms and Life Satisfaction cont.

\begin{tabular}{|c|c|c|c|c|}
\hline \multicolumn{5}{|c|}{ Volunteer organizations } \\
\hline & \multicolumn{2}{|c|}{ Depressive symptoms } & \multicolumn{2}{|c|}{ Life satisfaction } \\
\hline & Step 1 & Step 2 & Step 1 & Step 2 \\
\hline Variable & $\beta$ & $\beta$ & $\beta$ & $\beta$ \\
\hline Age & .06 & .06 & .08 & .08 \\
\hline Gender & -.003 & -.005 & -.02 & -.01 \\
\hline Education & .06 & .06 & .09 & .08 \\
\hline ADL & $-.35 * *$ & $-.34 *$ & .13 & .12 \\
\hline VFQ & -.05 & -.05 & $.31 * *$ & $.31 * *$ \\
\hline Volunteer orgs. & & -.02 & & .03 \\
\hline$R^{2}$ & .15 & .15 & .17 & .17 \\
\hline$F$ & $3.34 * *$ & $2.76 *$ & $3.94 * *$ & $3.27 * *$ \\
\hline$\Delta R^{2}$ & & .00 & & .001 \\
\hline$\Delta F$ & & .03 & & .31 \\
\hline
\end{tabular}

Note. $N=101$. Significant results are shown in boldface. ADLs $=$ Activities of Daily Living Scale, $\mathrm{VFQ}=\mathrm{Visual}$ Function Questionnaire.

$* p<.05, * * p<.01, * * * p<.001$. 
Table 8.

Hierarchical Regressions of Volunteer Behavior as Predictor of Reasons for Living

\begin{tabular}{|c|c|c|c|c|c|c|}
\hline \multicolumn{7}{|c|}{ Volunteer hours } \\
\hline \multirow[b]{3}{*}{ Variable } & \multicolumn{6}{|c|}{ Reasons for living } \\
\hline & \multicolumn{3}{|c|}{ Step 1} & \multicolumn{3}{|c|}{ Step 2} \\
\hline & $\mathrm{b}$ & SE & $95 \% \mathrm{CI}$ & $\mathrm{b}$ & $\mathrm{SE}$ & $95 \% \mathrm{CI}$ \\
\hline Age & $.02 * *$ & .005 & {$[.01, .03]$} & $.02 *$ & .005 & {$[.007, .03]$} \\
\hline Gender & -.17 & .10 & {$[-.38, .05]$} & -.15 & .10 & {$[-.37,-.01]$} \\
\hline Education & -.07 & .04 & {$[-.16, .01]$} & $-.08 *$ & .04 & {$[-.16, .004]$} \\
\hline ADL & -.07 & .13 & {$[-.33, .18]$} & -.13 & .14 & {$[-.40, .09]$} \\
\hline VFQ & $.006 *$ & .002 & {$[.001, .01]$} & $.006 * *$ & .002 & {$[.002, .01]$} \\
\hline Volunteer hours & & & & $.07 *$ & .02 & {$[.01, .13]$} \\
\hline$R^{2}$ & .34 & & & .36 & & \\
\hline$F$ & $9.86 * *$ & & & 8.93* & & \\
\hline \multicolumn{7}{|c|}{ Volunteer Status } \\
\hline & \multicolumn{6}{|c|}{ Reasons for living } \\
\hline & \multicolumn{3}{|c|}{ Step 1} & \multicolumn{3}{|c|}{ Step 2} \\
\hline Variable & $\mathrm{b}$ & SE & $95 \% \mathrm{CI}$ & $\mathrm{b}$ & $\mathrm{SE}$ & $95 \% \mathrm{CI}$ \\
\hline Age & $.02 * *$ & .005 & {$[.01, .03]$} & $.02 *$ & .006 & {$[.004, .03]$} \\
\hline Gender & -.17 & .10 & {$[-.38, .05]$} & $-.20 *$ & .08 & {$[-.36,-.02]$} \\
\hline Education & -.07 & .04 & {$[-.16, .01]$} & -.06 & .03 & {$[-.13, .003]$} \\
\hline ADL & -.07 & .13 & {$[-.33, .18]$} & -.17 & .13 & {$[-.42, .08]$} \\
\hline VFQ & $.006 *$ & .002 & {$[.001, .01]$} & .005 & .003 & {$[-.001, .01]$} \\
\hline Volunteer status & & & & $.23 *$ & .09 & {$[.04, .41]$} \\
\hline$R^{2}$ & .34 & & & .35 & & \\
\hline$F$ & $9.86 * *$ & & & 8.92* & & \\
\hline$\Delta R^{2}$ & & & & .01 & & \\
\hline$\Delta F$ & & & & 2.29 & & \\
\hline
\end{tabular}


Table 8 .

Hierarchical Regressions of Volunteer Behavior as Predictor of Reasons for Living cont.

\begin{tabular}{|c|c|c|c|c|c|c|}
\hline \multirow[b]{4}{*}{ Variable } & \multicolumn{5}{|c|}{ Volunteer organizations } & \\
\hline & \multicolumn{6}{|c|}{ Reasons for living } \\
\hline & \multicolumn{3}{|c|}{ Step 1} & \multicolumn{3}{|c|}{ Step 2} \\
\hline & $\mathrm{b}$ & SE & $95 \% \mathrm{CI}$ & $\mathrm{b}$ & SE & $95 \% \mathrm{CI}$ \\
\hline Age & $.02 * *$ & .005 & {$[.01, .03]$} & $.02 * *$ & .006 & {$[.003, .03]$} \\
\hline Gender & -.17 & .10 & {$[-.38, .05]$} & $-.20 *$ & .08 & {$[-.37,-.03]$} \\
\hline Education & -.07 & .04 & {$[-.16, .01]$} & -.06 & .03 & {$[-.13, .003]$} \\
\hline ADL & -.07 & .13 & {$[-.33, .18]$} & -.13 & .12 & {$[-.38, .12]$} \\
\hline VFQ & $.006 *$ & .002 & {$[.001, .01]$} & .004 & .002 & {$[-.001, .01]$} \\
\hline Volunteer orgs. & & & & .09 & .04 & {$[.04, .41]$} \\
\hline$R^{2}$ & .34 & & & .34 & & \\
\hline$F$ & $9.86 * *$ & & & 8.11* & & \\
\hline$\Delta R^{2}$ & & & & .005 & & \\
\hline$\Delta F$ & & & & .72 & & \\
\hline
\end{tabular}

Note. $N=101$. Significant results are shown in boldface. ADLs = Activities of Daily Living Scale, VFQ = Visual Function Questionnaire.

$* p<.05, * * p<.01, * * * p<.001$. 
Table 9.

Hierarchical Logistic Regressions of Volunteer Behavior as Predictor of the Presence of Suicide Ideation

\begin{tabular}{|c|c|c|c|c|}
\hline \multicolumn{5}{|c|}{ Volunteer hours } \\
\hline \multirow[b]{3}{*}{ Variable } & \multicolumn{4}{|c|}{ Suicide ideation } \\
\hline & \multicolumn{2}{|c|}{ Step 1} & \multicolumn{2}{|c|}{ Step 2} \\
\hline & OR & $95 \% \mathrm{CI}$ & OR & $95 \% \mathrm{CI}$ \\
\hline Age & .92 & {$[.81,1.05]$} & .91 & {$[.80,1.04]$} \\
\hline Gender & .66 & {$[.10,4.32]$} & .56 & {$[.08,3.90]$} \\
\hline Education & 1.03 & {$[.49,2.16]$} & 1.11 & {$[.53,2.30]$} \\
\hline ADL & .45 & {$[.03,6.49]$} & .83 & {$[.05,14.23]$} \\
\hline VFQ & .96 & {$[.92,1.09]$} & .96 & {$[.91,1.07]$} \\
\hline Volunteer hours & & & .62 & {$[.26,1.51]$} \\
\hline$\chi^{2}$ & 8.50 & & 9.94 & \\
\hline \multicolumn{5}{|c|}{ Volunteer status } \\
\hline & \multicolumn{4}{|c|}{ Suicide ideation } \\
\hline & \multicolumn{2}{|c|}{ Step 1} & \multicolumn{2}{|c|}{ Step 2} \\
\hline Variable & OR & $95 \% \mathrm{CI}$ & OR & $95 \% \mathrm{CI}$ \\
\hline Age & .92 & {$[.81,1.05]$} & .92 & {$[.80,1.05]$} \\
\hline Gender & .66 & {$[.10,4.32]$} & .49 & {$[.07,3.52]$} \\
\hline Education & 1.03 & {$[.49,2.16]$} & 1.13 & {$[.53,2.38]$} \\
\hline ADL & .45 & {$[.03,6.49]$} & 1.14 & {$[.05,24.40]$} \\
\hline VFQ & .96 & {$[.92,1.09]$} & .96 & {$[.91,1.01]$} \\
\hline Volunteer status & & & .17 & {$[.01,2.20]$} \\
\hline$\chi^{2}$ & 8.50 & & 10.75 & \\
\hline$\Delta \chi^{2}$ & & & 2.25 & \\
\hline
\end{tabular}


Table 9.

Hierarchical Logistic Regressions of Volunteer Behavior as Predictor of the Presence of Suicide Ideation cont.

\begin{tabular}{|c|c|c|c|c|}
\hline \multicolumn{5}{|c|}{ Volunteer organizations } \\
\hline \multirow[b]{3}{*}{ Variable } & \multicolumn{4}{|c|}{ Suicide ideation } \\
\hline & \multicolumn{2}{|c|}{ Step 1} & \multicolumn{2}{|c|}{ Step 2} \\
\hline & OR & $95 \% \mathrm{CI}$ & OR & $95 \% \mathrm{CI}$ \\
\hline Age & .92 & {$[.81,1.05]$} & .92 & {$[.81,1.05]$} \\
\hline Gender & .66 & {$[.10,4.32]$} & .64 & {$[.10,4.25]$} \\
\hline Education & 1.03 & {$[.49,2.16]$} & 1.05 & {$[.50,2.23]$} \\
\hline $\mathrm{ADL}$ & .45 & {$[.03,6.49]$} & .51 & {$[.03,8.48]$} \\
\hline VFQ & .96 & {$[.92,1.09]$} & .96 & {$[.92,1.01]$} \\
\hline Volunteer orgs. & & & .84 & {$[.25,2.85]$} \\
\hline$\chi^{2}$ & 8.50 & & 8.58 & \\
\hline$\Delta \chi^{2}$ & & & .08 & \\
\hline
\end{tabular}

Note. $N=101$. Significant results are shown in boldface. ADLs $=$ Activities of Daily Living Scale, VFQ $=$ Visual Function Questionnaire.

$* p<.05, * * p<.01, * * * p<.001$. 
Table 10.

Hierarchical Regression of Perceived Satisfaction with Support Received as Predictor of Depressive Symptoms and Life Satisfaction

\begin{tabular}{|c|c|c|c|c|}
\hline \multirow[b]{3}{*}{ Variable } & \multicolumn{2}{|c|}{ Depressive symptoms } & \multicolumn{2}{|c|}{ Life satisfaction } \\
\hline & Step 1 & Step 2 & Step 1 & Step 2 \\
\hline & $\beta$ & $\beta$ & $\beta$ & $\beta$ \\
\hline Age & .06 & .05 & .08 & .08 \\
\hline Gender & -.003 & -.03 & -.02 & -.001 \\
\hline Education & .06 & .05 & .09 & .09 \\
\hline ADL & $-.35 * *$ & $-.34 * *$ & .13 & .12 \\
\hline VFQ & -.05 & .001 & $.31 * *$ & $.28 *$ \\
\hline PSR & & $-.21 *$ & & .13 \\
\hline$R^{2}$ & .15 & .19 & .17 & .19 \\
\hline$F$ & $3.34 * *$ & $3.67 * *$ & $3.94 * *$ & $3.63 * *$ \\
\hline
\end{tabular}

Note. $N=101$. Significant results are shown in boldface. ADLs $=$ Activities of Daily Living Scale, $V F Q=$ Visual Function Questionnaire, PSR $=$ Perceived satisfaction with support received.

$* p<.05, * * p<.01, * * * p<.001$. 
Table 11.

Hierarchical Regression of Perceived Satisfaction with Support Received as Predictor of Reasons for Living

\begin{tabular}{|c|c|c|c|c|c|c|}
\hline \multirow[b]{3}{*}{ Variable } & \multicolumn{4}{|c|}{ Reasons for living } & & \\
\hline & \multicolumn{3}{|c|}{ Step 1} & \multicolumn{3}{|c|}{ Step 2} \\
\hline & $\mathrm{b}$ & SE & $95 \% \mathrm{CI}$ & $\mathrm{b}$ & $\mathrm{SE}$ & $95 \% \mathrm{CI}$ \\
\hline Age & $.02 * *$ & .005 & {$[.01, .03]$} & $.02 * *$ & .005 & {$[.008, .03]$} \\
\hline Gender & -.17 & .10 & {$[-.38, .05]$} & $-.18 *$ & .10 & {$[-.43,-.002]$} \\
\hline Education & -.07 & .04 & {$[-.16, .01]$} & -.04 & .03 & {$[-.11, .02]$} \\
\hline ADL & .07 & .13 & {$[-.33, .18]$} & .10 & .13 & {$[-.38, .17]$} \\
\hline VFQ & $.006 *$ & .002 & {$[.001, .01]$} & .004 & .002 & {$[-.001, .01]$} \\
\hline PSR & & & & $.51 * *$ & .19 & {$[.12, .90]$} \\
\hline$R^{2}$ & .34 & & & .37 & & \\
\hline$F$ & $9.86 * *$ & & & $9.28 * *$ & & \\
\hline
\end{tabular}

Note. $N=101$. Significant results are shown in boldface. ADLs $=$ Activities of Daily Living Scale, VFQ $=$ Visual Function Questionnaire, PSR $=$ Perceived satisfaction with support received.

$* p<.05, * * p<.01, * * * p<.001$. 
Table 12.

Hierarchical Logistic Regression of Perceived Satisfaction with Support Received as a Predictor of Suicide Ideation

\begin{tabular}{ccccccc}
\hline & \multicolumn{3}{c}{ Suicide ideation } & & \\
\cline { 2 - 3 } & \multicolumn{2}{c}{ Step 1 } & & \multicolumn{2}{c}{ Step 2 } \\
\cline { 2 - 3 } \cline { 5 - 6 } Variable & OR & $95 \%$ CI & & OR & $95 \%$ CI \\
\hline Age & .92 & {$[.81,1.05]$} & & .87 & {$[.73,1.03]$} \\
Gender & .66 & {$[.10,4.32]$} & & .16 & {$[.01,2.38]$} \\
Education & 1.03 & {$[.49,2.17]$} & & .92 & {$[.39,2.16]$} \\
ADL & .45 & {$[.03,6.49]$} & & .69 & {$[.03,14.25]$} \\
VFQ & .96 & {$[.92,1.01]$} & & .97 & {$[.92,1.07]$} \\
PSR & & & & $\mathbf{0 2}$ & {$[<.001, .52]$} \\
$\chi^{2}$ & 8.50 & & & $\mathbf{1 4 . 8 0} *$ & \\
\hline
\end{tabular}

Note. $N=101$. Significant results are shown in boldface. ADLs $=$ Activities of Daily Living Scale, VFQ $=$ Visual Function Questionnaire, PSR $=$ Perceived satisfaction with support received.

$* p<.05, * * p<.01, * * * p<.001$. 
Table 13.

Hierarchical Regression of Informal Support Giving as a Predictor of Perceived Satisfaction with Support Received

\begin{tabular}{|c|c|c|}
\hline \multirow[b]{3}{*}{ Variable } & \multicolumn{2}{|c|}{ PSR } \\
\hline & Step 1 & Step 2 \\
\hline & $\beta$ & $\beta$ \\
\hline Age & -.04 & -.11 \\
\hline Gender & -.12 & -.06 \\
\hline Education & -.03 & -.02 \\
\hline ADL & -.04 & -.08 \\
\hline VFQ & .24 & $.31 *$ \\
\hline Support received & .17 & .25 \\
\hline Informal support & & -.16 \\
\hline$R^{2}$ & .10 & .12 \\
\hline$F$ & 1.84 & 1.84 \\
\hline
\end{tabular}

Note. $N=101$. Significant results are shown in boldface.. ADLs $=$ Activities of Daily Living Scale, VFQ $=$ Visual Function Questionnaire, PSR $=$ Perceived satisfaction with support received.

$* p<.05, * * p<.01, * * * p<.001$. 
Table 14.

Hierarchical Regressions of Moderating Model of Perceived Satisfaction with Support Received on Disability and Depressive Symptoms and Life Satisfaction

\begin{tabular}{|c|c|c|c|c|}
\hline \multicolumn{5}{|c|}{ Activities of daily living*Satisfaction with support received } \\
\hline & \multicolumn{2}{|c|}{ Depressive symptoms } & \multicolumn{2}{|c|}{ Life satisfaction } \\
\hline & Step 1 & Step 2 & Step 1 & Step 2 \\
\hline Variable & $\beta$ & $\beta$ & $\beta$ & $\beta$ \\
\hline Age & .05 & .05 & .08 & .08 \\
\hline Gender & -.03 & -.05 & .01 & .04 \\
\hline Education & .05 & .05 & .12 & .12 \\
\hline PSR- centered & $-.21 *$ & -.17 & .18 & .12 \\
\hline ADLs- centered & $-.34 * * *$ & $-.32 * *$ & $.27 * *$ & $.24 *$ \\
\hline PRS*ADL & & .15 & & $-.22 *$ \\
\hline$R^{2}$ & .19 & .21 & .14 & .19 \\
\hline$F$ & $4.45 * * *$ & $4.15 * * *$ & $3.12 * *$ & $3.48 *$ \\
\hline \multicolumn{5}{|c|}{ Visual functioning* Satisfaction with support received } \\
\hline & \multicolumn{2}{|c|}{ Depressive symptoms } & \multicolumn{2}{|c|}{ Life satisfaction } \\
\hline & Step 1 & Step 2 & Step 1 & Step 2 \\
\hline Variable & $\beta$ & $\beta$ & $\beta$ & $\beta$ \\
\hline Age & .08 & .07 & .08 & .08 \\
\hline Gender & -.04 & -.06 & .002 & .05 \\
\hline Education & .05 & .06 & .09 & .07 \\
\hline PSR- centered & $-.22 *$ & -.17 & .14 & .04 \\
\hline VFQ- centered & .19 & -.16 & $.35 * * *$ & $.29 * *$ \\
\hline PRS*VFQ & & .16 & & $-.31 * *$ \\
\hline$R^{2}$ & .12 & .13 & .18 & .26 \\
\hline$F$ & $2.49 *$ & $2.49 *$ & $4.14 * *$ & $5.45 * * *$ \\
\hline
\end{tabular}

Note. $N=101$. Significant results are shown in boldface. ADLs $=$ Activities of Daily Living Scale, VFQ $=$ Visual Function Questionnaire, PSR $=$ Perceived satisfaction with support received.

$* p<.05, * * p<.01, * * * p<.001$. 
Table 15.

Hierarchical Regressions of Moderating Model of Perceived Satisfaction with Support Received on Disability and Reasons for Living

\begin{tabular}{|c|c|c|c|c|c|c|}
\hline \multicolumn{7}{|c|}{ Activities of daily living*Satisfaction with support received } \\
\hline \multirow[b]{3}{*}{ Variable } & \multicolumn{6}{|c|}{ Reasons for living } \\
\hline & \multicolumn{3}{|c|}{ Step 1} & \multicolumn{3}{|c|}{ Step 2} \\
\hline & $\mathrm{b}$ & SE & $95 \% \mathrm{CI}$ & $\mathrm{b}$ & SE & $95 \% \mathrm{CI}$ \\
\hline Age & $.02 * * *$ & .005 & {$[.01, .03]$} & $.02 *$ & .006 & {$[.004, .03]$} \\
\hline Gender & -.14 & .11 & {$[-.36, .08]$} & -.19 & .08 & {$[-.36,-.03]$} \\
\hline Education & -.05 & .04 & {$[-.13, .04]$} & -.06 & .04 & {$[-.13, .02]$} \\
\hline PSR- centered & $.40 * * *$ & .21 & {$[.19,1.02]$} & $.14 *$ & .05 & {$[.02, .25]$} \\
\hline ADLs- centered & .04 & .11 & {$[-.18, .27]$} & .08 & .22 & {$[-.36, .53]$} \\
\hline PRS*ADL & & & & -.02 & .08 & {$[-.18, .15]$} \\
\hline$R^{2}$ & .29 & & & .30 & & \\
\hline \multirow[t]{4}{*}{$F$} & $8.20 * * *$ & & & $6.71 * * *$ & & \\
\hline & \multicolumn{6}{|c|}{ Visual functioning*Satisfaction with support received } \\
\hline & \multicolumn{6}{|c|}{ Reasons for living } \\
\hline & \multicolumn{3}{|c|}{ Step 1} & \multicolumn{3}{|c|}{ Step 2} \\
\hline Variable & $\mathrm{b}$ & SE & $95 \% \mathrm{CI}$ & $\mathrm{b}$ & SE & $95 \% \mathrm{CI}$ \\
\hline Age & $.02 * * *$ & .005 & {$[.01, .03]$} & $.02 * *$ & .006 & {$[.005, .03]$} \\
\hline Gender & -.15 & .11 & {$[-.36, .08]$} & $-.20 *$ & .08 & {$[-.36,-.03]$} \\
\hline Education & -.06 & .04 & {$[-.13, .04]$} & -.06 & .03 & {$[-.14, .03]$} \\
\hline PSR- centered &. $\mathbf{4 0} * * *$ & .21 & {$[.19,1.02]$} & $.12 *$ & .05 & {$[.02, .23]$} \\
\hline VFQ- centered & .005 & .11 & {$[-.18, .27]$} & .001 & .005 & {$[-.009, .01]$} \\
\hline PRS*VFQ & & & & .003 & .002 & {$[-.004, .006]$} \\
\hline$R^{2}$ & .34 & & & .34 & & \\
\hline$F$ & $9.92 * * *$ & & & $8.07 * * *$ & & \\
\hline
\end{tabular}

Note. $N=101$. Significant results are shown in boldface. ADLs $=$ Activities of Daily Living Scale, VFQ $=$ Visual Function Questionnaire, PSR $=$ Perceived satisfaction with support received.

$* p<.05, * * p<.01, * * * p<.001$. 
Table 16.

Hierarchical Logistic Regressions of Moderating Model of Perceived Satisfaction with Support Received on Disability and Suicide Ideation

Activities of daily living*Satisfaction with support received

\begin{tabular}{|c|c|c|c|c|}
\hline \multirow[b]{3}{*}{ Variable } & \multicolumn{4}{|c|}{ Suicide ideation } \\
\hline & \multicolumn{2}{|c|}{ Step 1} & \multicolumn{2}{|c|}{ Step 2} \\
\hline & OR & $95 \% \mathrm{CI}$ & OR & $95 \% \mathrm{CI}$ \\
\hline Age & .87 & {$[.74,1.02]$} & .87 & {$[.74,1.02]$} \\
\hline Gender & .01 & {$[.01,2.67]$} & .17 & {$[.01,2.67]$} \\
\hline Education & .76 & {$[.36,1.63]$} & .73 & {$[.34,1.58]$} \\
\hline PSR- centered & $<.001$ & {$[<.001, .31]$} & $<.001$ & {$[<.001, .29]$} \\
\hline ADLs- centered & .02 & {$[.02,2.03]$} & .09 & {$[.004,1.99]$} \\
\hline PRS*ADL & & & .02 & {$[<.001,169.53]$} \\
\hline$\chi^{2}$ & $13.43 *$ & & $14.21 *$ & \\
\hline
\end{tabular}

Visual functioning*Satisfaction with support received

\begin{tabular}{|c|c|c|c|c|}
\hline \multirow[b]{3}{*}{ Variable } & \multicolumn{4}{|c|}{ Suicide ideation } \\
\hline & \multicolumn{2}{|c|}{ Step 1} & \multicolumn{2}{|c|}{ Step 2} \\
\hline & OR & $95 \% \mathrm{CI}$ & OR & $95 \% \mathrm{CI}$ \\
\hline Age & .87 & {$[.73,1.03]$} & .87 & {$[.74,1.04]$} \\
\hline Gender & .16 & {$[.01,2.34]$} & .17 & {$[.01,2.52]$} \\
\hline Education & .94 & {$[.41,2.15]$} & .93 & {$[.40,2.15]$} \\
\hline PSR- centered & .004 & {$[<.001, .47]$} & .003 & {$[<.001, .914]$} \\
\hline VFQ- centered & .93 & {$[.92,1.005]$} & .96 & {$[.93,1.01]$} \\
\hline PRS*VFQ & & & .99 & {$[.84,1.16]$} \\
\hline$\chi^{2}$ & $14.75 *$ & & $14.77 *$ & \\
\hline
\end{tabular}

Note. $N=101$. Significant results are shown in boldface. ADLs $=$ Activities of Daily Living Scale, VFQ $=$ Visual Function Questionnaire, PSR $=$ Perceived satisfaction with support received.

$* p<.05$, ** $p<.01$, *** $p<.001$. 
Table 17.

Hierarchical Regressions of Moderating Model of Informal Support Giving on Disability and Depressive Symptoms and Life Satisfaction

\begin{tabular}{|c|c|c|c|c|}
\hline \multicolumn{5}{|c|}{ Activities of daily living* Informal support giving } \\
\hline & \multicolumn{2}{|c|}{ Depressive symptoms } & \multicolumn{2}{|c|}{ Life satisfaction } \\
\hline & Step 1 & Step 2 & Step 1 & Step 2 \\
\hline Variable & $\beta$ & $\beta$ & $\beta$ & $\beta$ \\
\hline Age & .09 & .09 & .08 & .08 \\
\hline Gender & -.002 & -.003 & -.01 & -.02 \\
\hline Education & .03 & .01 & .11 & .13 \\
\hline Informal- centered & .13 & .13 & .03 & .03 \\
\hline ADLs- centered & $-.40 * * *$ & $-.39 * *$ & $.30 * *$ & $.29 * *$ \\
\hline Informal*ADL & & -.07 & & -.07 \\
\hline$R^{2}$ & .16 & .17 & .11 & .12 \\
\hline$F$ & $3.69 * *$ & $3.20 * *$ & $2.37 *$ & 2.06 \\
\hline \multicolumn{5}{|c|}{ Visual functioning* Informal support giving } \\
\hline & \multicolumn{2}{|c|}{ Depressive symptoms } & \multicolumn{2}{|c|}{ Life satisfaction } \\
\hline & Step 1 & Step 2 & Step 1 & Step 2 \\
\hline Variable & $\beta$ & $\beta$ & $\beta$ & $\beta$ \\
\hline Age & .10 & .12 & .08 & .09 \\
\hline Gender & -.01 & -.007 & -.01 & -.01 \\
\hline Education & .04 & .05 & .08 & .08 \\
\hline Informal- centered & .07 & .07 & .06 & .06 \\
\hline VFQ- centered & $-.25 * *$ & $-.25 * *$ & $.38 * * *$ & $.38 * * *$ \\
\hline Informal*VFQ & & -.08 & & -.06 \\
\hline$R^{2}$ & .08 & .08 & .16 & .17 \\
\hline$F$ & 1.57 & 1.41 & $3.76 * *$ & $3.17 * *$ \\
\hline
\end{tabular}

Note. $N=101$. Significant results are shown in boldface. ADLs $=$ Activities of Daily Living Scale, VFQ $=$ Visual Function Questionnaire $* p<.05, * * p<.01, * * * p<.001$. 
Table 18.

Hierarchical Regressions of Moderating Model of Informal Support Giving on Disability and Reasons for Living

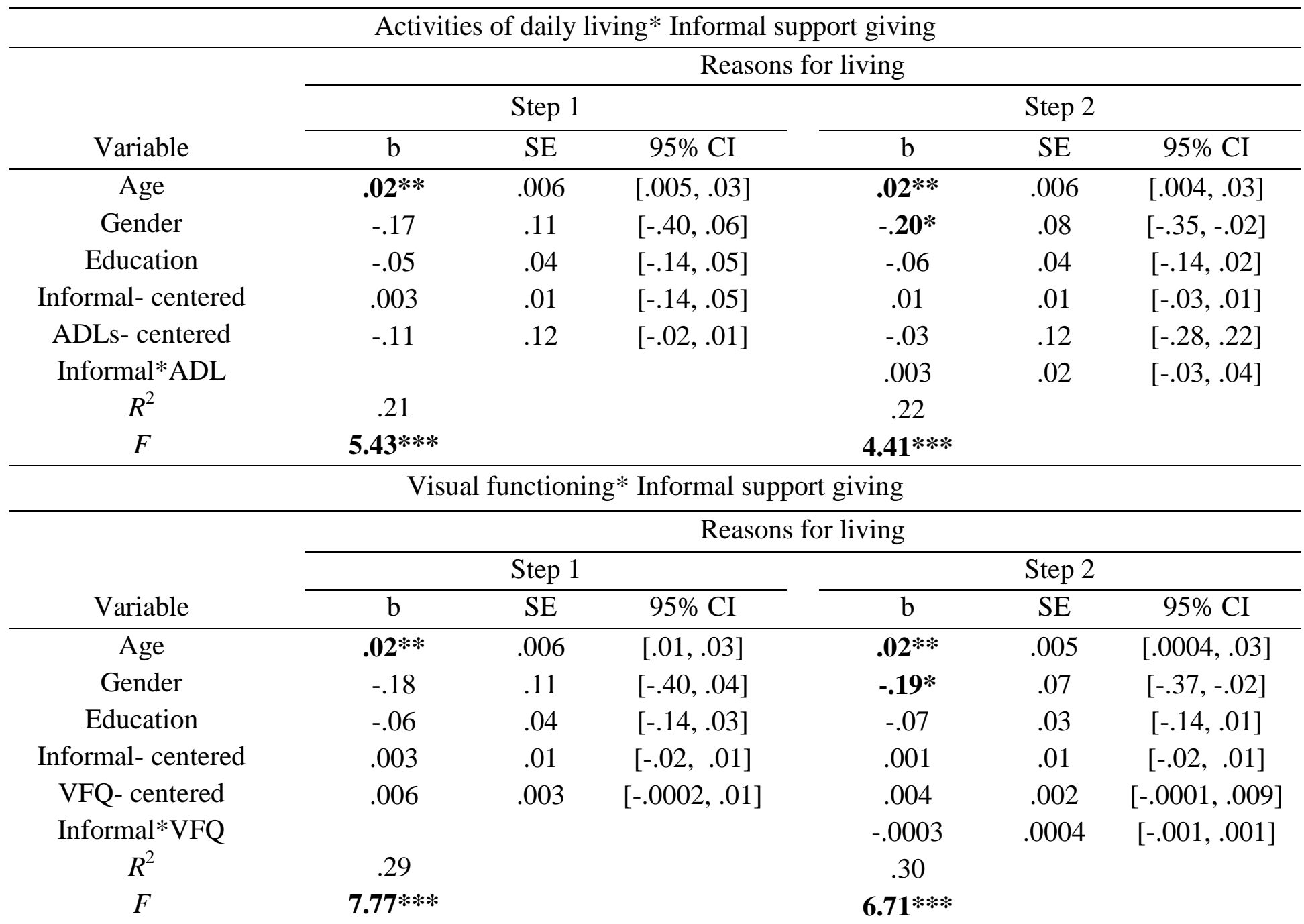

Note. $N=101$. Significant results are shown in boldface. ADLs $=$ Activities of Daily Living Scale, VFQ $=$ Visual Function Questionnaire,

$* p<.05, * * p<.01, * * * p<.001$. 
Table 19.

Hierarchical Logistic Regressions of Moderating Model of Informal Support Giving on Disability and Suicide Ideation

\begin{tabular}{|c|c|c|c|c|}
\hline \multicolumn{5}{|c|}{ Activities of daily living* Informal support giving } \\
\hline \multirow[b]{3}{*}{ Variable } & \multicolumn{4}{|c|}{ Suicide ideation } \\
\hline & \multicolumn{2}{|c|}{ Step 1} & \multicolumn{2}{|c|}{ Step 2} \\
\hline & OR & $95 \% \mathrm{CI}$ & OR & $95 \% \mathrm{CI}$ \\
\hline Age & .86 & {$[.73,1.01]$} & .86 & {$[.73,1.02]$} \\
\hline Gender & .46 & {$[.06,3.49]$} & .49 & {$[.06,3.83]$} \\
\hline Education & .83 & {$[.40,1.74]$} & .81 & {$[.38,1.71]$} \\
\hline Informal- centered & .83 & {$[.40,1.002]$} & .86 & {$[.71,1.04]$} \\
\hline ADLs- centered & .19 & {$[.02,1.79]$} & .38 & {$[.02,7.50]$} \\
\hline Informal*ADL & & & 1.20 & {$[.75, .1 .92]$} \\
\hline$\chi^{2}$ & 10.62 & & 11.20 & \\
\hline \multicolumn{5}{|c|}{ ing } \\
\hline & \multicolumn{4}{|c|}{ Suicide ideation } \\
\hline & \multicolumn{2}{|c|}{ Step 1} & \multicolumn{2}{|c|}{ Step 2} \\
\hline Variable & OR & $95 \% \mathrm{CI}$ & OR & $95 \% \mathrm{CI}$ \\
\hline Age & .87 & {$[.74,1.02]$} & .85 & {$[.72,1.01]$} \\
\hline Gender & .35 & {$[.04,3.26]$} & .35 & {$[.03,3.50]$} \\
\hline Education & 1.03 & {$[.49,2.17]$} & 1.01 & {$[.47,2.20]$} \\
\hline Informal- centered & .82 & {$[.68, .99]$} & .90 & {$[.74,1.09]$} \\
\hline VFQ- centered & .95 & {$[.91, .99]$} & .96 & {$[.91,1.01]$} \\
\hline Informal*VFQ & & & 1.01 & {$[.99,1.02]$} \\
\hline$\chi^{2}$ & $14.75 *$ & & $16.53 *$ & \\
\hline
\end{tabular}

Note. $N=101$. Significant results are shown in boldface. ADLs $=$ Activities of Daily Living Scale, VFQ $=$ Visual Function Questionnaire

$* p<.05, * * p<.01, * * * p<.001$. 
Table 20.

Hierarchical Regressions of Moderating Model of Volunteer Hours on Disability and Depressive Symptoms and Life Satisfaction

\begin{tabular}{|c|c|c|c|c|}
\hline \multicolumn{5}{|c|}{ Activities of daily living*Volunteer hours } \\
\hline & \multicolumn{2}{|c|}{ Depressive symptoms } & \multicolumn{2}{|c|}{ Life satisfaction } \\
\hline & Step 1 & Step 2 & Step 1 & Step 2 \\
\hline Variable & $\beta$ & $\beta$ & $\beta$ & $\beta$ \\
\hline Age & .06 & .06 & .07 & .07 \\
\hline Gender & -.01 & -.01 & -.01 & -.01 \\
\hline Education & .06 & .06 & .12 & .12 \\
\hline Vol hrs.- centered & -.05 & -.07 & .009 & -.03 \\
\hline ADLs- centered & $-.36 * *$ & $-.34 * *$ & $.30 * *$ & $.33 * *$ \\
\hline Vol hrs.*ADL & & .03 & & -.06 \\
\hline$R^{2}$ & .15 & .15 & .11 & .11 \\
\hline$F$ & $3.36 * *$ & $2.79 *$ & 2.36 & 2.00 \\
\hline \multicolumn{5}{|c|}{ Visual functioning* Volunteer hours } \\
\hline & \multicolumn{2}{|c|}{ Depressive symptoms } & \multicolumn{2}{|c|}{ Life satisfaction } \\
\hline & Step 1 & Step 2 & Step 1 & Step 2 \\
\hline Variable & $\beta$ & $\beta$ & $\beta$ & $\beta$ \\
\hline Age & .08 & .08 & .07 & .07 \\
\hline Gender & -.03 & -.03 & -.01 & -.01 \\
\hline Education & .08 & .08 & .08 & .08 \\
\hline Vol hrs.- centered & -.14 & -.14 & .05 & .05 \\
\hline VFQ- centered & $-.22 *$ & $-.23 *$ & $.37 * * *$ & $.37 * * *$ \\
\hline Vol hrs.*VFQ & & -.02 & & -.01 \\
\hline$R^{2}$ & .09 & .09 & .16 & .16 \\
\hline$F$ & 1.87 & 1.55 & $3.72 * *$ & 3.07 \\
\hline
\end{tabular}

Note. $N=101$. Significant results are shown in boldface. ADLs $=$ Activities of Daily Living Scale, VFQ $=$ Visual Function Questionnaire $* p<.05, * * p<.01, * * * p<.001$. 
Table 21.

Hierarchical Regressions of Moderating Model of Volunteer Hours on Disability and Reasons for Living

\begin{tabular}{|c|c|c|c|c|c|c|}
\hline \multicolumn{7}{|c|}{ Activities of daily living* Volunteer hours } \\
\hline \multirow[b]{3}{*}{ Variable } & \multicolumn{6}{|c|}{ Reasons for living } \\
\hline & \multicolumn{3}{|c|}{ Step 1} & \multicolumn{3}{|c|}{ Step 2} \\
\hline & $\mathrm{b}$ & SE & $95 \% \mathrm{CI}$ & $\mathrm{b}$ & SE & $95 \% \mathrm{CI}$ \\
\hline Age & $.02 * *$ & .005 & {$[.01, .03]$} & $.02 * *$ & .006 & {$[.01, .03]$} \\
\hline Gender & -.16 & .11 & {$[-.37, .06]$} & $-.20 *$ & .08 & {$[-.39,-.06]$} \\
\hline Education & -.06 & .04 & {$[-.15, .03]$} & -.07 & .04 & {$[-.14, .01]$} \\
\hline Vol hrs.- centered & .04 & .03 & {$[-.03, .18]$} & $.10 *$ & .03 & {$[.02, .18]$} \\
\hline ADLs- centered & .16 & .13 & {$[-.22, .45]$} & .16 & .14 & {$[-.11, .45]$} \\
\hline Vol hrs.*ADL & & & & -.08 & .09 & {$[-.12, .28]$} \\
\hline$R^{2}$ & .24 & & & .25 & & \\
\hline$F$ & $6.35 * * *$ & & & $5.22 * * *$ & & \\
\hline \multicolumn{7}{|c|}{ Visual functioning* Volunteer hours } \\
\hline & \multicolumn{6}{|c|}{ Reasons for living } \\
\hline & \multicolumn{3}{|c|}{ Step 1} & \multicolumn{3}{|c|}{ Step 2} \\
\hline Variable & $\mathrm{b}$ & SE & $95 \% \mathrm{CI}$ & $\mathrm{b}$ & SE & $95 \%$ CI \\
\hline Age & $.02 * *$ & .005 & {$[.01, .03]$} & $.02 * *$ & .006 & {$[.01, .03]$} \\
\hline Gender & -.17 & .10 & {$[-.38, .04]$} & $-.20 *$ & .08 & {$[-.39,-.06]$} \\
\hline Education & -.07 & .04 & {$[-.15, .02]$} & -.07 & .03 & {$[-.14, .01]$} \\
\hline Vol hrs.- centered & .03 & .03 & {$[-.03, .10]$} & $.07 *$ & .03 & {$[.01, .13]$} \\
\hline VFQ- centered & .01 & .003 & {$[-.001, .01]$} & .003 & .002 & {$[-.002, .0007]$} \\
\hline Vol hrs.*VFQ & & & & -.001 & .002 & {$[-.005, .002]$} \\
\hline$R^{2}$ & .30 & & & .32 & & \\
\hline$F$ & $8.52 * * *$ & & & $7.37 * * *$ & & \\
\hline
\end{tabular}

Note. $N=101$. Significant results are shown in boldface. ADLs $=$ Activities of Daily Living Scale, VFQ $=$ Visual Function Questionnaire,

$* p<.05, * * p<.01, * * * p<.001$. 
Table 22.

Hierarchical Logistic Regressions of Moderating Model of Volunteer Hours on Disability and Suicide Ideation

\begin{tabular}{|c|c|c|c|c|}
\hline \multicolumn{5}{|c|}{ Activities of daily living* Volunteer hours } \\
\hline \multirow[b]{3}{*}{ Variable } & \multicolumn{4}{|c|}{ Suicide ideation } \\
\hline & \multicolumn{2}{|c|}{ Step 1} & \multicolumn{2}{|c|}{ Step 2} \\
\hline & OR & $95 \% \mathrm{CI}$ & OR & $95 \% \mathrm{CI}$ \\
\hline Age & .92 & {$[.83,1.03]$} & .92 & {$[.82,1.05]$} \\
\hline Gender & .69 & {$[.15,3.20]$} & .67 & {$[.15,3.02]$} \\
\hline Education & .94 & {$[.54,1.66]$} & .92 & {$[.52,1.63]$} \\
\hline Vol hrs.- centered & .79 & {$[.44,1.46]$} & .67 & {$[.31,1.54]$} \\
\hline ADLs- centered & .87 & {$[.04,17.20]$} & .88 & {$[.04,17.67]$} \\
\hline Vol hrs.*ADL & & & 3.14 & {$[.04,22.53]$} \\
\hline$\chi^{2}$ & 4.93 & & 6.11 & \\
\hline \multicolumn{5}{|c|}{ Visual functioning* Volunteer hours } \\
\hline & \multicolumn{4}{|c|}{ Suicide ideation } \\
\hline & \multicolumn{2}{|c|}{ Step 1} & \multicolumn{2}{|c|}{ Step 2} \\
\hline Variable & OR & $95 \% \mathrm{CI}$ & OR & $95 \% \mathrm{CI}$ \\
\hline Age & .92 & {$[.80,1.04]$} & .91 & {$[.79,1.04]$} \\
\hline Gender & .56 & {$[.08,3.83]$} & .47 & {$[.06,3.66]$} \\
\hline Education & 1.12 & {$[.55,2.29]$} & 1.20 & {$[.55,2.58]$} \\
\hline Vol hrs.- centered & .61 & {$[.26,1.43]$} & .49 & {$[.10,2.33]$} \\
\hline VFQ- centered & .96 & {$[.92, .99]$} & 1.00 & {$[.90,1.13]$} \\
\hline Vol hrs.*VFQ & & & 1.05 & {$[.97,1.14]$} \\
\hline$\chi^{2}$ & 9.92 & & $13.27 *$ & \\
\hline
\end{tabular}

Note. $N=101$. Significant results are shown in boldface. ADLs $=$ Activities of Daily Living Scale, VFQ $=$ Visual Function Questionnaire

$* p<.05, * * p<.01, * * * p<.001$. 
Table 23.

Hierarchical Regressions of Moderating Model of Volunteer Status on Disability and Depressive Symptoms and Life Satisfaction

\begin{tabular}{|c|c|c|c|c|}
\hline \multicolumn{5}{|c|}{ Activities of daily living*Volunteer status } \\
\hline & \multicolumn{2}{|c|}{ Depressive symptoms } & \multicolumn{2}{|c|}{ Life satisfaction } \\
\hline & Step 1 & Step 2 & Step 1 & Step 2 \\
\hline Variable & $\beta$ & $\beta$ & $\beta$ & $\beta$ \\
\hline Age & .06 & .06 & .07 & .07 \\
\hline Gender & -.01 & -.01 & -.005 & -.004 \\
\hline Education & .06 & .06 & .11 & .11 \\
\hline Vol status- centered & -.03 & -.03 & .04 & .03 \\
\hline ADL- centered & $-.36 * *$ & $-.35 * *$ & $.29 *$ & $.31 *$ \\
\hline Vol status*ADL & & .03 & & -.05 \\
\hline$R^{2}$ & .15 & .15 & .11 & .11 \\
\hline$F$ & $3.31 * * *$ & $2.76 *$ & $2.39 *$ & 2.00 \\
\hline$\Delta R^{2}$ & & .001 & & .002 \\
\hline$\Delta F$ & & .14 & & .20 \\
\hline \multicolumn{5}{|c|}{ Visual functioning*Volunteer status } \\
\hline & \multicolumn{2}{|c|}{ Depressive symptoms } & \multicolumn{2}{|c|}{ Life satisfaction } \\
\hline & Step 1 & Step 2 & Step 1 & Step 2 \\
\hline Variable & $\beta$ & $\beta$ & $\beta$ & $\beta$ \\
\hline Age & .08 & .08 & .07 & .08 \\
\hline Gender & -.03 & -.03 & -.001 & -.005 \\
\hline Education & .08 & .08 & .07 & .07 \\
\hline Vol status- centered & -.12 & -.12 & .09 & .10 \\
\hline VFQ- centered & $-.25 *$ & $-.22 *$ & $.37 * *$ & $.35 * *$ \\
\hline Vol status*ADL & & .04 & & -.08 \\
\hline$R^{2}$ & .09 & .09 & .17 & .17 \\
\hline$F$ & 1.77 & 1.48 & $3.85 * *$ & $3.29 * *$ \\
\hline$\Delta R^{2}$ & & .001 & & .005 \\
\hline
\end{tabular}


Table 23.

Hierarchical Regressions of Moderating Model of Volunteer Status on Disability and Depressive Symptoms and Life Satisfaction cont.

$\Delta F \quad .14 \quad 61$

Note. $N=101$. Significant results are shown in boldface. ADLs $=$ Activities of Daily Living Scale, VFQ $=$ Visual Function Questionnaire,

$* p<.05, * * p<.01, * * * p<.001$. 
Table 24.

Hierarchical Regressions of Moderating Model of Volunteer Status on Disability and Reasons for Living

\begin{tabular}{|c|c|c|c|c|c|c|}
\hline \multicolumn{7}{|c|}{ Activities of daily living*Volunteer status } \\
\hline \multicolumn{7}{|c|}{ Reasons for living } \\
\hline & \multicolumn{3}{|c|}{ Step 1} & \multicolumn{3}{|c|}{ Step 2} \\
\hline Variable & $\mathrm{b}$ & SE & $95 \% \mathrm{CI}$ & $\mathrm{b}$ & SE & $95 \% \mathrm{CI}$ \\
\hline Age & $.02 *$ & .005 & {$[.005, .03]$} & $-.02 *$ & .006 & {$[.001, .03]$} \\
\hline Gender & -.13 & .11 & {$[-.36, .09]$} & $-.19 *$ & .08 & {$[-.36,-.03]$} \\
\hline Education & -.06 & .04 & {$[-.15, .02]$} & -.07 & .03 & {$[-.14, .02]$} \\
\hline Vol status- centered & $.23 *$ & .10 & {$[.03, .42]$} & $.30 *$ & .10 & {$[.09, .51]$} \\
\hline ADLs- centered & .01 & .12 & {$[-.23, .25]$} & .12 & .12 & {$[-.12, .37]$} \\
\hline Vol status*ADL & & & & .22 & .22 & {$[-.24, .69]$} \\
\hline$R^{2}$ & .26 & & & .27 & & \\
\hline$F$ & $7.15 * * *$ & & & $5.79 * * *$ & & \\
\hline$\Delta R^{2}$ & & & & .01 & & \\
\hline$\Delta F$ & & & & 1.06 & & \\
\hline \multicolumn{7}{|c|}{ Visual functioning*Volunteer status } \\
\hline \multicolumn{7}{|c|}{ Reasons for living } \\
\hline & \multicolumn{3}{|c|}{ Step 1} & \multicolumn{3}{|c|}{ Step 2} \\
\hline Variable & $\mathrm{b}$ & SE & $95 \% \mathrm{CI}$ & $\mathrm{b}$ & SE & $95 \% \mathrm{CI}$ \\
\hline Age & $.02 * *$ & .005 & {$[.01, .03]$} & $.02 * *$ & .006 & {$[.003, .03]$} \\
\hline Gender & -.15 & .10 & {$[-.36, .06]$} & $-.20 *$ & .07 & {$[-.36,-.04]$} \\
\hline Education & -.07 & .04 & {$[-.16, .01]$} & $-.08 *$ & .03 & {$[-.15,-.002]$} \\
\hline Vol status- centered & $.19 *$ & .09 & {$[.09, .38]$} & $.26 *$ & .09 & {$[.08, .45]$} \\
\hline VFQ- centered & .005 & .003 & {$[.003, .01]$} & .003 & .002 & {$[-.001, .008]$} \\
\hline Vol status*VFQ & & & & .004 & .004 & {$[-.02, .007]$} \\
\hline$R^{2}$ & .33 & & & .35 & & \\
\hline$F$ & $9.44 * * *$ & & & $10.47 * * *$ & & \\
\hline$\Delta R^{2}$ & & & & .02 & & \\
\hline$\Delta F$ & & & & 3.51 & & \\
\hline
\end{tabular}


Table 24.

Hierarchical Regressions of Moderating Model of Volunteer Status on Disability and Reasons for Living cont.

Note. $N=101$. Significant results are shown in boldface. ADLs $=$ Activities of Daily Living Scale, VFQ $=$ Visual Function Questionnaire.

$* p<.05, * * p<.01, * * * p<.001$. 
Table 25.

Hierarchical Logistic Regressions of Moderating Model of Volunteer Status on Disability and Suicide Ideation

\begin{tabular}{|c|c|c|c|c|}
\hline \multicolumn{5}{|c|}{ Activities of daily living*Volunteer status } \\
\hline \multirow[b]{3}{*}{ Variable } & \multicolumn{2}{|c|}{ Suicide ideation } & & \\
\hline & \multicolumn{2}{|c|}{ Step 1} & \multicolumn{2}{|c|}{ Step 2} \\
\hline & OR & $95 \% \mathrm{CI}$ & \multicolumn{2}{|r|}{$95 \% \mathrm{CI}$} \\
\hline Age & .92 & {$[.82,1.03]$} & .92 & {$[.82,1.03]$} \\
\hline Gender & .60 & {$[.12,2.88]$} & .61 & {$[.13,2.82]$} \\
\hline Education & .93 & {$[.53,1.64]$} & .91 & {$[.52,1.62]$} \\
\hline Vol status- centered & .32 & {$[.05,2.93]$} & .34 & {$[.04,2.81]$} \\
\hline ADL- centered & .31 & {$[.05,1.91]$} & .98 & {$[.94,1.01]$} \\
\hline Vol status*ADL & \multirow{3}{*}{\multicolumn{2}{|c|}{8.33}} & 1.05 & {$[.97,1.14]$} \\
\hline$\chi^{2}$ & & & 11.20 & \\
\hline$\Delta \chi^{2}$ & & & 2.87 & \\
\hline \multicolumn{5}{|c|}{ Visual functioning*Volunteer status } \\
\hline \multicolumn{5}{|c|}{ Suicide ideation } \\
\hline & \multicolumn{2}{|c|}{ Step 1} & \multicolumn{2}{|c|}{ Step 2} \\
\hline Variable & OR & $95 \% \mathrm{CI}$ & OR & $95 \% \mathrm{CI}$ \\
\hline Age & .92 & {$[.80,1.04]$} & .91 & {$[.79,1.04]$} \\
\hline Gender & .50 & {$[.07,3.49]$} & .47 & {$[.06,3.75]$} \\
\hline Education & 1.12 & {$[.54,2.35]$} & 1.19 & {$[.55,2.57]$} \\
\hline Vol status- centered & .18 & {$[.02,1.90]$} & .18 & {$[.003,12.55]$} \\
\hline VFQ- centered & .96 & {$[.92, .99]$} & .99 & {$[.90,1.11]$} \\
\hline Vol status* VFQ & & & 1.13 & {$[.90,1.43]$} \\
\hline$\chi^{2}$ & 10.74 & & $13.81 *$ & \\
\hline$\Delta \chi^{2}$ & & & 3.07 & \\
\hline
\end{tabular}

Note. $N=101$. Significant results are shown in boldface. ADLs $=$ Activities of Daily Living Scale, VFQ $=$ Visual Function Questionnaire. $* p<.05, * * p<.01, * * * p<.001$. 
Table 26.

Hierarchical Regressions of Moderating Model of Volunteer Organizations on Disability and Depressive Symptoms and Life Satisfaction

\begin{tabular}{|c|c|c|c|c|}
\hline \multicolumn{5}{|c|}{ Activities of daily living*Volunteer organizations } \\
\hline & \multicolumn{2}{|c|}{ Depressive symptoms } & \multicolumn{2}{|c|}{ Life satisfaction } \\
\hline & Step 1 & Step 2 & Step 1 & Step 2 \\
\hline Variable & $\beta$ & $\beta$ & $\beta$ & $\beta$ \\
\hline Age & .06 & .06 & .07 & .07 \\
\hline Gender & -.007 & -.008 & -.006 & -.005 \\
\hline Education & .06 & .06 & .11 & .11 \\
\hline Vol orgs- centered & -.02 & -.04 & .05 & .06 \\
\hline ADLs-centered & $-.37 * * *$ & $-.35 * *$ & $.29 *$ & $.28 *$ \\
\hline Vol orgs*ADL & & .04 & & -.01 \\
\hline$R^{2}$ & .15 & .15 & .11 & .11 \\
\hline$F$ & $3.31 * *$ & $2.79 *$ & $2.41 *$ & 1.99 \\
\hline$\Delta R^{2}$ & & .002 & & 0 \\
\hline$\Delta F$ & & .17 & & .02 \\
\hline \multicolumn{5}{|c|}{ Visual functioning* Volunteer organizations } \\
\hline & \multicolumn{2}{|c|}{ Depressive symptoms } & \multicolumn{2}{|c|}{ Life satisfaction } \\
\hline & Step 1 & Step 2 & Step 1 & Step 2 \\
\hline Variable & $\beta$ & $\beta$ & $\beta$ & $\beta$ \\
\hline Age & .09 & .08 & .07 & .07 \\
\hline Gender & -.02 & -.02 & -.01 & -.01 \\
\hline Education & .08 & .08 & .08 & .07 \\
\hline Vol orgs- centered & -.09 & -.13 & .06 & .10 \\
\hline VFQ- centered & $-.23 *$ & -.19 & $-.37 * *$ & $-.34 * *$ \\
\hline Vol orgs*ADL & & .08 & & -.07 \\
\hline$R^{2}$ & .08 & .09 & .17 & .17 \\
\hline$F$ & 1.62 & 1.22 & $3.74 * *$ & $3.17 * *$ \\
\hline$\Delta R^{2}$ & & .005 & & .004 \\
\hline$\Delta F$ & & .46 & & .40 \\
\hline
\end{tabular}


Table 26.

Hierarchical Regressions of Moderating Model of Volunteer Organizations on Disability and Depressive Symptoms and Life Satisfaction cont.

Note. $N=101$. Significant results are shown in boldface. ADLs $=$ Activities of Daily Living Scale, VFQ $=$ Visual Function Questionnaire,

$* p<.05, * * p<.01, * * * p<.001$. 
Table 27.

Hierarchical Regressions of Moderating Model of Volunteer Organizations on Disability and Reasons for Living

\begin{tabular}{|c|c|c|c|c|c|c|}
\hline \multicolumn{7}{|c|}{ Activities of daily living*Volunteer organizations } \\
\hline \multirow[b]{3}{*}{ Variable } & \multicolumn{4}{|c|}{ Reasons for living } & & \\
\hline & \multicolumn{3}{|c|}{ Step 1} & \multicolumn{3}{|c|}{ Step 2} \\
\hline & $\mathrm{b}$ & SE & $95 \% \mathrm{CI}$ & $\mathrm{b}$ & SE & $95 \% \mathrm{CI}$ \\
\hline Age & $.02 *$ & .005 & {$[.01, .03]$} & $.02 *$ & .006 & {$[.01, .03]$} \\
\hline Gender & -.15 & .11 & {$[-.37, .08]$} & $-.19 *$ & .03 & {$[-.36,-.04]$} \\
\hline Education & -.07 & .04 & {$[-.15, .02]$} & -.07 & .03 & {$[-.14, .02]$} \\
\hline Vol orgs- centered & $.10 *$ & .04 & {$[.01, .18]$} & $.11 *$ & .05 & {$[.02, .21]$} \\
\hline ADLs- centered & .02 & .12 & {$[-.22, .25]$} & -.05 & .12 & {$[-.16, .35]$} \\
\hline Vol orgs*ADL & & & & -.07 & .10 & {$[-.15, .33]$} \\
\hline$R^{2}$ & .25 & & & .28 & & \\
\hline$F$ & $6.74 * * *$ & & & $6.09 * * *$ & & \\
\hline$\Delta R^{2}$ & & & & .04 & & \\
\hline \multirow[t]{4}{*}{$\Delta F$} & & & & 3.51 & & \\
\hline & \multicolumn{4}{|c|}{ Visual functioning*Volunteer organizations } & & \\
\hline & \multicolumn{4}{|c|}{ Reasons for living } & & \\
\hline & \multicolumn{3}{|c|}{ Step 1} & \multicolumn{3}{|c|}{ Step 2} \\
\hline Variable & $\mathrm{b}$ & $\mathrm{SE}$ & $95 \% \mathrm{CI}$ & $\mathrm{b}$ & $\mathrm{SE}$ & $95 \% \mathrm{CI}$ \\
\hline Age & $.02 * *$ & .005 & {$[.01, .03]$} & $.02 * *$ & .006 & {$[.003, .03]$} \\
\hline Gender & -.16 & .11 & {$[-.38, .06]$} & $-.20 *$ & .08 & {$[-.37,-.05]$} \\
\hline Education & -.07 & .04 & {$[-.16, .009]$} & -.07 & .03 & {$[-.15, .005]$} \\
\hline Vol orgs- centered & .07 & .04 & {$[-.01, .16]$} & $.10 *$ & .05 & {$[.02, .21]$} \\
\hline VFQ- centered & .005 & .003 & {$[-.001, .01]$} & .003 & .002 & {$[-.002, .007]$} \\
\hline Vol orgs*VFQ & & & & -.004 & .002 & {$[-.01, .001]$} \\
\hline$R^{2}$ & .31 & & & .33 & & \\
\hline$F$ & 8.72 & & & 7.72 & & \\
\hline$\Delta R^{2}$ & & & & .02 & & \\
\hline$\Delta F$ & & & & 2.82 & & \\
\hline
\end{tabular}


Table 27.

Hierarchical Regressions of Moderating Model of Volunteer Organizations on Disability and Reasons for Living cont.

Note. $N=101$. Significant results are shown in boldface. ADLs $=$ Activities of Daily Living Scale, VFQ $=$ Visual Function Questionnaire.

$* p<.05, * * p<.01, * * * p<.001$. 
Table 28.

Hierarchical Logistic Regressions of Moderating Model of Volunteer Organizations on Disability and Suicide Ideation

\begin{tabular}{|c|c|c|c|c|}
\hline \multicolumn{5}{|c|}{ Activities of daily living*Volunteer organizations } \\
\hline \multirow[b]{3}{*}{ Variable } & \multicolumn{2}{|c|}{ Suicide ideation } & & \\
\hline & \multicolumn{2}{|c|}{ Step 1} & \multicolumn{2}{|c|}{ Step 2} \\
\hline & OR & $95 \% \mathrm{CI}$ & OR & $95 \% \mathrm{CI}$ \\
\hline Age & .93 & {$[.84,1.03]$} & .92 & {$[.83,1.03]$} \\
\hline Gender & .73 & {$[.16,3.37]$} & .69 & {$[.15,3.16]$} \\
\hline Education & .92 & {$[.51,1.64]$} & .89 & {$[.50,1.57]$} \\
\hline Vol orgs- centered & .94 & {$[.38,2.23]$} & .84 & {$[.27,1.57]$} \\
\hline ADL- centered & .22 & {$[.03,1.41]$} & .44 & {$[.03,6.28]$} \\
\hline Vol orgs*ADL & & & 5.56 & {$[.45,68.84]$} \\
\hline$\chi^{2}$ & 4.33 & & 6.63 & \\
\hline \multirow[t]{4}{*}{$\Delta \chi^{2}$} & & & 2.33 & \\
\hline & \multicolumn{4}{|c|}{ Visual functioning*Volunteer organizations } \\
\hline & \multicolumn{2}{|c|}{ Suicide ideation } & & \\
\hline & \multicolumn{2}{|c|}{ Step 1} & \multicolumn{2}{|c|}{ Step 2} \\
\hline Variable & OR & $95 \% \mathrm{CI}$ & OR & $95 \% \mathrm{CI}$ \\
\hline Age & .93 & {$[.82,1.05]$} & .90 & {$[.79,1.04]$} \\
\hline Gender & .62 & {$[.09,4.11]$} & .48 & {$[.06,3.94]$} \\
\hline Education & 1.07 & {$[.52,2.21]$} & 1.16 & {$[.55,2.44]$} \\
\hline Vol orgs- centered & .77 & {$[.23,2.51]$} & .49 & {$[.09,2.67]$} \\
\hline VFQ- centered & .96 & {$[.92, .99]$} & .99 & {$[.92,1.07]$} \\
\hline Vol orgs*VFQ & & & 1.08 & {$[.99,1.17]$} \\
\hline$\chi^{2}$ & 8.36 & & $13.90 *$ & \\
\hline$\Delta \chi^{2}$ & & & 5.54 & \\
\hline
\end{tabular}

Note. $N=101$. Significant results are shown in boldface. ADLs = Activities of Daily Living Scale, VFQ = Visual Function Questionnaire. $* p<.05, * * p<.01, * * * p<.001$. 
Table 29.

Volunteer Hours as Mediator of Disability and Mental Health Outcomes

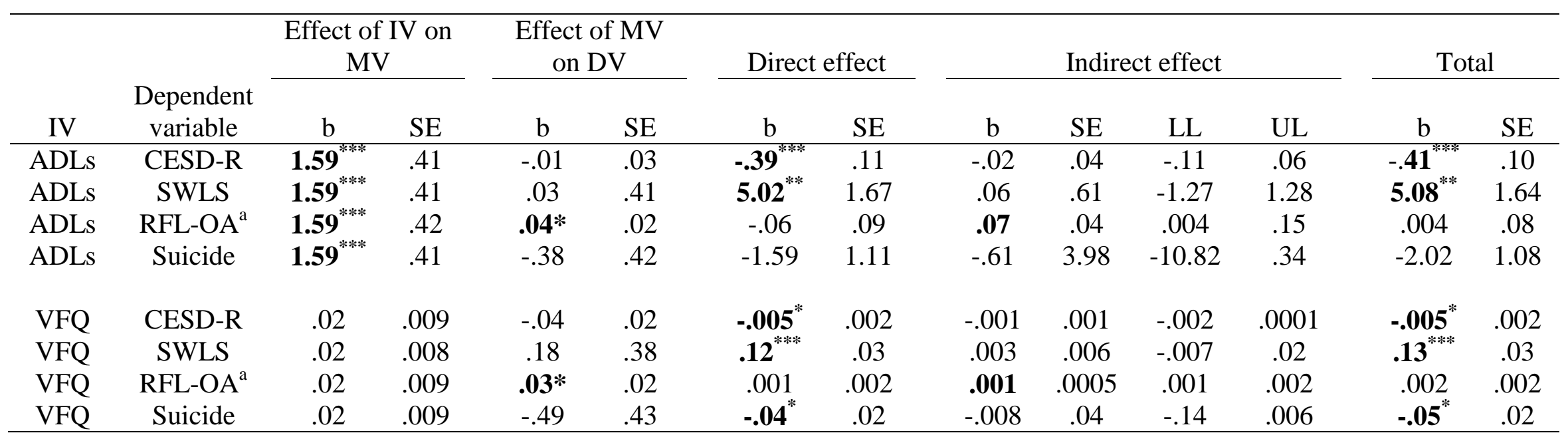

Note. $N=101$. Significant results are shown in boldface. $\mathrm{IV}=$ independent variable, $\mathrm{MV}=$ mediating variable, $\mathrm{MV}=\mathrm{Volunteer}$ Hours, DV = dependent variable. CESD-R = Center for Epidemiological Studies Depression Scale-Revised, SWLS = Satisfaction with Life Scale, RFL-OA = Reasons for Living Older Adults, ADLs = Activities of Daily Living Scale, VFQ = Visual Function Questionnaire.

${ }^{\mathrm{a}} n=96$ due to missing data.

$* p<.05, * * p<.01, * * * p<.001$. 
Table 30.

Volunteer Organizations as Mediator of Disability and Mental Health Outcomes

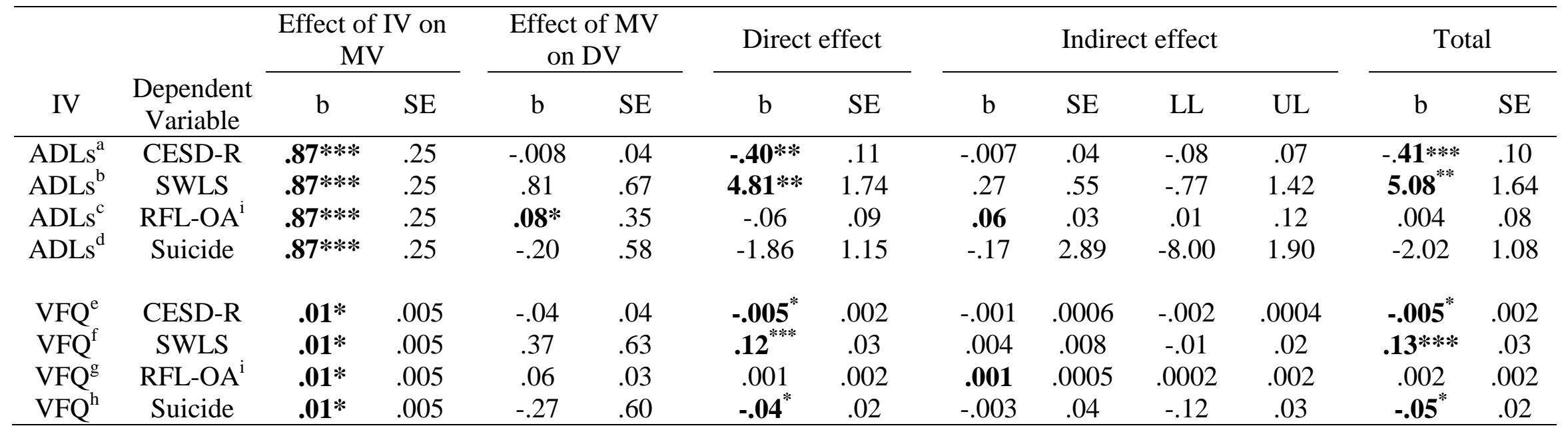

Note. $N=101$. Significant results are shown in boldface. IV = independent variable, $\mathrm{MV}=$ mediating variable, $\mathrm{DV}=$ dependent variable. $\mathrm{MV}$ is Volunteer Groups. CESD-R = Center for Epidemiological Studies Depression Scale-Revised, SWLS = Satisfaction with Life Scale, RFL-OA = Reasons for Living Older Adults, ADLs = Activities of Daily Living Scale, VFQ = Visual Function Questionnaire.

${ }^{\mathrm{a}} F(5,96)=3.31, p=.009, R^{2}=.15 .{ }^{\mathrm{b}} F(5,96)=2.41, p=.04, R^{2}=.11 .{ }^{\mathrm{c}} F(5,91)=4.33, p=.001, R^{2}=.19 .{ }^{\mathrm{d}} \chi^{2}(5, N=101)=5.57, p$ $=.06 .{ }^{\mathrm{e}} F(5,96)=1.62, p=.16, R^{2}=.08 .{ }^{\mathrm{f}} F(5,96)=3.74, p=.004, R^{2}=.16 .{ }^{\mathrm{g}} F(5,91)=4.30, p=.002, R^{2}=.19$.

${ }^{\mathrm{h}} \chi^{2}(5, N=101)=8.36, p=.05$. ${ }^{\mathrm{i}} n=96$ due to missing data.

$* p<.05, * * p<.01, * * * p<.001$. 
Table 31.

Perceived Satisfaction with Support Received as Mediator of Disability and Mental Health Outcomes

\begin{tabular}{|c|c|c|c|c|c|c|c|c|c|c|c|c|c|}
\hline \multirow[b]{2}{*}{ IV } & \multirow[b]{2}{*}{$\begin{array}{c}\text { Dependent } \\
\text { Variable }\end{array}$} & \multicolumn{2}{|c|}{$\begin{array}{c}\text { Effect of IV } \\
\text { on MV }\end{array}$} & \multicolumn{2}{|c|}{$\begin{array}{c}\text { Effect of MV } \\
\text { on DV }\end{array}$} & \multicolumn{2}{|c|}{ Direct effect } & \multicolumn{4}{|c|}{ Indirect effect } & \multicolumn{2}{|c|}{ Total } \\
\hline & & b & $\mathrm{SE}$ & b & SE & $b$ & SE & b & SE & LL & UL & $\mathrm{b}$ & SE \\
\hline ADLs & SWLS & .09 & .05 & 5.79 & 3.14 & $4.54 * *$ & 1.64 & .54 & .56 & -.17 & .14 & 5.08 & 1.64 \\
\hline ADLs & $\mathrm{RFL}^{-O A^{\mathrm{a}}}$ & .09 & .05 & .32 & .16 & .03 & .08 & .03 & .03 & -.008 & .09 & .004 & .08 \\
\hline ADLs & Suicide & .09 & .05 & $-5.74 *$ & 2.39 & -1.52 & 1.14 & -.55 & 1.20 & -2.63 & 2.57 & -2.01 & 1.08 \\
\hline VFQ & SWLS & $.003 * *$ & .001 & 4.45 & 3.13 & $.11 * * *$ & .03 & .01 & .01 & -.003 & .05 & $.13 * * *$ & .03 \\
\hline VFQ & $\mathrm{RFL}^{-O A^{\mathrm{a}}}$ & $.003 * *$ & .001 & .28 & .17 & .001 & .002 & .001 & .0005 & .0001 & .002 & .002 & .002 \\
\hline VFQ & Suicide & $.003 * *$ & .001 & $-5.58 *$ & 2.46 & -.04 & .02 & -.02 & .03 & -.06 & .06 & -.05 & .02 \\
\hline
\end{tabular}

Note. $N=101$. Significant results are shown in boldface. $\mathrm{IV}=$ independent variable, $\mathrm{MV}=$ mediating variable, $\mathrm{DV}=\mathrm{dependent}$ variable. MV is Perceived satisfaction with support Received. CESD-R = Center for Epidemiological Studies Depression ScaleRevised, SWLS = Satisfaction with Life Scale, RFL-OA = Reasons for Living Older Adults, ADLs = Activities of Daily Living Scale, VFQ = Visual Function Questionnaire.

${ }^{\mathrm{a}} n=96$ due to missing data.

$* p<.05, * * p<.01, * * * p<.001$ 
Table 32.

Informal Support Giving as Mediator of Disability and Mental Health Outcomes

\begin{tabular}{|c|c|c|c|c|c|c|c|c|c|c|c|c|c|}
\hline \multirow[b]{2}{*}{ IV } & \multirow{2}{*}{$\begin{array}{l}\text { Dependent } \\
\text { Variable }\end{array}$} & \multicolumn{2}{|c|}{$\begin{array}{c}\text { Effect of IV on } \\
\text { MV }\end{array}$} & \multicolumn{2}{|c|}{$\begin{array}{c}\text { Effect of MV } \\
\text { on DV }\end{array}$} & \multicolumn{2}{|c|}{ Direct effect } & \multicolumn{4}{|c|}{ Indirect effect } & \multicolumn{2}{|c|}{ Total } \\
\hline & & $\mathrm{b}$ & SE & $\mathrm{b}$ & SE & $\mathrm{b}$ & SE & $\mathrm{b}$ & SE & LL & UL & $\mathrm{b}$ & SE \\
\hline ADLs & CESD-R & 2.59 & 1.66 & .008 & .51 & $-.43 * * *$ & .11 & .02 & .03 & -.02 & .01 & $-.41 * * *$ & .10 \\
\hline ADLs & SWLS & 2.59 & 1.66 & .03 & .10 & $5.01 * *$ & 1.67 & .06 & .33 & -.58 & .72 & $5.08 * *$ & 1.63 \\
\hline ADLs & $\mathrm{RFL}^{-O A^{\mathrm{a}}}$ & 2.66 & 1.71 & .002 & .005 & .01 & .09 & -.006 & .02 & -.05 & .02 & .005 & .08 \\
\hline ADLs & Suicide & 2.59 & 1.66 & -.18 & .09 & -1.69 & 1.16 & -.47 & .60 & -1.54 & .47 & -2.02 & 1.08 \\
\hline VFQ & CESD-R & .01 & .03 & .005 & .55 & $-.005 *$ & .002 & $<.001$ & .0003 & -.003 & .001 & $-.005 *$ & .002 \\
\hline VFQ & SWLS & .01 & .03 & .06 & .10 & $.12 * * *$ & .03 & .001 & .004 & -.004 & .01 & $.13 * * *$ & .03 \\
\hline VFQ & $\mathrm{RFL}^{-O A^{\mathrm{a}}}$ & .01 & .04 & .003 & .005 & .002 & .002 & $<.001$ & .0002 & -.0002 & .001 & .002 & .002 \\
\hline VFQ & Suicide & .01 & .03 & $-.199 *$ & -.09 & $-.05 *$ & .02 & -.002 & .02 & -.03 & .03 & $-.05 *$ & .02 \\
\hline
\end{tabular}

Note. $N=101$. Significant results are shown in boldface. $\mathrm{IV}=$ independent variable, $\mathrm{MV}=$ mediating variable, $\mathrm{DV}=\mathrm{dependent}$ variable. MV is Informal Support Giving. CESD-R = Center for Epidemiological Studies Depression Scale-Revised, SWLS = Satisfaction with Life Scale, RFL-OA = Reasons for Living Older Adults, ADLs = Activities of Daily Living Scale, VFQ = Visual Function Questionnaire.

${ }^{\mathrm{a}} n=96$ due to missing data.

$* p<.05, * * p<.01, * * * p<.001$ 


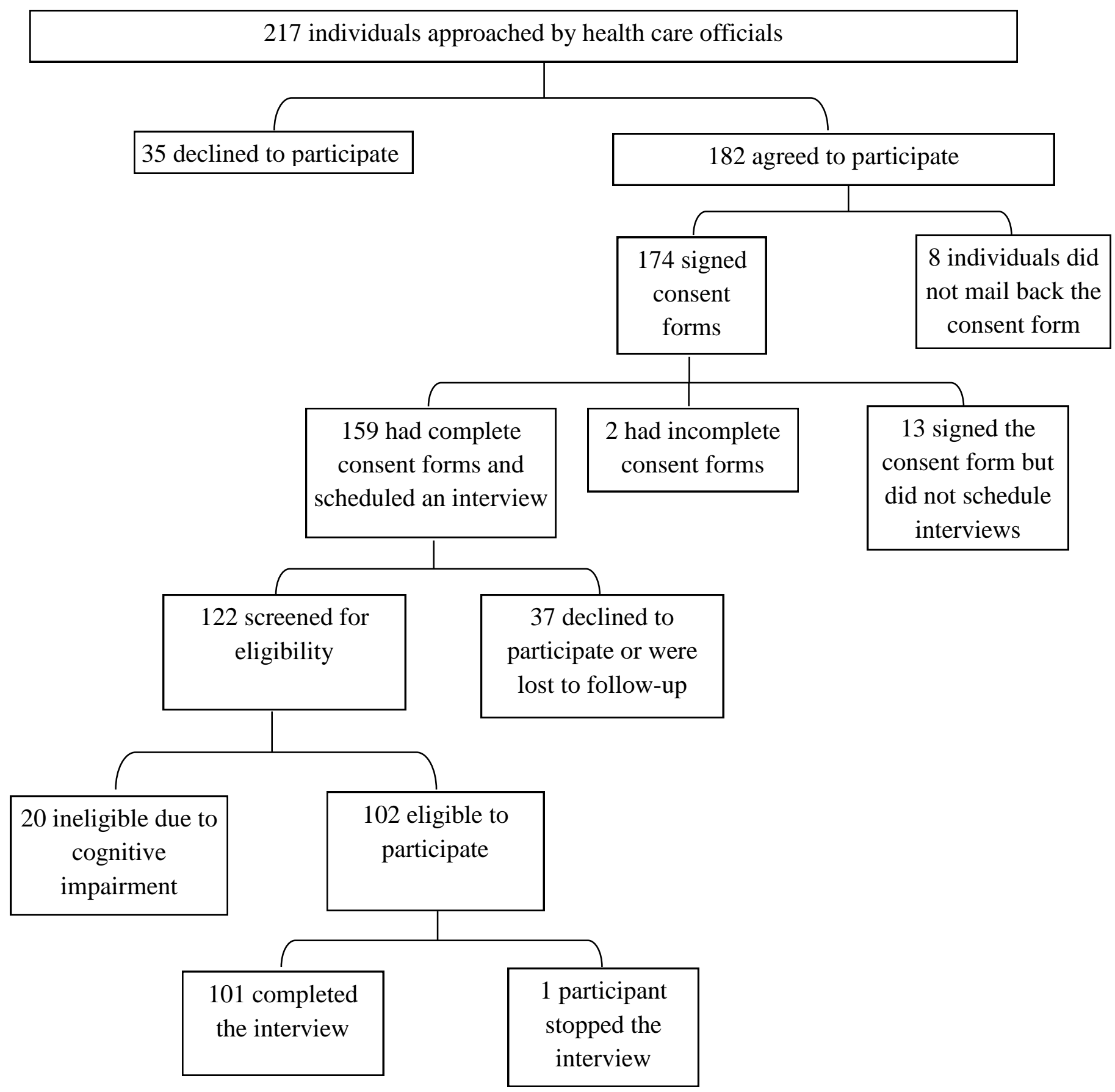

Figure 1. Response rate throughout the recruitment and interviewing processes. 


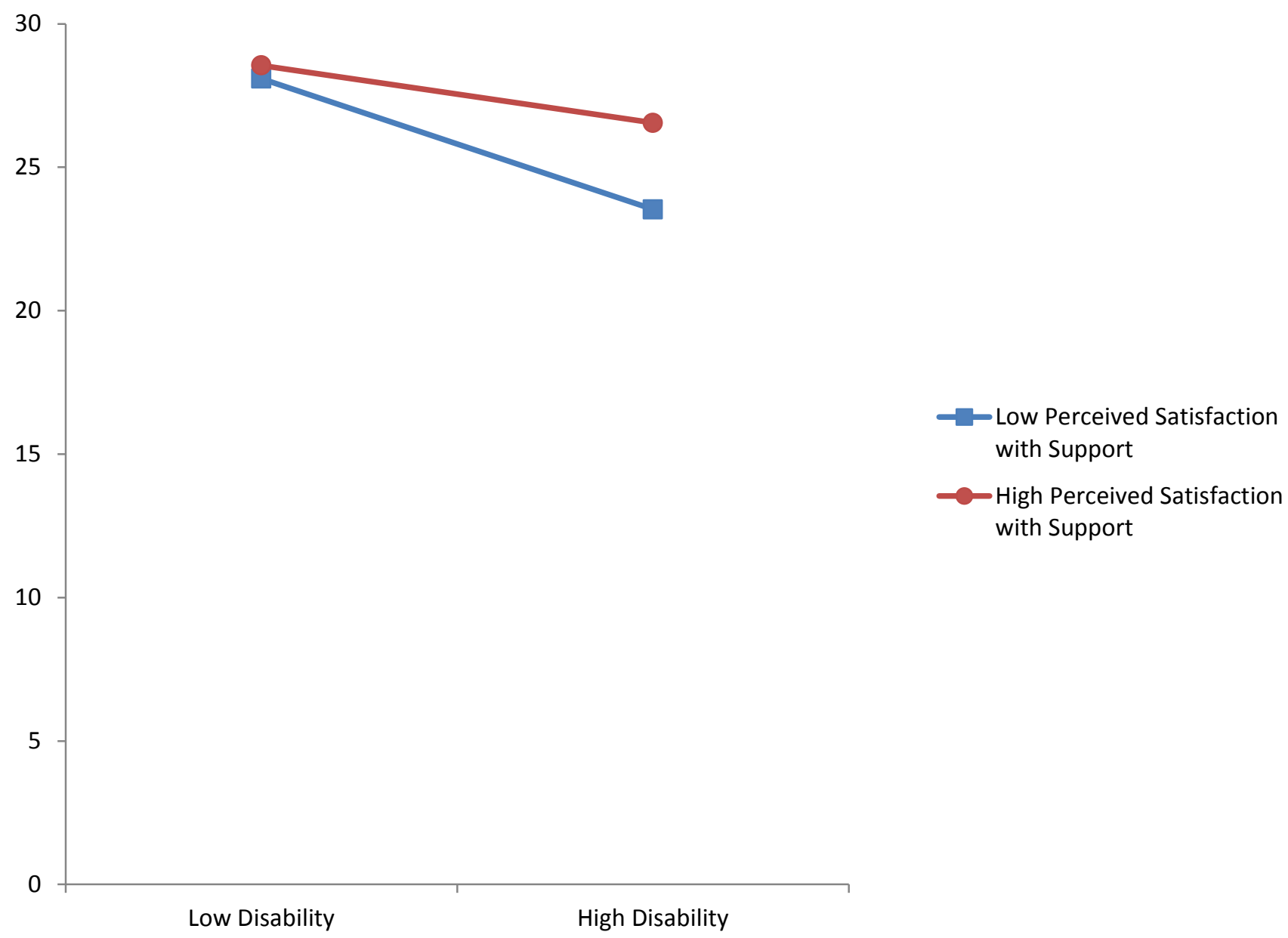

Figure 2. Interaction Effect of Satisfaction with Support Received From Others by General Disability on Life Satisfaction. 


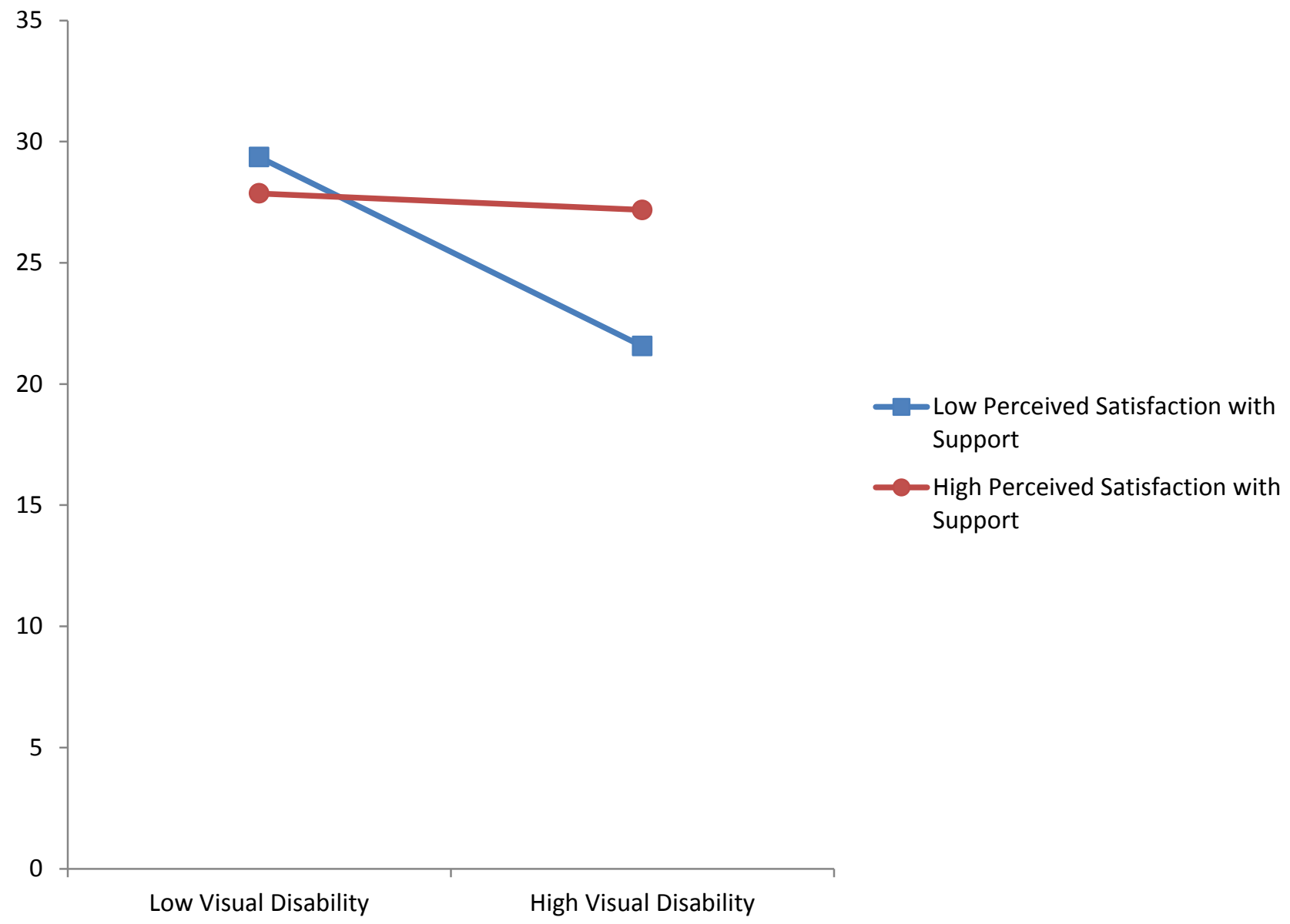

Figure 3. Interaction Effect of Satisfaction with Support Received From Others by Visual Disability on Life Satisfaction. 


\section{Appendix A. Provided Informal Support}

In this section, I will ask you questions about the type of support you have provided to family, friends, or neighbors within the past year. Within the past year, have family, friends, or neighbors...

1. Depended on you for your guidance and advice

\begin{tabular}{|l|l|l|l|}
\hline Never & Once in a while & Fairly often & Very often \\
\hline
\end{tabular}

2. Depended on you for financial help

3. Talked over their problems and private feelings with you

4. Depended on you for transportation

5. Depended on you for something they needed (a physical object other than money)

6. Helped someone with their household chores

7. Helped someone with their shopping

8. Been right there with someone (physically) when they were experiencing a stressful situation

9. Comforted someone by showing them physical affection

10. Expressed interest and concern in someone's well-being

11. Told someone what you did a stressful situation that was similar to one they were going through

12. Suggested some action someone should take to deal with a problem they were having

13. Told someone where they could go for assistance with a problem they were having 


\section{Appendix B. Volunteer Behaviors}

In this next section, I will ask you about your volunteer activity within the past 12 months.

1. a) During the last 12 months, did you do volunteer work for any of the following: a church, synagogue or other religious organization?

\begin{tabular}{|c|c|}
\hline Yes & No \\
\hline
\end{tabular}

If yes: $1 \mathrm{~b}$ ) Please describe the type of volunteer work you did for this organization:

2. a) During the last 12 months, did you do volunteer work for any of the following: a school or educational organization in the last 12 months?

\begin{tabular}{l|l} 
Yes & No
\end{tabular}

If yes: 2 b) Please describe the type of volunteer work you did for this organization:

3. a) During the last 12 months, did you do volunteer work for any of the following: a political group or labor union (in the last 12 months)?

\begin{tabular}{|c|c|}
\hline Yes & No \\
\hline
\end{tabular}

If yes: 3 b) Please describe the type of volunteer work you did for this organization:

4. a) During the last 12 months, did you do volunteer work for any of the following: a senior citizen group or related organization (in the last 12 months)?

\begin{tabular}{|c|c|}
\hline Yes & No \\
\hline
\end{tabular}

If yes: 4 b) Please describe the type of volunteer work you did for this organization:

5. During the last 12 months, did you do volunteer work for any of the following: any other national or local organization, including the United Way, hospitals, and the like (again, in the last 12 months)?

\begin{tabular}{|l|c|} 
Yes & No \\
\hline
\end{tabular}

If yes: 5 b) Please describe the type of volunteer work you did for this organization:

6. Altogether, about how many hours did you spend on volunteer work during the last 12 months, (that is doing volunteer work for: a church, synagogue or other religious organization OR a school or educational organization OR a political group or labor union OR a senior citizen group or related organization OR another national or local organization?). Would you say, less than 20 hours, 20 to 39 hours, 40-79 hours, 80-159 hours, or 160 hours or more (over the last 12 months)?

\begin{tabular}{|c|c|c|c|c|}
\hline $\begin{array}{c}\text { Less than 20 } \\
\text { hours }\end{array}$ & $20-39$ hours & $40-79$ hours & $80-159$ hours & $\begin{array}{c}160 \text { hours or } \\
\text { more }\end{array}$ \\
\hline
\end{tabular}




\section{Appendix C. Received Social Support}

In this section, I will ask you questions about the type of support you have received from family, friends, or neighbors within the past year. Within the past year, have family, friends, or neighbors...

1. Told you what they did in a stressful situation that was similar to one you were experiencing

\begin{tabular}{|l|l|l|l|}
\hline Never & Once in a while & Fairly often & Very often \\
\hline
\end{tabular}

2. Suggested some action that you should take in dealing with a problem you were having

3. Gave you information that made a difficult situation clearer and easier to understand

4. Helped you understand why you didn't do something well

5. Told you who you should see for assistance with a problem that you were having

6. Commented on how you were dealing with a problem without saying it was good or bad

7. Checked back with you to see if you followed advice you were given on how to deal with a problem

8. Provided you with a place where you could get away for a while

9. Watched after your possessions while you were away

10. Gave or loaned you over $\$ 25$

11. Provided you with some transportation

12. Loaned or gave you something (a physical object other than money) that you needed

13. Provided you with a place to stay overnight

14. Pitched in to help you do something that needed to get done, like household chores or yard work

15. Looked after a family or household member while you were away

16. Helped you with shopping

17. Right there with you (physically) in a stressful situation

18. Told you were OK just the way you are

19. Comforted you by showing you physical affection

20. Listened to you talk about your private feelings

21. Told you they felt very close to you

22. Joked and kidded to try to cheer you up

23. Expressed interest and concern in your well-being

24. Went with you to see someone who helped you with a problem that you were having

25. Told you that they would keep the things you talked about privately just between the two of you

26. Did some activity together with you to help you get your mind off things

27. Told you how they felt in a situation that was similar to yours 


\section{Appendix D. Satisfaction with support Received}

In this section, I will ask you questions about whether you were satisfied with the support you received in the past year or if you wanted more support or less support.

1. During the last few minutes I've asked you some questions about the amount of information that people may have given you to help you deal with problems you might have had. During the past year, do you feel like this type of help was provided often enough, or do you wish it was given to you more often or less often?

\begin{tabular}{|c|c|c|}
\hline More Often & Satisfied & Less often \\
\hline
\end{tabular}

2. For the last few minutes we've been talking about things that people might have done for you or things they might have given you. Thinking back over the past year, would you say you feel satisfied with this type of help or do you wish it was provided more often or less often

\begin{tabular}{|c|c|c|}
\hline More Often & Satisfied & Less often \\
\hline
\end{tabular}

3. For the last few minutes we've talked about the amount of emotional support that you might have received from others in the past year. Are you satisfied with the amount of emotional support that you have received from others, or do you wish that others gave you this type of help more often or less often

\begin{tabular}{|c|c|c|}
\hline More Often & Satisfied & Less often \\
\hline
\end{tabular}




\section{Appendix E. Center for Epidemiological Studies-Depression Scale Revised}

This section will ask you questions about your mood. Below is a list of the ways you might have felt or behaved. Please tell me how often you have felt this way in the past week or so from not at all or less than 1 day, 1-2 days, 3-4 days, 5-7 days, nearly everyday for 2 weeks.

\begin{tabular}{|c|c|c|c|c|c|}
\hline & $\begin{array}{l}\text { Not at all } \\
\text { or less } \\
\text { than } 1 \text { day }\end{array}$ & $\begin{array}{l}1-2 \\
\text { days }\end{array}$ & $\begin{array}{l}\text { 3-4 } \\
\text { days }\end{array}$ & $\begin{array}{l}5-7 \\
\text { days }\end{array}$ & \begin{tabular}{|l} 
Nearly \\
every \\
day for \\
2 weeks
\end{tabular} \\
\hline \multicolumn{6}{|l|}{ 1. My appetite was poor. } \\
\hline \multicolumn{6}{|l|}{ 2. I could not shake off the blues. } \\
\hline \multicolumn{6}{|l|}{$\begin{array}{l}\text { 3. I had trouble keeping my mind on } \\
\text { what I was doing. }\end{array}$} \\
\hline \multicolumn{6}{|l|}{ 4. I felt depressed } \\
\hline \multicolumn{6}{|l|}{ 5. My sleep was restless. } \\
\hline \multicolumn{6}{|l|}{ 6. I felt sad } \\
\hline \multicolumn{6}{|l|}{ 7. I could not get going } \\
\hline \multicolumn{6}{|l|}{ 8. Nothing made me happy } \\
\hline \multicolumn{6}{|l|}{ 9. I felt like a bad person. } \\
\hline \multicolumn{6}{|l|}{ 10. I lost interest in my usual activities. } \\
\hline \multicolumn{6}{|l|}{ 11. I slept much more than usual. } \\
\hline \multicolumn{6}{|l|}{ 12. I felt like I was moving too slowly. } \\
\hline \multicolumn{6}{|l|}{ 13. I felt fidgety. } \\
\hline \multicolumn{6}{|l|}{ 14. I wished I were dead. } \\
\hline \multicolumn{6}{|l|}{ 15. I wanted to hurt myself } \\
\hline \multicolumn{6}{|l|}{ 16. I was tired all the time } \\
\hline \multicolumn{6}{|l|}{ 17. I did not like myself. } \\
\hline \multicolumn{6}{|l|}{ 18. I lost a lot of weight without trying to } \\
\hline \multicolumn{6}{|l|}{ 19. I had a lot of trouble getting to sleep } \\
\hline $\begin{array}{l}\text { 20. I could not focus on the important } \\
\text { things }\end{array}$ & & & & & \\
\hline
\end{tabular}


Appendix F. Modified Scale for Suicide Ideation

In this section, I will ask you questions about whether you have ever had thoughts about suicide. Many people have had thoughts about suicide. Please answer honestly. Your responses will be kept confidential.

1. Wish to die: Over the past day or two have you thought about wanting to die? Do you want to die now? (If the patient wants to die ask: Over the past day or two how often have you had the thought that you wanted to die? A little? Quite often? a lot? When you have wished for death, how strong has the desire been? Weak? Moderately strong? Very strong?)

0. None no current wish to die, hasn't had any thought about wanting to die.

1. Weak unsure about whether he/she wants to die, seldom thinks about death, or intensity seems low.

2. Moderate current desire to die, may be preoccupied with ideas about death, or intensity seems greater than a rating of 1 .

3. Strong current death wish, high frequency or high intensity during the past day or two.

2. Wish to live: Over the past day or two have you thought that you want to live? Do you care if you live or die? (If the patient wants to live ask: Over the past day or two how often have you thought about wanting to live? A little? Quite often? A lot? How sure are you that you really want to live?)

0. Strong current desire to live, high frequency or high intensity.

1. Moderate current desire to live, thinks about wanting to live quite often, can easily turn his/her thoughts away from death or intensity seems more than a rating of

2. Weak unsure about whether he/she wants to live, occasional thoughts about living or intensity seems low.

3. None, patient has no wish to live.

3. Desire to make an active suicide attempt: Over the past day or two when you have thought about suicide did you want to kill yourself? How often? A little? Quite often? A lot? Do you want to kill yourself now?

0. None patient may have had thoughts but does not want to make an attempt.

1. Weak patient isn't sure whether he/she wants to make an attempt.

2. Moderate wanted to act on thoughts at least once in the last 48 hours.

3. Strong wanted to act on thoughts several times and/or almost certain he wants to kill self.

4. Passive suicide desire: Right now would you deliberately ignore taking care of your health? Do you feel like trying to die by eating too much (too little), drinking too much (too little), or by not taking needed medications? Have you felt like doing any of these things over the past day or two? Over the past day or two, have you thought it might be good to leave life or death to chance, for example, carelessly crossing a busy street, driving recklessly, or even walking alone 
at night in a rough part of town?

0 None would take precautions to maintain life.

1 Weak not sure whether he/she would leave life/death to chance, or has thought about gambling with fate at least once in the last two days.

2 Moderate would leave life/death to chance, almost sure he/she would gamble.

3 Strong avoided steps necessary to maintain or save life, e.g., stopped taking needed medications.

5. Duration of thoughts: Over the past day or two when you have thought about suicide how long did the thoughts last? Were they fleeting, e.g., a few seconds? Did they occur for a while, then stop, e.g., a few minutes? Did they occur for longer periods, e.g., an hour at a time? Is it to the point where you cannot seem to get them out of your mind?

0 Brief fleeting periods.

1 Short duration several minutes.

2 Longer than hour or more.

3 Almost continuous patient finds it hard to turn attention away from suicidal thoughts, cannot seem to get them out of his/her mind.

6. Frequency of ideation: Over the last day or two how often have you thought about suicide? Once a day? Once an hour? More than that? All the time?

0 Rare once in the past 48 hours.

1 Low frequency twice or more over the last 48 hours.

2 Intermittent approximately every hour

3 Persistent several times an hour.

7. Intensity of ideation: Over the past day or two, when you have thought about suicide, have they been intense (powerful)? How intense have they been? Weak? Somewhat strong? Moderately strong? Very strong?

0 Very weak.

1 Weak.

2 Moderate.

3 Strong.

8. Deterrent to active attempt: Can you think of anything that would keep you from killing yourself? (Your religion, consequences for your family, chance that you may injure yourself seriously if unsuccessful).

0 Definite deterrent wouldn't attempt suicide because of deterrents. Patient must name one deterrent.

1 Probable deterrent can name at least one deterrent, but does not definitely rule out suicide.

2 Questionable deterrent patient has trouble naming any deterrents, seems focused on 
the advantages to suicide, minimal concern over deterrents.

3 No deterrents no concern over consequences to self or others.

9. Reasons for living: Right now can you think of any reasons why you should stay alive? What about over the past day or two? Over the past day or two have you thought that there are things happening in your life that make you want to die? (If the patient says there are clear reasons for living and dying, ask what they are and write them verbatim in the section provided. Ask the remaining questions).

Do you think that your reasons for dying are better than your reasons for living? Would you say that your reasons for living are better than your reasons for dying? Are your reasons for living and dying about equal in strength, 5050?

0 Patient has no reasons for dying, never occurred to him/her to weigh reasons.

1 Has reasons for living and occasionally has thought about reasons for dying.

2 Not sure about which reasons are more powerful, living and dying are about equal, or those for dying slightly outweigh those for living.

3 Reasons for dying strongly outweigh those for living, can't think of any reasons for living.

10. Degree of specificity: Over the last day or two have you been thinking about a way to kill yourself, the method you might use? Do you know where to get these materials? Have you thought about jumping from a high place? Where would you jump? Have you thought about using a car to kill yourself? Your own? Someone else's? What highway or road would you use? When would you try to kill yourself? Is there a special event (e.g., anniversary, birthday with which you would like to associate your suicide? Have you thought of any other ways you might kill yourself? (note details verbatim).

0 Not considered, method not thought about.

1 Minimal consideration.

2 Moderate consideration.

3 Details worked out, plans well formulated.

11. Method: Availability/opportunity: Over the past day or two have you thought methods are available to you to commit suicide? Would it take time/effort to create an opportunity to kill yourself? Do you foresee opportunities being available to you in the near future?

0 Method not available, no opportunity.

1 Method would take time/effort, opportunity not readily available, e.g., would have to purchase poisons, get prescription, borrow or buy a gun.

2 Future opportunity or availability anticipated if in hospital when patient got home, pills or gun available.

3 Method/opportunity available - pills, gun, car available, patient may have selected a specific time.

12. Sense of courage to carry out attempt: Do you think you have the courage to commit suicide? 
0 No courage, too weak, afraid.

1 Unsure of courage.

2 Quite sure.

3 Very sure.

13. Competence: Do you think you have the ability to carry out your suicide? Can you carry out the necessary steps to insure a successful suicide? How convinced are you that you would be effective in bringing an end to your life?

0 Not competent.

1 Unsure.

2 Somewhat sure.

3 Convinced that he/she can do it.

14. Expectancy of attempt: Over the last day or two have you thought that suicide is something you really might do sometime? Right now what are the chances you would try to kill yourself if left alone to your own devices? Would you say the chances are less than 50\%? About equal? More than 50\%?

0 Patient says he/she definitely would not make an attempt.

1 Unsure might make an attempt but chances are less than 50\% or about equal, 5050.

2 Almost certain chances are greater than $50 \%$ that he/she would try to commit suicide.

3 Certain patient will make an attempt if left by self (i.e., if not in hospital or not watched).

15. Talk about death/suicide: Over the last day or two have you noticed yourself talking about death more than usual? Can you recall whether or not you spoke to anybody, even jokingly, that you might welcome death or try to kill yourself? Have you confided in a close friend, religious person, or professional helper that you intend to commit suicide?

0 No talk of death/suicide.

1 Probably talked about death more than usual but no specific mention of death wish. May have alluded to suicide using humor.

2 Specifically said that he/she wants to die.

3 Confided that he/she plans to commit suicide.

16. Writing about death/suicide: Have you written about death/suicide e.g. poetry, in a personal diary?

0 No written material.

1 General comments regarding death.

2 Specific reference to death wish.

3 Specific reference to plans for suicide.

17. Suicide note: Over the last day or two have you thought about leaving a note or writing a 
letter to somebody about your suicide? Do you know what you'd say? Who would you leave it for? Have you written it out yet? Where did you leave it?

0 None hasn't thought about a suicide note.

1 "Mental note" has thought about a suicide note, those he/she might give it to, possibly worked out general themes which would be put in the note (e.g., being a burden to others, etc.)

2 Started suicide note partially written, may have misplaced it.

3 Completed note written out, definite plans about content, addressee.

18. Preparation: Over the past day or two have you actually done anything to prepare for your suicide, e.g., collected material, pills, guns, etc.?

0 None no preparation.

1 Probable preparation patient not sure, may have started to collect materials.

2 Partial preparation definitely started to organize method of suicide.

3 Complete has pills, gun, or other devices that he needs to kill self. 


\section{Appendix G. Reasons for Living -Older Adult}

In this section I will read specific reasons that people sometimes have for taking their own lives, if the thought were to occur to them or if someone were to suggest it to them. Please indicate how important each reason is to you for not committing taking your own life. The importance of each reason can range from extremely unimportant, quite unimportant, somewhat unimportant, somewhat important, quite important, and extremely important. Please use the whole range of choices, so as not to rate only at the middle or only at the extremes

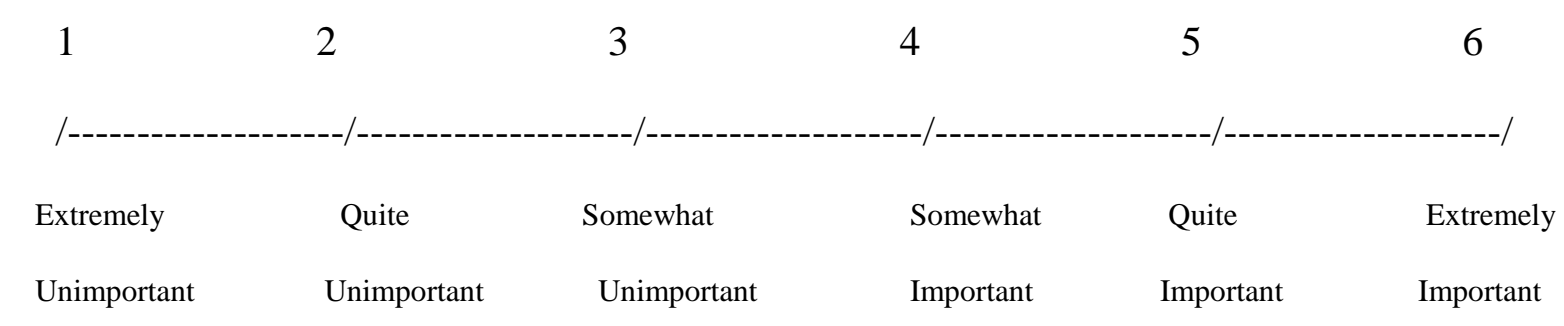

1. It would hurt my family too much, I would not want them to suffer.

2. My spouse requires care.

3. I believe I can find other solutions to my problems.

4. I want the opportunity for fellowship or worship with my church family.

5. My religious beliefs forbid it.

6. I have a love of life.

7. I want to travel to see the beauty of God's work.

8. I believe only God has the right to end life.

9. I have a responsibility to my pet.

10. I am afraid of going to hell.

11. Tomorrow I may feel better.

12. No matter how badly I feel, I know that it will not last.

13. I want to see my grandchildren grow up.

14. I believe I can learn to adjust or cope with my problems.

15. Committing suicide would be stupid or foolish.

16. I do not believe that things get miserable or hopeless enough that I would rather be dead.

17. Committing suicide would prevent me from going to heaven.

18. Through prayer, God will give me the will to live.

19. God's spirit would prevent me from even considering committing suicide.

20. I love and enjoy my family too much and could not leave them.

21. I want to experience all life has to offer.

22. There are many experiences I haven't had yet which I want to have.

23. I have a loving family who supports me through bad times.

24. God knows how much I can bear and will not over burden me.

25. I want to enjoy my life's achievements.

26. I am a coward and do not have the guts to do it. 
27. I have coped before and I can do it again.

28. I have the hope that things will improve and the future will be happier.

29. I have learned to laugh at my troubles and not take life too seriously.

30. I see no reason to hurry death along.

31. I'm looking forward to developing new personal relationships.

32. I am afraid that my method of killing myself would fail.

33. I want to show others God's way.

34. I still have many things left to do.

35. I have faith in God.

36. I am in good health.

37. I am curious about what will happen in the future.

38. I believe I have control over my life and destiny.

39. My financial affairs are good.

40. I am still capable of doing many things.

41. I feel needed by others.

42. I care enough about myself to live.

43. My family depends on me and needs me.

44. The future may hold new cures for my illness.

45. I enjoy my grandchildren and/or great grandchildren.

46. Life is too beautiful and precious to end it.

47. I have future plans I am looking forward to carrying out.

48. I fear the hereafter.

49. I am still able to contribute to others.

50. Life is a gift.

51. I can always think of someone else who is worse off than I am.

52. I am happy and content with my life.

53. I don't want to leave my earthly possessions.

54. I have a desire to live.

55. I am concerned about what others would think of me.

56. Suicide is a sign of defeat.

57. Some parts of my life are getting better as I age.

58. I do not want to abandon my spouse.

59. Everyone has a time to die.

60. I do not want to die.

61 . I consider it morally wrong.

62. I am afraid of death.

63. My life insurance policy would not be valid if I committed suicide.

64. My religion gives me the strength and peace to carry on.

65. I am afraid of the Unknown.

66. I am just beginning to experience the benefits of what I have worked for. 
67. I put my life in God's hands.

68. I have an excellent job.

69. I want to spend time with friends and loved ones. 
Appendix H. Satisfaction with Life Scale

In this section, I will read five statements with which you may agree or disagree. Please use the 1-7 scale where, 1 equals strongly disagree, 2 equals disagree, 3 equals slightly disagree, 4 equals neither agree or disagree, 5 equals slightly agree, 6 equals agree and 7 equals strongly disagree.

1. In most ways my life is close to my ideal

\begin{tabular}{|l|l|l|l|l|l|l|}
\hline $\begin{array}{l}\text { Strong } \\
\text { disagree }\end{array}$ & Disagree & $\begin{array}{l}\text { Slightly } \\
\text { disagree }\end{array}$ & $\begin{array}{l}\text { Neither } \\
\text { agree/disagree }\end{array}$ & $\begin{array}{l}\text { Slightly } \\
\text { agree }\end{array}$ & Agree & $\begin{array}{l}\text { Strongly } \\
\text { disagree }\end{array}$ \\
\hline
\end{tabular}

2. The conditions of my life are excellent.

\begin{tabular}{|l|l|l|l|l|l|l|}
\hline $\begin{array}{l}\text { Strong } \\
\text { disagree }\end{array}$ & Disagree & $\begin{array}{l}\text { Slightly } \\
\text { disagree }\end{array}$ & $\begin{array}{l}\text { Neither } \\
\text { agree/disagree }\end{array}$ & $\begin{array}{l}\text { Slightly } \\
\text { agree }\end{array}$ & Agree & $\begin{array}{l}\text { Strongly } \\
\text { disagree }\end{array}$ \\
\hline
\end{tabular}

3. I am satisfied with my life.

\begin{tabular}{|l|l|l|l|l|l|l|}
\hline $\begin{array}{l}\text { Strong } \\
\text { disagree }\end{array}$ & Disagree & $\begin{array}{l}\text { Slightly } \\
\text { disagree }\end{array}$ & $\begin{array}{l}\text { Neither } \\
\text { agree/disagree }\end{array}$ & $\begin{array}{l}\text { Slightly } \\
\text { agree }\end{array}$ & Agree & $\begin{array}{l}\text { Strongly } \\
\text { disagree }\end{array}$ \\
\hline
\end{tabular}

4. So far I have gotten the important things I want in life

\begin{tabular}{|l|l|l|l|l|l|l|}
\hline $\begin{array}{l}\text { Strong } \\
\text { disagree }\end{array}$ & Disagree & $\begin{array}{l}\text { Slightly } \\
\text { disagree }\end{array}$ & $\begin{array}{l}\text { Neither } \\
\text { agree/disagree }\end{array}$ & $\begin{array}{l}\text { Slightly } \\
\text { agree }\end{array}$ & Agree & $\begin{array}{l}\text { Strongly } \\
\text { disagree }\end{array}$ \\
\hline
\end{tabular}

5. If I could live my life over, I would change almost nothing.

\begin{tabular}{|l|l|l|l|l|l|l|}
\hline $\begin{array}{l}\text { Strong } \\
\text { disagree }\end{array}$ & Disagree & $\begin{array}{l}\text { Slightly } \\
\text { disagree }\end{array}$ & $\begin{array}{l}\text { Neither } \\
\text { agree/disagree }\end{array}$ & $\begin{array}{l}\text { Slightly } \\
\text { agree }\end{array}$ & Agree & $\begin{array}{l}\text { Strongly } \\
\text { disagree }\end{array}$ \\
\hline
\end{tabular}




\section{Appendix I. Functional Disability Scale}

In this section I will ask you a little about your daily chores, i.e. things we all have to do daily in our lives. I would like to know if you can perform these things without help from anybody, if you need some help, or if you can't do them at all.

Can you:

1) eat?

2) dress and undress?

3) take care of your appearance, eg. comb your hair (for men) shave?

4) do laundry?

5) walk?

6) walk up and down stairs?

7) get in and out of bed?

8) get in and out of the bathtub?

9) shower and bathe?

10) stand up if you have been seated on an ordinary chair without arms?

11) reach above shoulder height?

12) bend down to pick up something from the floor?

13) manage small things with your fingers, eg. write?

14) use the telephone?

15) get to places that are not in walkingdistance?

16) handle your money?
Yes, without help, With some help, Can not

Yes, without help, With some help, Can not 
17) take your medicine?

18) do grocery shopping?

19) prepare your meals?

20) take care of your housework?

21) do maintenance in your home? 
Appendix J. Vision Functioning Questionnaire -25

In this next section I will ask you questions about your vision and how your vision may affect your ability to do daily activities.

\section{PART 1 - GENERAL HEALTH AND VISION}

1. In general, would you say your overall health is:

\begin{tabular}{|l|l|l|l|l|}
\hline Excellent & Very Good & Good & Fair & Poor \\
\hline
\end{tabular}

2. At the present time, would you say your eyesight using both eyes (with glasses or contact lenses, if you wear them) is excellent, good, fair, poor, or very poor or are you completely blind?

\begin{tabular}{|l|l|l|l|l|}
\hline Excellent & Good & Poor & Completely Blind \\
\hline
\end{tabular}

3. How much of the time do you worry about your eyesight?

\begin{tabular}{|l|l|l|l|l|}
\hline None of the time & $\begin{array}{l}\text { A little of the } \\
\text { time }\end{array}$ & Some of the time & $\begin{array}{l}\text { Most of the } \\
\text { time }\end{array}$ & All of the time \\
\hline
\end{tabular}

4. How much pain or discomfort have you had in and around your eyes (for example, burning, itching, or aching)? Would you say it is:

\begin{tabular}{|l|l|l|l|l|}
\hline None & Mild & Moderate & Severe & Very Severe \\
\hline
\end{tabular}

\section{PART 2 - DIFFICULTY WITH ACTIVITIES}

The next questions are about how much difficulty, if any, you have doing certain activities wearing your glasses or contact lenses if you use them for that activity.

5. How much difficulty do you have reading ordinary print in newspapers? Would you say you have:

\begin{tabular}{|l|l|l|l|l|l|}
\hline $\begin{array}{l}\text { No difficulty } \\
\text { at all }\end{array}$ & $\begin{array}{l}\text { A little } \\
\text { difficulty }\end{array}$ & $\begin{array}{l}\text { Moderate } \\
\text { difficulty }\end{array}$ & $\begin{array}{l}\text { Extreme } \\
\text { difficulty }\end{array}$ & $\begin{array}{l}\text { Stopped doing } \\
\text { this because } \\
\text { of your } \\
\text { eyesight }\end{array}$ & $\begin{array}{l}\text { Stopped } \\
\text { doing this } \\
\text { for other } \\
\text { reasons }\end{array}$ \\
\hline
\end{tabular}

6. How much difficulty do you have doing work or hobbies that require you to see well up close, such as cooking, sewing, fixing things around the house, or using hand tools? Would you say:

\begin{tabular}{|l|l|l|l|l|l|}
\hline $\begin{array}{l}\text { No difficulty } \\
\text { at all }\end{array}$ & $\begin{array}{l}\text { A little } \\
\text { difficulty }\end{array}$ & $\begin{array}{l}\text { Moderate } \\
\text { difficulty }\end{array}$ & $\begin{array}{l}\text { Extreme } \\
\text { difficulty }\end{array}$ & $\begin{array}{l}\text { Stopped doing } \\
\text { this because } \\
\text { of your } \\
\text { eyesight }\end{array}$ & $\begin{array}{l}\text { Stopped } \\
\text { doing this } \\
\text { for other } \\
\text { reasons }\end{array}$ \\
\hline
\end{tabular}


7. Because of your eyesight, how much difficulty do you have finding something on a crowded shelf?

\begin{tabular}{|l|l|l|l|l|l|}
\hline $\begin{array}{l}\text { No difficulty } \\
\text { at all }\end{array}$ & $\begin{array}{l}\text { A little } \\
\text { difficulty }\end{array}$ & $\begin{array}{l}\text { Moderate } \\
\text { difficulty }\end{array}$ & $\begin{array}{l}\text { Extreme } \\
\text { difficulty }\end{array}$ & $\begin{array}{l}\text { Stopped doing } \\
\text { this because } \\
\text { of your } \\
\text { eyesight }\end{array}$ & $\begin{array}{l}\text { Stopped } \\
\text { doing this } \\
\text { for other } \\
\text { reasons }\end{array}$ \\
\hline
\end{tabular}

8. How much difficulty do you have reading street signs or the names of stores?

\begin{tabular}{|l|l|l|l|l|l|}
\hline $\begin{array}{l}\text { No difficulty } \\
\text { at all }\end{array}$ & $\begin{array}{l}\text { A little } \\
\text { difficulty }\end{array}$ & $\begin{array}{l}\text { Moderate } \\
\text { difficulty }\end{array}$ & $\begin{array}{l}\text { Extreme } \\
\text { difficulty }\end{array}$ & $\begin{array}{l}\text { Stopped doing } \\
\text { this because } \\
\text { of your } \\
\text { eyesight }\end{array}$ & $\begin{array}{l}\text { Stopped } \\
\text { doing this } \\
\text { for other } \\
\text { reasons }\end{array}$ \\
\hline
\end{tabular}

9. Because of your eyesight, how much difficulty do you have going down steps, stairs, or curbs in dim light or at night?

\begin{tabular}{|l|l|l|l|l|l|}
\hline $\begin{array}{l}\text { No difficulty } \\
\text { at all }\end{array}$ & $\begin{array}{l}\text { A little } \\
\text { difficulty }\end{array}$ & $\begin{array}{l}\text { Moderate } \\
\text { difficulty }\end{array}$ & $\begin{array}{l}\text { Extreme } \\
\text { difficulty }\end{array}$ & $\begin{array}{l}\text { Stopped doing } \\
\text { this because } \\
\text { of your } \\
\text { eyesight }\end{array}$ & $\begin{array}{l}\text { Stopped } \\
\text { doing this } \\
\text { for other } \\
\text { reasons }\end{array}$ \\
\hline
\end{tabular}

10. Because of your eyesight, how much difficulty do you have noticing objects off to the side while you are walking along?

\begin{tabular}{|l|l|l|l|l|l|}
\hline $\begin{array}{l}\text { No difficulty } \\
\text { at all }\end{array}$ & $\begin{array}{l}\text { A little } \\
\text { difficulty }\end{array}$ & $\begin{array}{l}\text { Moderate } \\
\text { difficulty }\end{array}$ & $\begin{array}{l}\text { Extreme } \\
\text { difficulty }\end{array}$ & $\begin{array}{l}\text { Stopped doing } \\
\text { this because } \\
\text { of your } \\
\text { eyesight }\end{array}$ & $\begin{array}{l}\text { Stopped } \\
\text { doing this } \\
\text { for other } \\
\text { reasons }\end{array}$ \\
\hline
\end{tabular}

11. Because of your eyesight, how much difficulty do you have seeing how people react to things you say?

\begin{tabular}{|l|l|l|l|l|l|}
\hline $\begin{array}{l}\text { No difficulty } \\
\text { at all }\end{array}$ & $\begin{array}{l}\text { A little } \\
\text { difficulty }\end{array}$ & $\begin{array}{l}\text { Moderate } \\
\text { difficulty }\end{array}$ & $\begin{array}{l}\text { Extreme } \\
\text { difficulty }\end{array}$ & $\begin{array}{l}\text { Stopped doing } \\
\text { this because } \\
\text { of your } \\
\text { eyesight }\end{array}$ & $\begin{array}{l}\text { Stopped } \\
\text { doing this } \\
\text { for other } \\
\text { reasons }\end{array}$ \\
\hline
\end{tabular}

12. Because of your eyesight, how much difficulty do you have picking out and matching your own clothes?

\begin{tabular}{|l|l|l|l|l|l|}
\hline No difficulty & A little & Moderate & Extreme & $\begin{array}{l}\text { Stopped doing } \\
\text { this because }\end{array}$ & $\begin{array}{l}\text { Stopped } \\
\text { doing this }\end{array}$ \\
\hline
\end{tabular}




\begin{tabular}{|l|l|l|l|l|l|}
\hline at all & difficulty & difficulty & difficulty & $\begin{array}{l}\text { of your } \\
\text { eyesight }\end{array}$ & $\begin{array}{l}\text { for other } \\
\text { reasons }\end{array}$ \\
\hline
\end{tabular}

13. Because of your eyesight, how much difficulty do you have visiting with people in their homes, at parties, or in restaurants ?

\begin{tabular}{|l|l|l|l|l|l|}
\hline $\begin{array}{l}\text { No difficulty } \\
\text { at all }\end{array}$ & $\begin{array}{l}\text { A little } \\
\text { difficulty }\end{array}$ & $\begin{array}{l}\text { Moderate } \\
\text { difficulty }\end{array}$ & $\begin{array}{l}\text { Extreme } \\
\text { difficulty }\end{array}$ & $\begin{array}{l}\text { Stopped doing } \\
\text { this because } \\
\text { of your } \\
\text { eyesight }\end{array}$ & $\begin{array}{l}\text { Stopped } \\
\text { doing this } \\
\text { for other } \\
\text { reasons }\end{array}$ \\
\hline
\end{tabular}

14. Because of your eyesight, how much difficulty do you have going out to see movies, plays, or sports events?

\begin{tabular}{|l|l|l|l|l|l|}
\hline $\begin{array}{l}\text { No difficulty } \\
\text { at all }\end{array}$ & $\begin{array}{l}\text { A little } \\
\text { difficulty }\end{array}$ & $\begin{array}{l}\text { Moderate } \\
\text { difficulty }\end{array}$ & $\begin{array}{l}\text { Extreme } \\
\text { difficulty }\end{array}$ & $\begin{array}{l}\text { Stopped doing } \\
\text { this because } \\
\text { of your } \\
\text { eyesight }\end{array}$ & $\begin{array}{l}\text { Stopped } \\
\text { doing this } \\
\text { for other } \\
\text { reasons }\end{array}$ \\
\hline
\end{tabular}

15. Now, I'd like to ask about driving a car. Are you currently driving, at least once in a while?

\begin{tabular}{|l|l|}
\hline Yes (Skip To & No \\
\hline 15c) & \\
\hline
\end{tabular}

15a. IF NO, ASK: Have you never driven a car or have you given up driving?

\begin{tabular}{|l|l|}
\hline $\begin{array}{l}\text { Never drove } \\
\text { (Skip To Part }\end{array}$ & Gave up \\
$3, Q$ 17) & \\
\hline
\end{tabular}

15b. IF GAVE UP DRIVING: Was that mainly because of your eyesight, mainly for some other reason, or because of both your eyesight and other reasons?

\begin{tabular}{|l|l|l|}
\hline Mainly & Mainly other & Both eyesight \\
eyesight (Skip & reasons (Skip & and other \\
To Part 3, $Q$ & To Part 3, $Q$ & reasons (Skip \\
17) & 17) Part 3, $Q$ \\
& & 17) \\
\hline
\end{tabular}

15c. IF CURRENTLY DRIVING: How much difficulty do you have driving during the daytime in familiar places? Would you say you have:

\begin{tabular}{|l|l|l|l|}
\hline $\begin{array}{l}\text { No difficulty } \\
\text { at all }\end{array}$ & $\begin{array}{l}\text { A little } \\
\text { difficulty }\end{array}$ & $\begin{array}{l}\text { Moderate } \\
\text { difficulty }\end{array}$ & $\begin{array}{l}\text { Extreme } \\
\text { difficulty }\end{array}$ \\
\hline
\end{tabular}


16. How much difficulty do you have driving at night? Would you say you have:

\begin{tabular}{|l|l|l|l|l|l|}
\hline $\begin{array}{l}\text { No difficulty } \\
\text { at all }\end{array}$ & $\begin{array}{l}\text { A little } \\
\text { difficulty }\end{array}$ & $\begin{array}{l}\text { Moderate } \\
\text { difficulty }\end{array}$ & $\begin{array}{l}\text { Extreme } \\
\text { difficulty }\end{array}$ & $\begin{array}{l}\text { Stopped doing } \\
\text { this because } \\
\text { of your } \\
\text { eyesight }\end{array}$ & $\begin{array}{l}\text { Stopped } \\
\text { doing this } \\
\text { for other } \\
\text { reasons }\end{array}$ \\
\hline
\end{tabular}

16a. How much difficulty do you have driving in difficult conditions, such as in bad weather, during rush hour, on the freeway, or in city traffic? Would you say you have:

\begin{tabular}{|l|l|l|l|l|l|}
\hline $\begin{array}{l}\text { No difficulty } \\
\text { at all }\end{array}$ & $\begin{array}{l}\text { A little } \\
\text { difficulty }\end{array}$ & $\begin{array}{l}\text { Moderate } \\
\text { difficulty }\end{array}$ & $\begin{array}{l}\text { Extreme } \\
\text { difficulty }\end{array}$ & $\begin{array}{l}\text { Stopped doing } \\
\text { this because } \\
\text { of your } \\
\text { eyesight }\end{array}$ & $\begin{array}{l}\text { Stopped } \\
\text { doing this } \\
\text { for other } \\
\text { reasons }\end{array}$ \\
\hline
\end{tabular}

\section{PART 3: RESPONSES TO VISION PROBLEMS}

The next questions are about how things you do may be affected by your vision. For each one, I'd like you to tell me if this is true for you all, most, some, a little, or none of the time.

17. Do you accomplish less than you would like because of your vision?

\begin{tabular}{|l|l|l|l|l|}
\hline All of the time & $\begin{array}{l}\text { Most of the } \\
\text { time }\end{array}$ & $\begin{array}{l}\text { Some of the } \\
\text { time }\end{array}$ & $\begin{array}{l}\text { A little of the } \\
\text { time }\end{array}$ & $\begin{array}{l}\text { None of the } \\
\text { time }\end{array}$ \\
\hline
\end{tabular}

18. Are you limited in how long you can work or do other activities because of your vision?

\begin{tabular}{|l|l|l|l|l|}
\hline All of the time & $\begin{array}{l}\text { Most of the } \\
\text { time }\end{array}$ & $\begin{array}{l}\text { Some of the } \\
\text { time }\end{array}$ & $\begin{array}{l}\text { A little of the } \\
\text { time }\end{array}$ & $\begin{array}{l}\text { None of the } \\
\text { time }\end{array}$ \\
\hline
\end{tabular}

19. How much does pain or discomfort in or around your eyes, for example, burning, itching, or aching, keep you from doing what you'd like to be doing?

\begin{tabular}{|l|l|l|l|l|}
\hline All of the time & $\begin{array}{l}\text { Most of the } \\
\text { time }\end{array}$ & $\begin{array}{l}\text { Some of the } \\
\text { time }\end{array}$ & $\begin{array}{l}\text { A little of the } \\
\text { time }\end{array}$ & $\begin{array}{l}\text { None of the } \\
\text { time }\end{array}$ \\
\hline
\end{tabular}

For each of the following statements, please tell me if it is definitely true, mostly true, mostly false, or definitely false for you or you are not sure.

20. I stay home most of the time because of my eyesight

\begin{tabular}{|l|l|l|l|l|}
\hline Definitely true & Mostly true & Mostly false & $\begin{array}{l}\text { Definitely } \\
\text { false }\end{array}$ & Not sure \\
\hline
\end{tabular}


21. I feel frustrated a lot of the time because of my eyesight

\begin{tabular}{|l|l|l|l|l|}
\hline Definitely true & Mostly true & Mostly false & $\begin{array}{l}\text { Definitely } \\
\text { false }\end{array}$ & Not sure \\
\hline
\end{tabular}

22. I have much less control over what I do, because of my eyesight

\begin{tabular}{|l|l|l|l|l|}
\hline Definitely true & Mostly true & Mostly false & $\begin{array}{l}\text { Definitely } \\
\text { false }\end{array}$ & Not sure \\
\hline
\end{tabular}

23. Because of my eyesight, I have to rely too much on what other people tell me

\begin{tabular}{|l|l|l|l|l|}
\hline Definitely true & Mostly true & Mostly false & $\begin{array}{l}\text { Definitely } \\
\text { false }\end{array}$ & Not sure \\
\hline
\end{tabular}

24. I need a lot of help from others because of my eyesight

\begin{tabular}{|l|l|l|l|l|}
\hline Definitely true & Mostly true & Mostly false & $\begin{array}{l}\text { Definitely } \\
\text { false }\end{array}$ & Not sure \\
\hline
\end{tabular}

25. I worry about doing things that will embarrass myself or others, because of my eyesight.

\begin{tabular}{|l|l|l|l|l|}
\hline Definitely true & Mostly true & Mostly false & $\begin{array}{l}\text { Definitely } \\
\text { false }\end{array}$ & Not sure \\
\hline
\end{tabular}




\section{Appendix K. Demographic Questionnaire}

This next section will ask you general questions about yourself.

What is your age?

What is your gender?
a. female
b. male

What is your race or ethnic background? (please circle one):
a. White/Caucasian, not Hispanic
b. Black/African-American
c. Asian-American
d. Hispanic
e. Native American
f. Pacific Islander
g. Other or mixed (please specify:

What is your marital status?
a. single
b. married
c. live-in partner
d. separated
e. divorced
f. widowed

Highest level of education?
a. GED
b. High School
c. Some College
d. College Degree
h. Other (please specify:

What is your current job or occupation status?
a. Working full time
b. Working part time
c. Homemaker
d. Student
e. Looking for work, unemployed
f. Retired
g. Disabled - unable to work

What is the total yearly income (in US dollars) for everyone in your household put together? (please circle one):
a. Less than 10,000 
Giving Support 160
b. $10,000-14,999$
c. $15,000-24,999$
d. $25,000-34,999$
e. $35,000-49,999$
f. $50,000-74,999$
g. $75,000-99,999$
h. $100,000-149,999$
i. $150,000-199,999$
j. 200,000 or more
k. Don't know 


\section{Appendix L. TELE}

This section of the interview will ask you questions that test your memory. Some questions may be easy and other questions may be harder. Please try your best during this section.

(IF AN ITEM IS NOT ASKED, PUT THE REASON:)

$\mathrm{A}=$ refuses to do it , $\mathrm{B}=$ couldn't hear well enough , $\mathrm{C}=$ other reason, Could you tell me

1. How old are you?

\begin{tabular}{|l|l|l|}
\hline Right & Wrong & Not Asked \\
\hline
\end{tabular}

2. When were you born?

day and month

\begin{tabular}{|l|l|l|}
\hline Right & Wrong & Not Asked \\
\hline
\end{tabular}

\begin{tabular}{|l|l|l|}
\hline year & Wrong & Not Asked \\
\hline
\end{tabular}

3. Where are you living now? What is your address?

Street Address

\begin{tabular}{|l|l|l|}
\hline Right & Wrong & Not Asked \\
\hline
\end{tabular}

4. What county is that in?

\begin{tabular}{|l|l|l|}
\hline Right & Wrong & Not Asked \\
\hline
\end{tabular}

I'd like to ask some questions now that require use of memory.

5. What is today's date?

\begin{tabular}{ll} 
& \multicolumn{2}{r}{ right wrong } \\
year ( ) & $($ ) \\
month ( ) & $($ ) \\
day ( ) & $($ ) \\
not asked & $($ )
\end{tabular}

6. Please listen to these 3 words and tell them to me after I say them to you. The 3 words are "key, toothbrush, lamp". Could you tell the words to me now: 
(WRITE ANSWER FROM FIRST TRY)

(IF DOESN'T GET ALL 3, REPEAT. IF DOESN'T GET ALL THREE WORDS AFTER 3 TRIES, CHECK HERE:

7. Could you count backwards from 20 by 3's? (WRITE RESPONSES)

(IF UNABLE, CUE)

a. What is 20 take away 3 ? And then if you take away 3 more...

\begin{tabular}{|l|l|l|}
\hline Number correct without cuing & Number correct with cuing & Not Asked \\
\hline
\end{tabular}

(SCORE: number correct (a or b] $x 0.5$ points)

8. Who is the President now?(WRITE RESPONSE)

\begin{tabular}{|l|l|l|}
\hline Right & Wrong & Not Asked \\
\hline
\end{tabular}

9. Who was the President before him/her? (WRITE RESPONSE)

\begin{tabular}{|l|l|l|}
\hline Right & Wrong & Not Asked \\
\hline
\end{tabular}

(IF FAILED TO REGISTER 3 WORDS, SKIP 20 AND GO ON TO 21)

10. A few minutes ago I asked you to remember 3 words. Could you tell me now what they were: (WRITE ANSWER)

\section{number correct:}

\begin{tabular}{|l|l|l|l|l|}
\hline 0 & 1 & 2 & 3 & Not Asked \\
& & IF ALL 3 \\
& & CORRECT, GO \\
& & TO QUESTION 21 & \\
& & & \\
\hline
\end{tabular}

a.(IF DOESN'T SAY "KEY") I'm going to read you a list of words. Tell me which words were the ones from before. (CIRCLE ANY WORDS INDICATED) 


\begin{tabular}{|l|l|l|}
\hline Key & Ring & Chair \\
\hline
\end{tabular}

b.(IF DOESN'T SAY "TOOTHBRUSH") I'm going to read you a list of words. Tell me which words were the ones from before. (CIRCLE ANY WORDS INDICATED)

\begin{tabular}{|l|l|l|}
\hline Picture & Toothbrush & Door \\
\hline
\end{tabular}

c.(IF DOESN'T SAY "LAMP") I'm going to read you a list of words. Tell me which words were the ones from before. (CIRCLE ANY WORDS INDICATED)

\begin{tabular}{|l|l|l|}
\hline Pen & Table & Lamp \\
\hline
\end{tabular}

11. Now, I am going to say two things that are similar to each other in one or more ways. I would like you to tell me the greatest similarity between them.

a. For example, in what way are a dog and a lion similar to each other?

(WRITE ANSWER)

\begin{tabular}{|l|l|l|}
\hline $\begin{array}{l}\text { Right (both are animals; } \\
\text { score:1 point) }\end{array}$ & $\begin{array}{l}\text { Wrong (both have fur, 4 legs; } \\
\text { score: } 0 \text { point) }\end{array}$ & Not Asked \\
\hline
\end{tabular}

(IF ANSWERS WRONG, THEN SAY THE FOLLOWING BEFORE GOING ON TO THE NEXT QUESTION)

***If person says something partially correct, such as they both have fur or four legs, say "You could say that too, but isn't the greatest similarity between them that they are both animals?"

***If person can't give any similarity, say "The way a dog and a lion are similar to each other is that they are both animals. They both have fur and four legs, but the greatest similarity between them is that they are both animals."

b. Here is another, in what way are an orange and a banana similar to each other?

$$
\text { (WRITE ANSWER) }
$$

\begin{tabular}{|l|l|l|l|}
\hline $\begin{array}{l}\text { Right (both are fruit; } \\
\text { score: 1 point) }\end{array}$ & $\begin{array}{l}\text { Partially Right (both } \\
\text { are food, have peels, } \\
\text { same color; score: } 0.5 \\
\text { points) }\end{array}$ & $\begin{array}{l}\text { wrong (both contain } \\
\text { calories, or gives a } \\
\text { difference such as } \\
\text { "one is round"; }\end{array}$ & Not Asked \\
\hline
\end{tabular}




\begin{tabular}{|l|l|l|l|}
\hline & & score: 0 points $)$ & \\
\hline
\end{tabular}

(IF ANSWERS IN BOTH a AND b WRONG, SKIP c)

c. A table ... and a chair?

(WRITE ANSWER)

\begin{tabular}{|l|l|l|l|}
\hline Right (both are & Partially Right (both & wrong (both have 4 & Not Asked \\
furniture; score:1 & found in kitchen, used \\
point) & when you eat a meal; & legs, are made of & wood, or gives a \\
& score:0.5 points) & difference such as & \\
& & $\begin{array}{l}\text { "you sit on one"; } \\
\text { score: } \text { 0 points) }\end{array}$ & \\
& & & \\
\hline
\end{tabular}

